TIAGO POLES DE SOUZA

MÉTODOS DE AVALIAÇÃO DE CONTRIBUIÇÃO DE HARMÔNICOS POR CORRELAÇÃO E ANÁLISE FASORIAL 
TIAGO POLES DE SOUZA

\section{MÉTODOS DE AVALIAÇÃO DE CONTRIBUIÇÃO DE HARMÔNICOS POR CORRELAÇÃO E ANÁLISE FASORIAL}

Dissertação apresentada à Escola Politécnica da Universidade de São Paulo para obtenção do título de Mestre em Engenharia 
Este exemplar foi revisado e alterado em relação à versão original, sob responsabilidade única do autor e com a anuência de seu orientador.

São Paulo, 25 de Julho de 2011

Assinatura do autor:

Assinatura do orientador:

FICHA CATALOGRÁFICA

\section{Souza, Tiago Poles de}

Métodos de avaliação de contribuição de harmônicos por correlação e análise fasorial / T.P. de Souza. -- ed.rev. -- São Paulo, 2011.

$119 \mathrm{p}$.

Dissertação (Mestrado) - Escola Politécnica da Universidade de São Paulo. Departamento de Engenharia de Energia e Automação Elétricas.

1. Energia elétrica (Qualidade; Métodos estatísticos; Métodos analíticos; Medição) 2. Transmissão de energia elétrica I. Uni versidade de São Paulo. Escola Politécnica. Departamento de Engenharia de Energia e Automação Elétricas II. t. 
TIAGO POLES DE SOUZA

\section{MÉTODOS DE AVALIAÇÃO DE CONTRIBUIÇÃO DE HARMÔNICOS POR CORRELAÇÃO E ANÁLISE FASORIAL}

Dissertação apresentada à Escola Politécnica da Universidade de São Paulo para obtenção do título de Mestre em Engenharia

Área de Concentração: Sistemas de Potência

Orientador: Prof. Doutor Nelson Kagan 


\section{DEDICATÓRIA}

Para a minha dedicatória, gostaria de fazer uma citação ligeiramente modificada por mim da dedicatória escrita por Neil Gaiman, em seu livro "Os Filhos de Anansi":

"VOCÉ SABE COMO É. Você pega um livro, vai até a dedicatória e, mais uma vez, descobre que o autor dedicou o livro a outra pessoa.

Mas não desta vez.

Nós ainda não nos encontramos / temos uma relação distante / somos loucos um pelo outro / não nos vemos há muito tempo / nunca nos encontraremos, mas apesar disso, creio eu, sempre pensaremos com carinho um no outro...

Esta dissertação é dedicada a você.

Você sabe com o quê, e provavelmente também sabe porquê." 


\section{AGRADECIMENTOS}

Ao professor Nelson Kagan, pela orientação e pelo constante estímulo transmitido durante todo o trabalho.

Aos amigos Silvio Xavier Duarte, Nelson Massakazu Matsuo, Eduardo Luiz Ferrari, Dalton de Oliveira Campones do Brasil e José Roberto de Medeiros, pela oportunidade de trabalhar e contribuir nestes estudos, além de todo o apoio e paciência que tiveram comigo ao longo dos trabalhos.

E a todos que contribuíram direta ou indiretamente na execução deste trabalho. 


\section{RESUMO}

Este trabalho apresenta uma metodologia de tratamento e análise baseada em medições de tensões e correntes com conteúdo harmônico para avaliar a contribuição de harmônicos dos elementos da rede elétrica baseando-se somente nas medições sincronizadas de alguns pontos da rede. Os métodos de análise propostos neste trabalho consistem em análises por correlação entre as correntes harmônicas de dois locais diferentes, utilizando os registros semanais de valores eficazes das correntes harmônicas medidas, buscando identificar as linhas de transmissão que possuem o mesmo comportamento de correntes harmônicas quanto a sua variação semanal em amplitude e em análises de fasores medidos nestes locais para determinar os fluxos de correntes sobre as barras do sistema. Para demonstrar o método, é apresentado um estudo de caso de uma campanha de medição feita pelo Operador Nacional do Sistema e pela Universidade de São Paulo, nos anos de 2007 e 2008, sobre as correntes de $5^{\text {a }}$ harmônica que sobrecarregavam os filtros na Subestação de Ibiúna. O método foi utilizado para investigar as origens dessas correntes no sistema de alta tensão. Os resultados da análise por correlação indicaram as linhas de transmissão com maior contribuição para as correntes absorvidas pelos filtros. Essas correntes são originárias de duas subestações e foi possível detectar a influência dos cabos subterrâneos ligados a estas subestações na amplificação destas correntes. Análises fasoriais nas subestações ao longo dos corredores estudados serviram para validar os resultados obtidos da análise por correlação e uma simulação do fenômeno de ressonância harmônica foi realizada, confirmando a suspeita de amplificação das correntes de $5^{\text {a }}$ harmônica nos cabos subterrâneos.

Palavras-chave: Qualidade de Energia Elétrica. Transmissão de Energia Elétrica. 


\begin{abstract}
This MSc thesis presents a methodology of treatment and analysis based on measurements of harmonic voltage and current to evaluate the harmonic contribution of the network elements in power systems based only on synchronized measurements of few points in the network. The method consists in a correlation analysis of weekly recordings of RMS values of harmonic currents measurements, to identify power lines that present the same behavior in harmonic currents regarding their weekly variation in amplitude. Another approach performs a phasor analysis of currents measured to determine current flows incoming some specific network buses. In order to demonstrate the method, a case study is considered, which consists in a measurement campaign carried out by the ISO and the University of São Paulo, in the years of 2007 and 2008, on the pattern of $5^{\text {th }}$ harmonic currents that overload the filters installed at the Ibiúna Substation. The method was used to investigate the origins of these currents at the high voltage system. The outcome of the correlation analysis indicated the transmission lines with greater contribution to the currents absorbed by the filters. These currents originate from two substations and it was also detected the influence of underground cables connected to these substations in the amplification of these currents. Phasor analysis in substations applied to the studied power lines validated the results obtained from correlation analysis and a simulation of the phenomenon of harmonic resonance was performed, bringing confirmation of the amplification of the $5^{\text {th }}$ harmonic current on the underground cables.
\end{abstract}

Keywords: Power Quality. Power Transmission. 


\section{LISTA DE ILUSTRAÇÕES}

Figura 1 - Exemplo de decomposição de ondas não senoidais..........................24

Figura 2 - Exemplo de registro com intervalo sem medição. ..............................37

Figura 3 - Exemplo de montagem de um diagrama de dispersão. ......................42

Figura 4 - Exemplos gráficos de diferentes graus de correlação. ........................43

Figura 5 - Exemplo de gráfico semanal do valor eficaz da corrente harmônica $h$ de um local $X$

Figura 6 - Exemplo de diagrama de dispersão dos valores eficazes da corrente harmônica $h$ dos locais $X$ e $Y$.

Figura 7 - Exemplo de divisão por patamares de carga do gráfico de valor eficaz da corrente harmônica $h$ do local $X$.

Figura 8 - Agrupamento dos registros por patamar de carga. 48

Figura 9 - Diagramas de dispersão da corrente harmônica $h$ entre os locais $X$ e $Y$, divididos por patamar de carga.

Figura 10 - Diagramas fasoriais das correntes fundamental e harmônica de ordem $h$ das linhas conectadas a uma barra fictícia $P$. .50

Figura 11 - Classificação de fasores das linhas de carga e das linhas de geração..51

Figura 12 - Exemplo de cancelamento parcial das parcelas das linhas $L_{2}$ e $L_{3}$ 52

Figura 13 - Exemplo das correntes harmônicas medidas na barra $P$, se originando nas cargas e fluindo para as linhas de suprimento. .53

Figura 14 - Exemplo de correntes harmônicas medidas na barra $P$, com cancelamento de correntes entre as cargas 2 e 4 .53

Figura 15 - Exemplo de correntes harmônicas medidas na barra $P$, com cancelamento total das corrente apenas nas linhas das cargas, sem corrente resultante para as linhas de suprimento $\left(\mathrm{I}_{\mathrm{h}}{ }^{\mathrm{L} 1}=0\right)$.

Figura 16 - Bloco do Sistema de Transmissão em estudo. .56

Figura 17 - Circuito simplificado de ressonância harmônica. .96

Figura 18 - llustração do Sistema Modelado para a Simulação do Fenômeno de Amplificação.

Figura 19 - Modelo equivalente dos três Cabos Subterrâneos da LT XavantesBandeirantes. 
Figura 20 - Modelo m-equivalente das LTs Ibiúna-Interlagos e Interlagos-Xavantes. 101

Figura 21 - Modelo dos três Filtros Paralelos de $3^{\mathrm{a}}$ e $5^{\mathrm{a}}$ Harmônicas de lbiúna.....104 Figura 22 - Modelo da Impedância Equivalente do SIN na Barra de Ibiúna...........105 Figura 23 - Circuito Modelado para a Simulação de Amplificação de Harmônicos.106 


\section{LISTA DE GRÁFICOS}

Gráfico 1 - Registro semanal dos valores eficazes das correntes da LT lbiúnaInterlagos, realizado na SE Ibiúna.

Gráfico 2 - Registro semanal dos valores eficazes das correntes da LT IbiúnaInterlagos, realizado na SE Interlagos.

Gráfico 3 - Diagramas de dispersão das correntes fundamentais medidas no início e fim da LT Ibiúna-Interlagos.

Gráfico 4 - Diagramas de dispersão das correntes de $3^{a}$ ordem medidas no início e fim da LT Ibiúna-Interlagos.

Gráfico 5 - Diagramas de dispersão das correntes de $5^{a}$ ordem medidas no início e fim da LT Ibiúna-Interlagos.

Gráfico 6 - Diagramas de dispersão das correntes de $5^{a}$ ordem entre a LT IbiúnaInterlagos e um dos Filtros de $3^{a}$ e $5^{a}$ harmônicas (Domingo).

Gráfico 7 - Diagramas de dispersão das correntes de $5^{a}$ ordem entre a LT IbiúnaInterlagos e um dos Filtros de $3^{a}$ e $5^{a}$ harmônicas (Segunda a Sexta)...70

Gráfico 8 - Registro semanal dos valores eficazes das correntes de $5^{\text {a }}$ ordem harmônica da LT Xavantes-Bandeirantes, realizado na SE Xavantes. ..79

Gráfico 9 - Registro semanal dos valores eficazes das correntes de $5^{\text {a }}$ ordem harmônica da LT Xavantes-Bandeirantes, realizado na SE Bandeirantes.

Gráfico 10 - Registro semanal dos valores eficazes das correntes de $5^{\mathrm{a}}$ ordem harmônica da LT Norte-Miguel Reale, realizado na SE Norte.

Gráfico 11 - Registro semanal dos valores eficazes das correntes de $5^{\text {a }}$ ordem harmônica da LT Norte-Miguel Reale, realizado na SE Miguel Reale....86

Gráfico 12 - Registro dos fasores das correntes de $5^{\mathrm{a}}$ ordem harmônica das LTs da SE Ibiúna.

Gráfico 13 - Registro dos fasores das correntes de $5^{\mathrm{a}}$ ordem harmônica das LTs da SE Xavantes.

Gráfico 14 - Registro dos fasores das correntes de $5^{\mathrm{a}}$ ordem harmônica das LTs da SE Norte e dos extremos da LT Norte-Miguel Reale. .93

Gráfico 15 - Impedância Equivalente dos três Filtros de $3^{a}$ e $5^{a}$ Harmônicas de Ibiúna em função da frequência. 
Gráfico 16 - Correntes sobre os Trechos dos Cabos Subterrâneos......................107

Gráfico 17 - Correntes nas LTs Interlagos-Xavantes e Ibiúna-Interlagos. ..............108 Gráfico 18 - Comparação das Correntes na Entrada dos Cabos, nos Filtros e no

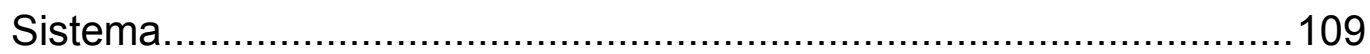




\section{LISTA DE TABELAS}

Tabela 1 - Diagrama de Medições Realizadas ao longo da Campanha (parte 1) ...57

Tabela 2 - Diagrama de Medições Realizadas ao longo da Campanha (parte 2) ...58

Tabela 3 - Resultados de correlação das correntes fundamentais entre início e fim da LT Ibiúna-Interlagos.

Tabela 4 - Resultados de correlação das correntes de $3^{a}$ ordem entre início e fim da LT Ibiúna-Interlagos.

Tabela 5 - Resultados de correlação das correntes de $5^{a}$ ordem entre início e fim da LT Ibiúna-Interlagos

Tabela 6 - Resultados de correlação das correntes de $5^{\text {a }}$ ordem medidas no elemento série e no reator paralelo dos Filtros de $3^{\text {a }}$ e $5^{\text {a }}$ harmônicas...67

Tabela 7 - Resultados de correlação das correntes de $5^{a}$ ordem medidas no elemento série e no capacitor paralelo dos Filtros de $3^{\mathrm{a}}$ e $5^{\mathrm{a}}$ harmônicas.

Tabela 8 - Resultados de correlação das correntes de $5^{\text {a }}$ ordem medidas na LT Ibiúna-Interlagos e em um dos Filtros de $3^{\mathrm{a}}$ e $5^{\mathrm{a}}$ harmônicas.

Tabela 9 - Resultados de correlação das correntes de $5^{\text {a }}$ ordem medidas na LT Ibiúna-Guarulhos e em um dos Filtros de $3^{\mathrm{a}}$ e $5^{\mathrm{a}}$ harmônicas.

Tabela 10 - Resultados de correlação das correntes de $5^{\mathrm{a}}$ ordem medidas na LT Ibiúna-Tijuco Preto e em um dos Filtros de $3^{\mathrm{a}}$ e $5^{\mathrm{a}}$ harmônicas.

Tabela 11 - Resultados de correlação das correntes de $5^{\text {a }}$ ordem medidas na LT Ibiúna-Bateias e em um dos Filtros de $3^{\mathrm{a}}$ e $5^{\mathrm{a}}$ harmônicas. .73

Tabela 12 - Resultados de correlação das correntes de $5^{\text {a }}$ ordem medidas na LT Ibiúna-Campinas e em um dos Filtros de $3^{\mathrm{a}}$ e $5^{\mathrm{a}}$ harmônicas. .74

Tabela 13 - Resultados de correlação das correntes de $5^{\mathrm{a}}$ ordem medidas nas LTs da SE Ibiúna com as correntes dos Filtros de $3^{\mathrm{a}}$ e $5^{\mathrm{a}}$ harmônicas.

Tabela 14 - Resultados de correlação das correntes de $5^{\text {a }}$ ordem medidas na LT Ibiúna-Interlagos e na LT Interlagos-Embuguaçú. .75

Tabela 15 - Resultados de correlação das correntes de $5^{\text {a }}$ ordem medidas na LT Ibiúna-Interlagos e na LT Interlagos-Xavantes.

Tabela 16 - Resultados de correlação das correntes de $5^{\text {a }}$ ordem medidas nas LTs de Interlagos com as correntes na LT Ibiúna-Interlagos. 
Tabela 17 - Resultados de correlação das correntes de $5^{\text {a }}$ ordem medidas na LT Interlagos-Xavantes e na LT Xavantes-Milton Fornasaro........................77

Tabela 18 - Resultados de correlação das correntes de $5^{\text {a }}$ ordem medidas na LT Interlagos-Xavantes e na LT Xavantes-Bandeirantes. ...........................78

Tabela 19 - Resultados de correlação das correntes de $5^{\text {a }}$ ordem medidas nas LTs de Xavantes com as correntes na LT Interlagos-Xavantes.

Tabela 20 - Resultados de correlação das correntes de $5^{\text {a }}$ ordem medidas na carga Carbocloro e nos Filtros de $3^{\mathrm{a}}$ e $5^{\mathrm{a}}$ harmônicas.

Tabela 21 - Resultados de correlação das correntes de $5^{\mathrm{a}}$ ordem medidas na carga Cosipa e nos Filtros de $3^{\mathrm{a}}$ e $5^{\mathrm{a}}$ harmônicas.

Tabela 22 - Resultados de correlação das correntes de $5^{\text {a }}$ ordem medidas na carga Gerdau e nos Filtros de $3^{\mathrm{a}}$ e $5^{\mathrm{a}}$ harmônicas.

Tabela 23 - Resultados de correlação das correntes de $5^{\text {a }}$ ordem medidas na carga CBA e nos Filtros de $3^{\mathrm{a}}$ e $5^{\mathrm{a}}$ harmônicas

Tabela 24 - Resultados de correlação das correntes de $5^{\mathrm{a}}$ ordem medidas nas cargas industriais com as correntes dos Filtros de $3^{\mathrm{a}}$ e $5^{\mathrm{a}}$ harmônicas. . 83

Tabela 25 - Resultados de correlação das correntes de $5^{\text {a }}$ ordem medidas na LT Ibiúna-Guarulhos e na LT Guarulhos- Anhanguera...............................84

Tabela 26 - Resultados de correlação das correntes de $5^{\text {a }}$ ordem medidas na LT Ibiúna-Guarulhos e na LT Guarulhos-Norte.

Tabela 27 - Resultados de correlação das correntes de $5^{\text {a }}$ ordem medidas nas LTs de Guarulhos com as correntes na LT Ibiúna-Guarulhos. .85 


\section{LISTA DE ABREVIATURAS E SIGLAS}

AC

ANEEL

DC

DHT

EPC

EPI

GPS

IEC

IEEE

LT

NR

NTP

ONS

P.A.C.

PRODIST

PROREDE

SE

SIN

TC

TP

USP
Alternate Current (Corrente Alternada)

Agência Nacional de Energia Elétrica

Direct Current (Corrente Contínua)

Distorção Harmônica Total

Equipamento de Proteção Coletiva

Equipamento de Proteção Individual

Global Positioning System (Sistema de Posicionamento Global)

International Electrotechnical Commission

Institute of Electrical and Electronics Engineers

Linha de Transmissão

Norma Regulamentadora

Network Time Protocol (Protocolo de Tempo para Redes)

Operador Nacional do Sistema Elétrico

Ponto de Acoplamento Comum

Procedimentos de Distribuição

Procedimentos de Rede

Subestação

Sistema Interligado Nacional

Transformador de Corrente

Transformador de Potencial

Universidade de São Paulo 


\section{LISTA DE SÍMBOLOS}

$a_{0}$

$A_{h}$

$a_{h}$ e $b_{h}$

C

F

$F_{D C}$

$F_{h}$

$F_{r m s}$

$f_{1}$

$f_{5}$

$f(t)$

$f_{h}(t)$

H

$h$

$H z$

$I_{1}^{X}$

$I_{h}{ }^{X}$

$i(t)$

$\mathrm{km}$

L

$\rho_{X, Y, h}$

$N_{X}$

$N_{Y}$

$n$

$p(t)$

$R$

Valor médio de uma função

Módulo de um fasor de ordem harmônica $h$

Coeficientes da série de Fourier para uma ordem harmônica $h$

Capacitância

Faraday

Componente contínua da função genérica $f(t)$

Valor de pico do sinal da componente harmônica de ordem $h$

Valor eficaz da função genérica $f(t)$

Frequência fundamental

Frequência de $5^{\mathrm{a}}$ harmônica

Valor instantâneo de uma função periódica no tempo $f$

Valor instantâneo da componente harmônica de ordem $h$ da função periódica no tempo $f$

Henry

Ordem Harmônica Individual

Hertz

Amplitude da Corrente da fase A na frequência fundamental, medida na barra $X$

Amplitude da Corrente da fase A na frequência harmônica $h$, medida na barra $X$

Valor instantâneo da corrente elétrica no instante de tempo $t$

Quilômetro

Indutância

Coeficiente de Correlação Linear de Pearson entre $X$ e $Y$, para a ordem harmônica $h$

Número de Amostras da grandeza $X$

Número de Amostras da grandeza $Y$

Número total de amostras

Valor instantâneo da potência elétrica, no instante de tempo $t$

Resistência elétrica 
Período de uma função em sua frequência fundamental Instante de tempo

$t_{i}$ Instante de tempo em que ocorreu a amostra $i$

$\checkmark$ Volt

$V_{1}{ }_{A}$

Amplitude da Tensão da fase $A$, na frequência fundamental, medida na barra $X$

$\hat{V}_{1}^{X}{ }^{\prime}$

Fasor normalizado da tensão da fase $A$, na frequência fundamental, medida na barra $X$.

$v(t) \quad$ Valor instantâneo da tensão elétrica no instante de tempo $t$

$X_{h}$ Grandeza genérica, de ordem harmônica $h$, medida no local $X$

$X_{h, i}$

$Y_{h}$

$Y_{h, i}$

$\Omega$

$\theta_{h}$

$\delta_{1}{ }^{X}$

$\varphi_{1}{ }^{X}$

$\varphi_{h}{ }^{X}$ Valor da amostra $i$ de uma grandeza $X$ para uma determinada ordem harmônica $h$

Grandeza genérica, de ordem harmônica $h$, medida no local $Y$

Valor da amostra $i$ de uma grandeza $Y$ para uma determinada ordem harmônica $h$

Impedância

Ohm

Ângulo de defasagem de um fasor de ordem harmônica $h$

Ângulo de defasagem da Tensão da fase $A$ na frequência fundamental, medida na barra $X$

Ângulo de defasagem da Corrente da fase $A$ na frequência fundamental, medida na barra $X$

Ângulo de defasagem da Corrente da fase $A$ na frequência harmônica $h$, medida na barra $\mathrm{X}$ 


\section{SUMÁRIO}

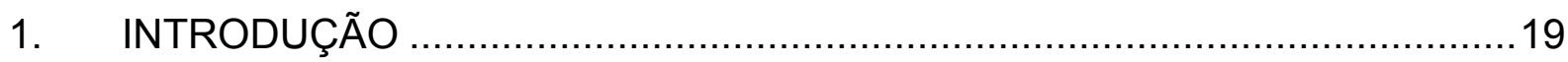

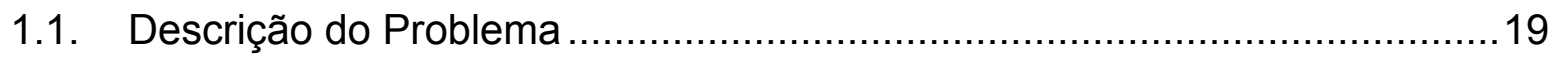

1.1.1. Fontes de Harmônicos.....................................................................21

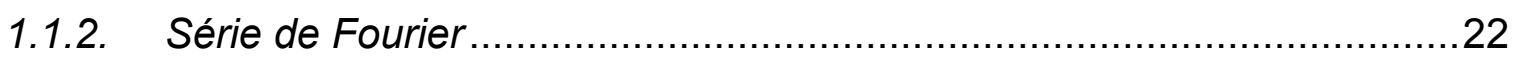

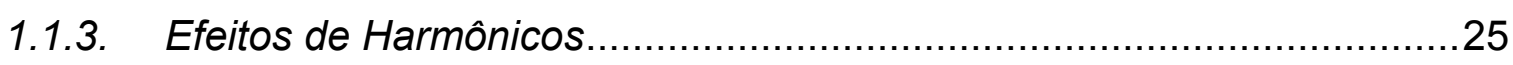

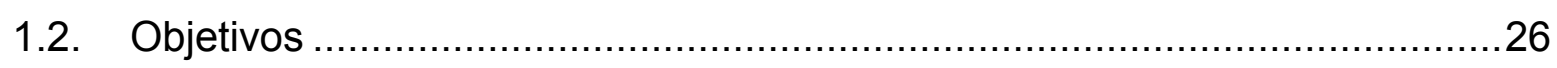

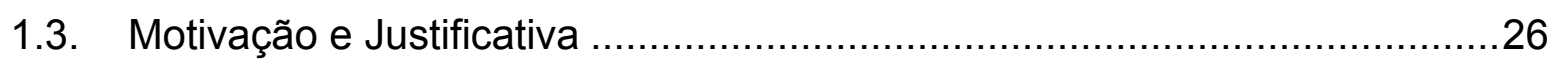

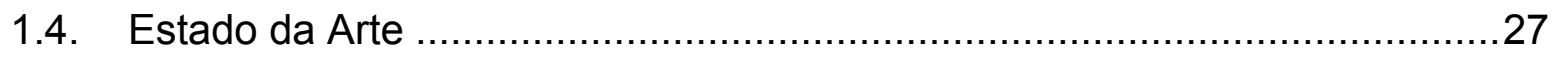

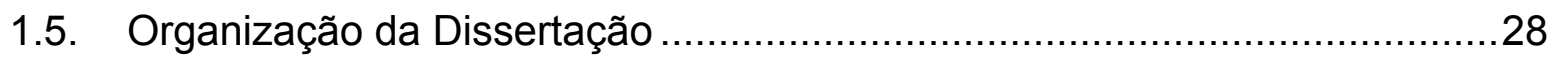

2. DESCRIÇÃO DO MÉTODO DE ANÁLISE PROPOSTO ……........................29

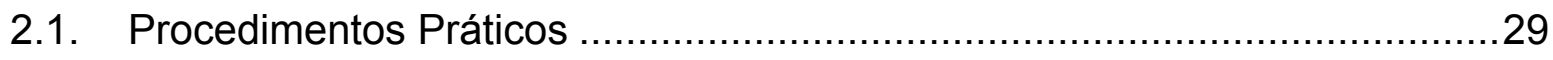

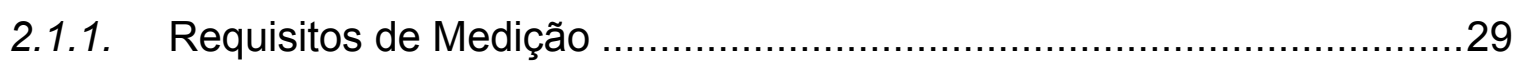

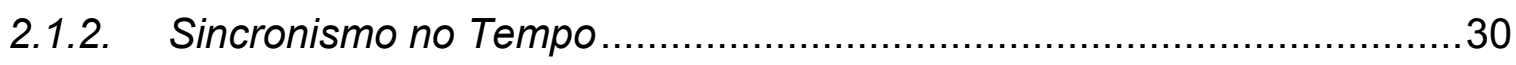

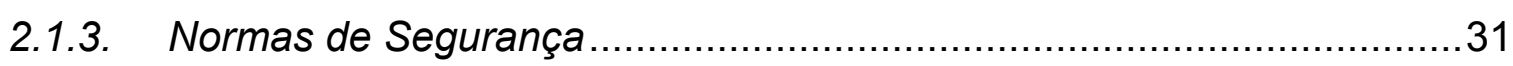

2.1.4. Conexão dos Medidores aos Pontos de Medição..................................32

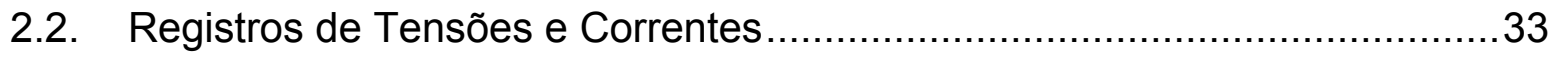

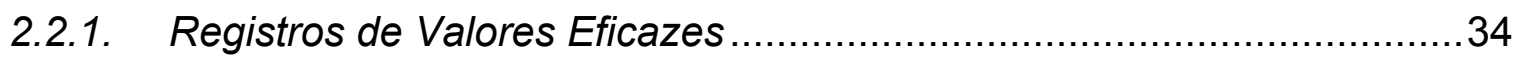

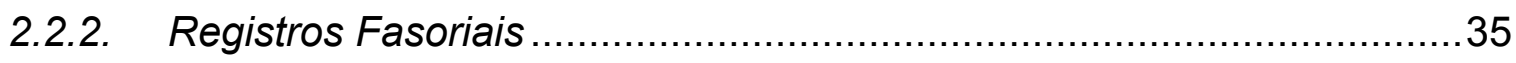

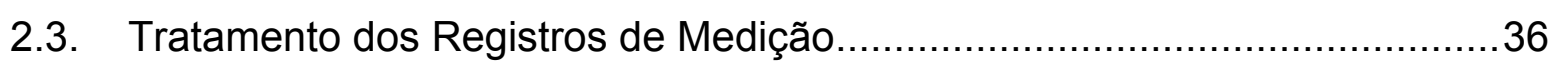

2.3.1. Tratamento de Registros de Valores Eficazes.....................................36

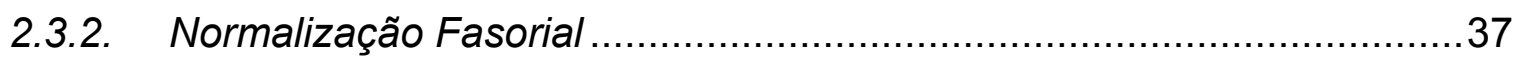

2.4. Análise Estatística por Correlação .......................................................

2.4.1. Diagrama de Dispersão ............................................................... 41

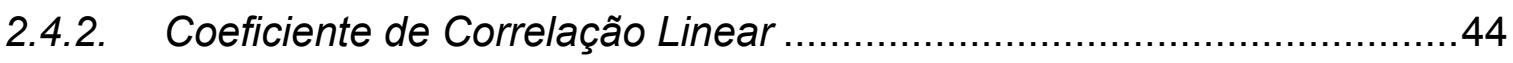

2.4.3. Análise por Patamares de Carga ........................................................ 45

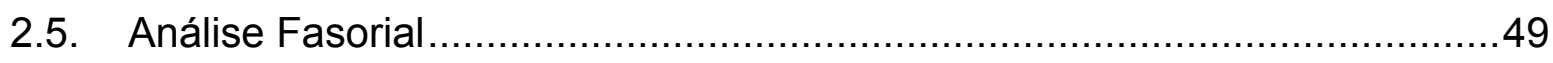

3. DESCRIÇÃO DA CAMPANHA DE MEDIÇÕES ….......................................55

3.1. Objetivos da Campanha de Medições......................................................58

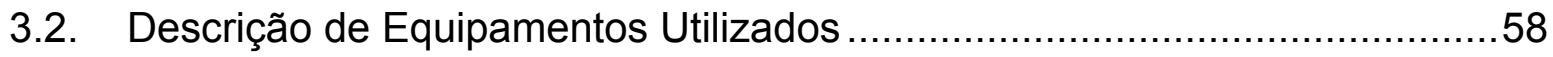

3.3. Instalação: Dificuldades Encontradas e Soluções.....................................59

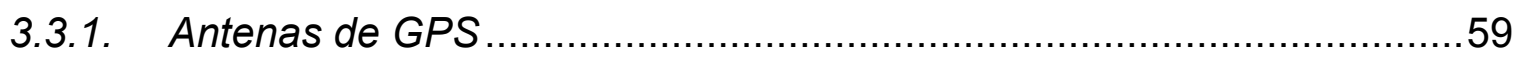




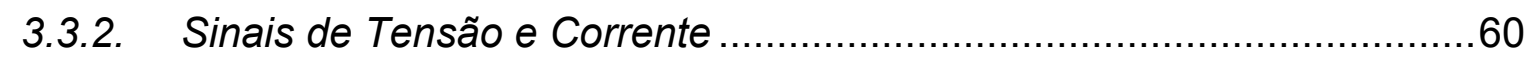

4. APRESENTAÇÃO DE RESULTADOS DE CORRELAÇÃO ESTATÍSTICA....61

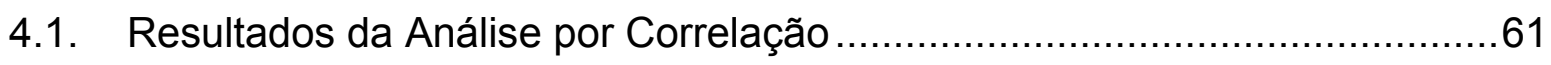

4.1.1. Avaliação dos Extremos das Linhas de Transmissão............................61

4.1.2. Avaliação das Correntes Sobre o Filtro em Ibiúna.................................67

4.1.3. Correlações das Linhas de Transmissão da SE Ibiúna .........................68

4.1.4. Correlações das Linhas da SE Interlagos..........................................75

4.1.5. Correlações das Linhas da SE Xavantes .......................................77

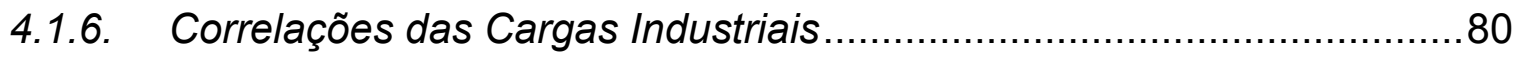

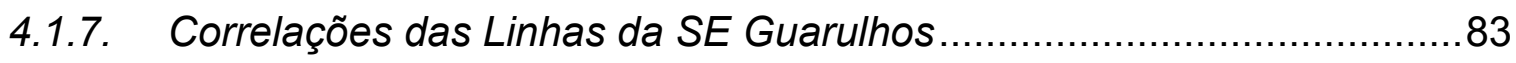

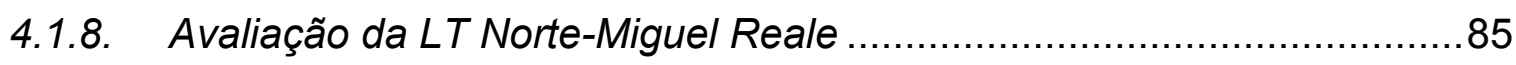

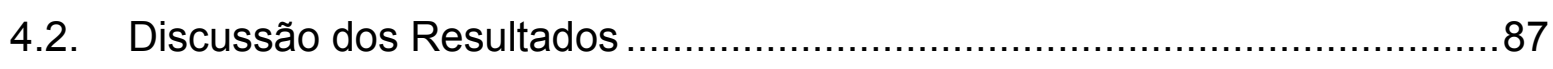

5. APRESENTAÇÃO DE RESULTADOS DA ANÁLISE FASORIAL ..................90

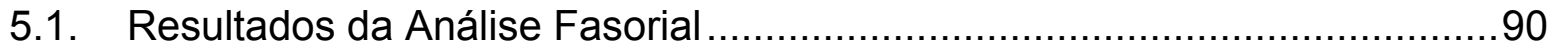

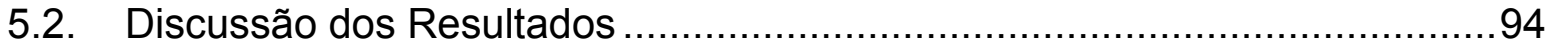

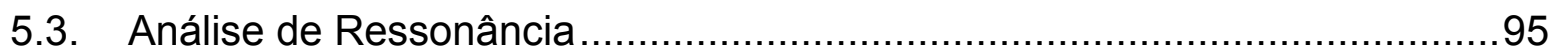

6. CONCLUSÕES E TÓPICOS PARA DESENVOLVIMENTO FUTURO ..........110

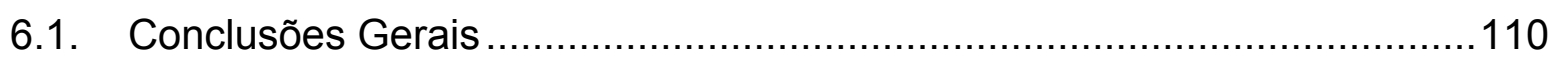

6.2. Tópicos para Desenvolvimento Futuro ................................................113

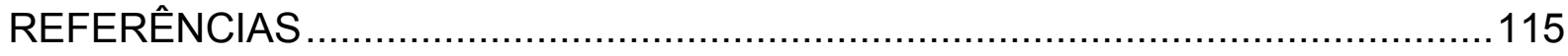




\section{INTRODUÇÃO}

Apresentam-se, nesta introdução, a descrição do problema de injeção de correntes harmônicas em estudo, as principais fontes de correntes harmônicas no sistema elétrico, uma breve introdução teórica às Séries de Fourier para uma compreensão básica da superposição de ondas em diferentes frequências, bem como comentários sobre os efeitos de harmônicos no sistema elétrico.

São apresentados os objetivos que esta dissertação busca alcançar, a motivação para o estudo de correntes harmônicas, a justificativa da importância do tema e a estrutura de organização deste trabalho.

\subsection{Descrição do Problema}

O sistema elétrico brasileiro foi concebido para trabalhar na sua frequência nominal de operação $(60 \mathrm{~Hz})$, conhecida como frequência fundamental. Com o passar do tempo, o aumento das cargas no sistema e o avanço na tecnologia da eletrônica de potência acabaram introduzindo distúrbios representados por ondas de frequências superiores, múltiplas da frequência nominal da rede elétrica, chamadas frequências harmônicas. Estas ondas são resultado de correntes distorcidas causadas por equipamentos não lineares que interagem com a rede elétrica causando distorções na tensão ou entrando em ressonância com elementos do sistema.

Explicando isso um pouco melhor, as correntes harmônicas causadas pelos equipamentos, ao circularem pelo sistema, produzem quedas de tensão ao longo do alimentador e, em consequência, a tensão na rede torna-se distorcida passando a conter, ela própria, componentes harmônicas. Essas componentes harmônicas causam efeitos indesejáveis como interferências em sinais elétricos, perdas na eficiência e até desgaste dos equipamentos ligados ao sistema elétrico. 
O aparecimento de harmônicos no sistema elétrico não é um problema recente, embora nos dias de hoje o seu crescimento tenha chamado a atenção. Entre 1915 e 1920, Steinmetz (2003) enfatizou os problemas de harmônicos causados pela saturação de transformadores e máquinas elétricas ligadas ao sistema elétrico.

Com o passar do tempo, houve um crescimento acentuado do uso de circuitos retificadores e de circuitos eletrônicos que distorcem a corrente através do uso de técnicas de chaveamento, em troca de um aumento da sua eficiência elétrica. Este crescimento trouxe a necessidade do estabelecimento de normas para definir limites aceitáveis de distorções harmônicas.

O Institute of Electrical and Electronics Engineers (IEEE) nos Estados Unidos e o International Electrotechnical Commission (IEC) na Europa são os principais órgãos no mundo que contribuem com o estabelecimento de normas para a qualidade de energia elétrica.

O IEEE estabeleceu a norma IEEE Std. 519-1992 (1992) que, a partir da revisão de 1992, estabeleceu limites de emissão de harmônicos toleráveis avaliados no ponto de acoplamento comum (P.A.C.) do consumidor com a rede elétrica. A norma também estabeleceu os níveis de distorção harmônica total (DHT) de tensão e corrente aceitáveis para serem avaliadas no mesmo ponto de conexão.

A IEC também estabeleceu sua própria norma, chamada de IEC 61000-3-2 (200110) que, além de possuir também limites para a DHT e para o P.A.C., também apresenta limites voltados para os equipamentos dos consumidores de baixa tensão com consumo de corrente de até 16 Ampères. Os equipamentos são classificados em diferentes classes e também pela forma de alimentação (monofásica ou trifásica), recebendo limites ajustados de acordo com a sua classificação.

No Brasil, através do submódulo 2.8 dos Procedimentos de Rede (PROREDE) do Operador Nacional do Sistema Elétrico (ONS, Procedimentos de Rede..., 2010) e do módulo 8 dos Procedimentos de Distribuição (PRODIST) da Agência Nacional de Energia Elétrica (ANEEL, Procedimentos de Distribuição..., 2010), são definidos os 
valores de referência para a DHT de tensão e, no PRODIST, também define valores de referência para as distorções harmônicas individuais de tensão, servindo como referências para a restrição da emissão de harmônicos para o sistema elétrico brasileiro.

\subsubsection{Fontes de Harmônicos}

A energia elétrica é fornecida aos consumidores através de uma tensão senoidal, em uma frequência fundamental bem definida que pode ser 50 ou $60 \mathrm{~Hz}$, dependendo do sistema elétrico. Quando uma carga é aplicada a esta tensão, a potência média é fornecida pelo produto descrito em Mack Grady (2001), na eq.(1).

$$
P_{\text {média }}=\frac{1}{T} \int_{t}^{t+T} p(t) \cdot d t=\frac{1}{T} \int_{t}^{t+T} v(t) \cdot i(t) \cdot d t
$$

Onde: $p(t)$ é o valor instantâneo da potência elétrica no instante de tempo $t$;

$v(t)$ é o valor instantâneo da tensão elétrica no instante de tempo $t$;

$i(t)$ é o valor instantâneo da corrente elétrica no instante de tempo $t$;

$T$ é o período da função em sua frequência fundamental.

Conforme definido em (IEEE 100, 2000), uma carga é dita linear se, ao ser alimentada por uma tensão senoidal, a corrente resultante possuir uma forma de onda também senoidal de mesma frequência da tensão que a alimenta. O ângulo de defasagem entre a onda da tensão e a onda da corrente não afeta a linearidade da carga. Cargas apresentando comportamentos puramente resistivos, indutivos, capacitivos ou mistura destes comportamentos são exemplos de cargas lineares.

Por outro lado, uma carga é dita não-linear quando, ao ser alimentada por uma tensão senoidal, a corrente resultante não possui uma forma de onda senoidal na frequência da tensão que a alimenta (IEEE 100, 2000). Estas cargas podem possuir elementos que interrompem ou afetam a corrente, tais como os semicondutores, equipamentos com núcleos ferromagnéticos, etc. 
Há poucas décadas atrás, as principais fontes de harmônicos conhecidas eram fornos a arco, a magnetização de máquinas elétricas ou de transformadores e lâmpadas fluorescentes. Atualmente fazem parte desta lista os equipamentos eletrônicos que convertem corrente alternada para corrente contínua (retificadores), corrente alternada para corrente alternada (inversores) ou que fazem uso de fontes chaveadas.

Na maioria das vezes, quando a corrente não-linear ainda se mantém periódica na frequência fundamental, esta corrente pode ser decomposta em uma série trigonométrica de ondas senoidais de frequências múltiplas da frequência fundamental, chamada de série de Fourier.

\subsubsection{Série de Fourier}

Qualquer função periódica no tempo pode ser decomposta em uma série trigonométrica, desde que esta função obedeça às seguintes regras:

- possua um número finito de descontinuidades em seu período;

- possua um valor médio finito em seu período;

- possua um número finito de valores positivos e negativos.

Uma vez que estas regras sejam obedecidas, uma função periódica $f(t)$ pode ser expressa por uma série trigonométrica, conforme descrita por Arrilaga (2003), apresentada na eq.(2).

$$
f(t)=a_{0}+\sum_{h=1}^{\infty}\left[a_{h} \cdot \cos \left(\frac{2 \cdot \pi \cdot h \cdot t}{T}\right)+b_{h} \cdot \operatorname{sen}\left(\frac{2 \cdot \pi \cdot h \cdot t}{T}\right)\right]
$$

Onde: $a_{0}$ é o valor médio da função $f(t)$, que também pode ser entendido como o valor da componente contínua de $f(t)$;

$h$ é o valor da ordem harmônica que compõe o sinal, composta por valores inteiros positivos; 
$a_{h}$ e $b_{h}$ são os valores dos coeficientes da série de Fourier para cada ordem harmônica $h$;

$T$ é o período da função em sua frequência fundamental $(h=1)$.

Os vetores das componentes harmônicas, obtidos a partir da decomposição em coeficientes da série de Fourier, são apresentados também por Arrilaga (2003) conforme descreve a eq.(3):

$$
\hat{A}_{h}=A_{h} \angle \theta_{h}=a_{h}+j \cdot b_{h}
$$

A amplitude $\left(A_{h}\right)$ e a defasagem $\left(\theta_{h}\right)$ do vetor que representa a componente harmônica de ordem $h$ podem ser obtidas a partir dos coeficientes da série de Fourier, apresentado por Arrilaga (2003) pela eq.(4) e eq.(5), respectivamente:

$$
\begin{aligned}
& A_{h}=\sqrt{a_{h}^{2}+b_{h}^{2}} \\
& \theta_{h}=\tan ^{-1}\left(\frac{b_{h}}{a_{h}}\right)
\end{aligned}
$$

Dessa forma, Arrilaga (2003) define que, se uma carga não-linear conectada à rede elétrica produz uma corrente não-senoidal, mas cíclica na frequência fundamental, então a corrente que esta carga está produzindo pode ser decomposta em uma somatória de correntes senoidais com diferentes frequências de oscilação.

Estas correntes senoidais que compõe a corrente da carga não-linear são classificadas como:

- fundamental: onda com a frequência fundamental do sistema, igual a frequência da tensão da rede elétrica;

- sub-harmônicos: ondas com frequências inferiores à fundamental;

- harmônicos: ondas com frequências superiores à fundamental, múltiplas inteiras da frequência fundamental;

- inter-harmônicos: ondas com frequências intermediárias às frequências harmônicas, que não são múltiplas inteiras da frequência fundamental. 
Esta dissertação tem seu foco limitado apenas às análises de frequências classificadas como frequências harmônicas, não abordando a teoria e a análise de sub-harmônicos e inter-harmônicos.

Por exemplo, a forma de onda apresentada na Figura 1 é uma forma de onda não senoidal, mas que pode ser decomposta em duas ondas senoidais: uma na frequência de $f_{1}=60 \mathrm{~Hz}$ (fundamental) e outra na frequência de $f_{5}=300 \mathrm{~Hz}\left(5^{\mathrm{a}}\right.$ ordem harmônica).
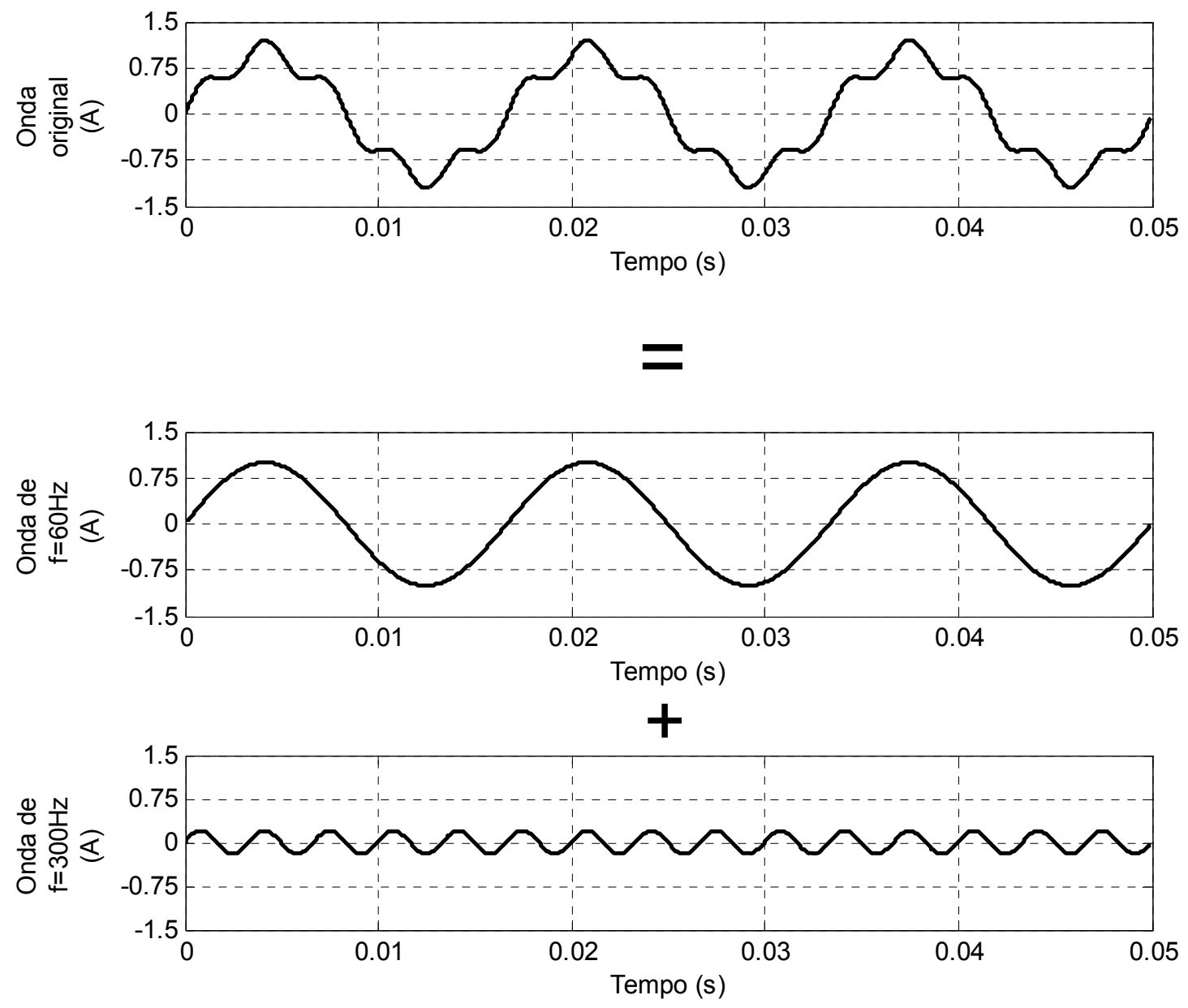

Figura 1 - Exemplo de decomposição de ondas não senoidais. 
O detalhamento da teoria de Séries de Fourier aplicada em harmônicos e interharmônicos pode ser encontrado em diversas referências como Arrilaga (2003), De La Rosa (2006), Mack Grady (2001), etc.

\subsubsection{Efeitos de Harmônicos}

De uma maneira geral, harmônicos possuem efeitos nocivos tanto no sistema elétrico quanto sobre os equipamentos dos consumidores.

No sistema elétrico, a corrente harmônica injetada em um ponto pode entrar em ressonância com o resto do sistema elétrico, resultando em uma maior circulação de correntes harmônicas no sistema e, por consequência, maior distorção da tensão. As correntes harmônicas podem degradar bancos de capacitores, queimar seus fusíveis devido a corrente elevada que circula por eles ou até mesmo levar à queima direta desses capacitores. A presença de harmônicos pode causar, ainda, um sobreaquecimento inesperado dos transformadores de distribuição, dentre outros efeitos.

Para os consumidores, alguns dos maiores problemas estão no sobreaquecimento de máquinas elétricas, na sobrecarga do condutor de neutro, em interferências nos sinais elétricos de equipamentos de telecomunicações e em equipamentos eletrônicos de controle.

Em relação aos efeitos das correntes harmônicas, um dos efeitos que será discutido neste trabalho é o da limitação para a transmissão de potência no Sistema Interligado Nacional (SIN). O aumento expressivo da circulação de corrente harmônica no SIN causa sobrecargas em filtros de harmônicos instalados ao longo do sistema de transmissão. Tais sobrecargas podem limitar ou restringir o fluxo de potência proveniente do elo de corrente contínua. 


\subsection{Objetivos}

Esta dissertação tem por objetivo descrever uma metodologia de tratamento e análise baseada em medições de tensões e correntes com conteúdo harmônico, para avaliar a contribuição de harmônicos pelos elementos da rede elétrica através da análise por correlações estatísticas validadas por análises fasoriais das barras do sistema.

Além disso, apresentar também os resultados da aplicação da metodologia descrita em uma campanha de estudos harmônicos realizada pelo Operador Nacional do Sistema Elétrico (ONS) e pela Universidade de São Paulo (USP) nas linhas do sistema elétrico de transmissão de Furnas, que teve como objetivo principal determinar as origens das correntes harmônicas que sobrecarregaram os filtros instalados na subestação de Ibiúna.

\subsection{Motivação e Justificativa}

O crescimento das injeções de correntes harmônicas no sistema elétrico nacional tem causado impactos em sua operação para os quais o sistema não foi dimensionado. Problemas de sobrecarga em filtros do sistema e em equipamentos de controle dos consumidores trazem preocupação sobre as injeções de correntes harmônicas, aproximando a necessidade de se tomar medidas para deteç̧ão de suas fontes e regulação de suas emissões.

A metodologia apresentada não utiliza métodos de estudo avançados baseados no uso dos valores das impedâncias do sistema, como simulações de fluxo de potência harmônico ou algoritmos de estimação de estados harmônicos, mas pode complementar tais estudos com uma avaliação preliminar que orientará a região da rede a se aplicar estes métodos. 


\subsection{Estado da Arte}

O estado da arte apresenta dois trabalhos parcialmente relacionados com os temas abordados nesta dissertação, no que diz respeito às medições sincronizadas e aos problemas de sobrecarga harmônica nos filtros de $3^{a}$ e $5^{a}$ harmônicas na SE de Ibiúna. Os trabalhos pesquisados tem como abordagem principal o uso de simulações computacionais, o que os diferencia deste trabalho.

O trabalho de Wiechowski (2007) apresenta os resultados do uso de medições de harmônicos sincronizadas por GPS em uma rede de transmissão dinamarquesa de $400 \mathrm{kV}$ para verificar a acuidade de um modelo computacional dessa rede. As medições de tensões e correntes foram realizadas simultaneamente em três subestações, realizando registros disparados em função do tempo. $O$ tratamento dos registros foi realizado através do programa $M a t l a b \otimes$ e a validação do modelo foi feita através da injeção das correntes harmônicas desequilibradas medidas nas subestações e comparação das tensões resultantes no sistema modelado com as tensões medidas.

O trabalho de Fernandes (2007) faz um estudo das medidas operativas paliativas para os problemas de sobrecarga dos filtros de $3^{\mathrm{a}}$ e $5^{\mathrm{a}}$ harmônicas na SE de Ibiúna através de simulações computacionais monofásicas do SIN usando o programa HarmZ®. Para compor o modelo do sistema, o autor utiliza as redes modeladas nos programas $A N A R E D E ®$ e ANATEM® obtidos do ONS. Obtém os valores médios das injeções harmônicas do elo de corrente contínua através de cálculos por simulações do programa $H V D C \circledR$. As injeções harmônicas no resto do sistema são estimadas através do uso de valores médios dos registros de medições anteriores de harmônicos do sistema realizadas nos anos de 2003 e 2006. Com este sistema, o autor busca quantificar a eficácia de medidas operatórias no sistema para eliminar as sobrecargas nos filtros. 
Salienta-se que, no que diz respeito à metodologia de análise por correlação apresentada neste trabalho, não foram encontrados na literatura acadêmica trabalhos que tenham feito o uso da análise por correlação entre correntes medidas em locais diferentes para o fenômeno de propagação de correntes harmônicas.

\subsection{Organização da Dissertação}

O Capítulo 2, Descrição do Método de Análise, apresenta o desenvolvimento dos métodos para solução e encaminhamento das medições e de sua análise.

O Capítulo 3 trata sobre a Definição da Campanha de Medições, apresentando algumas considerações sobre os objetivos da campanha em estudo, a instalação de equipamentos e as dificuldades encontradas na campanha.

O Capítulo 4, Apresentação de Resultados de Correlação Estatística, descreve os resultados obtidos pela aplicação do método de correlação desenvolvido na dissertação sobre a campanha de medições.

O Capítulo 5, Apresentação de Resultados de Análise Fasorial e Ressonância, descreve os resultados obtidos pela aplicação do método de análise fasorial sobre a campanha de medições, com discussão de resultados e análise da ressonância encontrada no sistema.

O Capítulo 6, Discussões Gerais, apresenta as conclusões gerais do trabalho e tópicos para desenvolvimento futuro. 


\section{DESCRIÇÃO DO MÉTODO DE ANÁLISE PROPOSTO}

O método apresentado é direcionado a avaliação de fluxos de correntes harmônicas em sistemas elétricos através de uma análise quantitativa das correntes que fluem pela rede e por inspeção fasorial.

Este método é orientado à aplicação de dois ou mais medidores, instalados em diferentes linhas de transmissão/distribuição ou locais do sistema elétrico em estudo. Para tanto, algumas considerações sobre a utilização destes medidores devem ser feitas.

\subsection{Procedimentos Práticos}

Neste item serão apresentados alguns procedimentos práticos requeridos para a aplicação da metodologia proposta nesta dissertação.

\subsubsection{Requisitos de Medição}

Os medidores devem registrar os valores eficazes para cada ordem harmônica desejada simultaneamente. Também devem ser capazes de obter registros de alguns ciclos das formas de onda das tensões e das correntes para a obtenção de fasores instantâneos para cada ordem harmônica de interesse.

Todos os registros devem ser realizados em intervalos cíclicos de tempo, ajustáveis e bem determinados. O disparo dos registros precisa ser realizado simultaneamente, fazendo-se necessário o uso de algum tipo de sinal para sincronismo no tempo entre os medidores. 


\subsubsection{Sincronismo no Tempo}

Embora o comportamento individual de uma carga seja previsível, o comportamento agregado das fontes de harmônicos é, em geral, imprevisível e inconstante, fortemente ligado ao comportamento das cargas do sistema elétrico, é importante que haja sincronismo dos registros dos sinais de tensões e correntes para que os valores medidos possam ser verdadeiramente comparáveis.

Há diferentes tecnologias que permitem manter o sincronismo no tempo, as quais são brevemente apresentadas:

- conexão entre os medidores para que todos se mantenham em sincronismo uns com os outros;

- conexão com satélites GPS (Global Positioning System), fazendo o uso de antenas apropriadas;

- conexão com um servidor (microcomputador) único, obtendo a referência de tempo do servidor, fazendo o uso de uma conexão por rede fechada ou intranet;

- conexão individual dos medidores com um servidor NTP (Network Time Protocol), fazendo o uso de uma conexão por rede global ou internet.

A conexão entre os medidores para que se mantenha o sincronismo nem sempre é possível, uma vez que na maioria dos casos os medidores não estão todos próximos uns dos outros para permitir a interconexão. $O$ sincronismo de tempo por satélites GPS é a tecnologia mais confiável para que se mantenha um bom sincronismo, dado que os satélites são regularmente calibrados para corrigir qualquer atraso. $O$ sincronismo por intermédio de um microcomputador próprio através de conexão por rede fechada sofre os riscos de ter a conexão interrompida, que o microcomputador trave ou perca a regulação de seu relógio, passando a transmitir aos medidores datas e horas incorretas, tornando necessário alocar pessoal para realizar a monitoração e manutenção constante do computador e da rede. O sincronismo através de um servidor NTP pela internet oferece o risco da conexão ser 
interrompida e de expor o medidor a acessos de terceiros, caso uma solução de segurança de rede não seja implementada.

Qualquer que seja a tecnologia escolhida, o sincronismo deve ser feito sempre a partir de uma mesma fonte para todos os medidores, visando evitar problemas de defasagens de tempo que podem ocorrer entre as diferentes fontes de sincronismo disponíveis.

$\mathrm{Na}$ aplicação prática da metodologia neste trabalho, optou-se pela tecnologia de conexão com satélites GPS.

\subsubsection{Normas de Segurança}

Para todo e quaisquer trabalhos realizados nas proximidades de instalações elétricas, devem ser seguidas as normas e procedimentos de segurança cabíveis. Estes procedimentos estão descritos na Norma Regulamentadora (NR) $N^{\circ} 10-$ "Segurança em Instalações e Serviços em Eletricidade" (BRASIL, 2004), e devem sempre ser postos em prática cuidadosamente.

A equipe, que deve consistir em pelo menos duas pessoas, deve possuir qualificação para executar o serviço comprovando a conclusão de um curso de capacitação na norma NR 10, com treinamento de reciclagem com periodicidade bienal em dia, se for o caso. Além da comprovação da qualificação, a equipe deve estar com exames de saúde em dia, em conformidade com a NR N 7 - "Programa de Controle Médico de Saúde Ocupacional" (BRASIL, 1998).

Em cada local em que for realizar algum serviço, a equipe deve ser submetida a um curso básico de segurança do trabalho do próprio local ou empresa em que for realizar o serviço, visando conhecer os procedimentos de segurança internos da empresa, pontos de encontro e normas de segurança adicionais do local. 
Além dos cursos, ao entrar nas imediações da subestação a equipe deve obedecer às regras de uso de EPIs (Equipamentos de Proteção Individual) e de EPCs (Equipamentos de Proteção Coletiva) de cada setor por onde a equipe transitar ou realizar o serviço e manterem-se sempre nos locais de trânsito e a distâncias seguras dos equipamentos.

Finalmente, enquanto estiver dentro da subestação, a equipe deverá sempre acompanhar e ser acompanhada por pelo menos um funcionário da empresa e a realização das conexões com os equipamentos da subestação, energizados ou desenergizados, só poderá ser realizada pelo funcionário técnico da empresa de energia que utilizará os EPIs necessários para o serviço.

\subsubsection{Conexão dos Medidores aos Pontos de Medição}

Os locais de medição, geralmente subestações, devem conter pontos de conexão para a medição das tensões já em nível de tensão adequado para a conexão com o medidor (seja por conexões diretas ou através de TPs), preferencialmente disponíveis nas três fases. Deve existir também acesso aos circuitos secundários dos TCs de medição, preferencialmente nas três fases.

De uma maneira geral, cada circuito que está conectado à subestação possui monitoramento de tensões e correntes para fins de proteção e gerenciamento da rede. Na sala de controle da subestação há painéis para cada circuito, onde estão os equipamentos de controle da proteção e mostradores analógicos ou digitais das tensões e correntes medidas.

Em cada painel, se houver medição das tensões do circuito, estas tensões estão disponibilizadas em réguas de bornes de conexão localizadas próximo a porta de acesso do painel, na parte dianteira ou traseira do interior dos painéis, já convertidas em níveis de baixa tensão através dos TPs instalados no circuito. Estas réguas permitem a conexão direta dos equipamentos de medição e programa-se o 
equipamento de medição com a relação de transformação dos TPs da subestação, para se ter as leituras dos níveis de tensão do circuito.

Os circuitos secundários dos TCs normalmente se encontram nestes painéis, geralmente dentro das calhas de passagem dos fios e conectadas ao equipamento de controle da proteção ou aos mostradores do painel.

A influência das respostas em frequência dos TCs deve ser verificada, pois quanto maior a frequência do sinal que se deseja investigar, maior deverá ser o erro encontrado em TCs de medição otimizados para a frequência fundamental.

Uma nota importante é que, via de regra, não se permite a abertura dos circuitos secundários dos TCs para a conexão com equipamentos que não façam parte da subestação. Os sistemas de medição, controle e proteção das companhias do setor elétrico dependem de uma medição confiável desses equipamentos e não pode permitir a ocorrência de falhas devido à inserção de equipamentos de terceiros que não façam parte dos seus sistemas.

Para contornar este problema, sugere-se fazer o uso de uma conexão indireta realizada através de um acoplamento magnético ao circuito secundário dos TCs. De um modo geral, são utilizados TCs com corrente do secundário de 0 a 5 ou de 0 a 10 Ampères. Em Saraiva (2007), os autores desenvolveram um equipamento simples para realizar este tipo de conexão e obter as mesmas formas de onda do secundário dos TCs, com amplitude de 0 a 5 Ampères.

\subsection{Registros de Tensões e Correntes}

Os registros dos valores de tensões e correntes harmônicas devem atender às seguintes especificações. 


\subsubsection{Registros de Valores Eficazes}

Para uma avaliação geral do comportamento das emissões de harmônicos no sistema elétrico, é conveniente realizar registros durante longos intervalos de tempo dos valores eficazes de cada ordem harmônica de interesse.

A finalidade destes registros é a de se permitir analisar o comportamento das fontes de harmônicos na rede elétrica ao longo do tempo, encontrando fundamentalmente um padrão aproximado da rotina de uso de equipamentos emissores de correntes harmônicas dos consumidores ou de mudanças na configuração da rede.

Por definição, o valor instantâneo de uma função genérica $f(t)$ periódica, que pode ser uma tensão ou corrente composta por diferentes frequências harmônicas, pode ser definido pela eq.(6) apresentada em De La Rosa (2006):

$$
f(t)=F_{D C}+\sum_{h=1}^{\infty} f_{h}(t)=F_{D C}+\sum_{h=1}^{\infty} F_{h} \cdot \operatorname{sen}\left(\frac{2 \cdot \pi \cdot h \cdot t}{T}+\theta_{h}\right)
$$

Onde: $t$ é o instante no tempo para o qual se deseja calcular o valor instantâneo;

$h$ é o valor da ordem harmônica que compõe o sinal, composta por valores inteiros positivos;

$F_{D C}$ é a componente contínua da função genérica $f(t)$;

$f_{h}(t)$ é o valor instantâneo da componente harmônica de ordem $h$ ao longo do tempo;

$F_{h}$ é o valor de pico do sinal da componente harmônica de ordem $h$;

$T$ é o período da função em sua frequência fundamental;

$\theta_{h}$ é o ângulo de defasagem de cada frequência harmônica $h$.

O valor eficaz $F_{r m s}$ desta função pode ser calculado através da eq.(7), segundo De La Rosa (2006): 


$$
F_{r m s}=\sqrt{\frac{1}{T} \cdot \int_{t}^{t+T} f^{2}(t) \cdot d t}=\sqrt{F_{D C}^{2}+\frac{1}{2} \cdot \sum_{h=1}^{\infty} F_{h}^{2}}
$$

Em sistemas elétricos de potência trifásicos, na corrente alternada, o valor de $F_{D C}$ geralmente é muito inferior a $F_{h}$ na frequência fundamental, podendo ser considerado nulo para que se obtenha uma boa aproximação na análise.

O medidor deve registrar os valores eficazes em intervalos regulares de tempo. Recomenda-se utilizar intervalos típicos de 5, 10, 15, 20 ou 30 minutos entre registros, mas qualquer intervalo regular pode ser utilizado, dependendo das capacidades do medidor e da característica de carga do sistema. Se o sistema contiver indústrias com fornos a arco, por exemplo, é conveniente realizar os registros em intervalos de tempo mais estreitos.

O período de medição depende do ciclo de carga do sistema em estudo. Recomenda-se como período de medição adequado para se permitir uma análise apropriada um tempo de, no mínimo, duas semanas que sejam representativas, sem que haja eventos especiais que possam afetar a rotina das cargas em estudo. Preferencialmente, um período de dois meses ou mais é recomendável para se obter uma melhor avaliação dos registros.

\subsubsection{Registros Fasoriais}

Os registros fasoriais instantâneos permitem a realização de uma estimação do fluxo harmônico, seja através de uma análise por inspeção ou através de algoritmos de estimação de estados harmônicos.

Para um determinado instante no tempo, um ciclo na frequência fundamental é processado para que se obtenham os módulos e os respectivos ângulos de defasagem na frequência fundamental e para cada ordem harmônica. 
Dada a definição de uma função genérica $f(t)$ periódica da eq.(6), os valores de interesse para os registros fasoriais são o valor de pico $F_{h}$ e o ângulo de defasagem $\theta_{h}$, respectivamente, para todas as ordens harmônicas de interesse.

Estes registros também devem ser feitos em intervalos regulares, mantendo-se o sincronismo de tempo entre os medidores. Os intervalos dependem da variação de carga, podendo variar entre intervalos de segundos ou até a cada 15 ou 30 minutos. $\mathrm{Na}$ prática pode-se realizar o registro em qualquer instante desde que todos os medidores estejam sincronizados no tempo e realizem o registro simultaneamente.

\subsection{Tratamento dos Registros de Medição}

Antes de realizar as análises, os registros de medição devem ser preparados para evitar inconsistências ou introdução de erros que possam causar resultados incoerentes nas análises executadas.

\subsubsection{Tratamento de Registros de Valores Eficazes}

Os registros devem ser verificados para que seja realizada a identificação de intervalos de registros perdidos ou afetados por fatores externos, tais como intervalos em que o medidor esteve desconectado da rede ou intervalos em que o local de medição esteve desenergizado para fins de manutenção ou operação, conforme ilustra a Figura 2. 


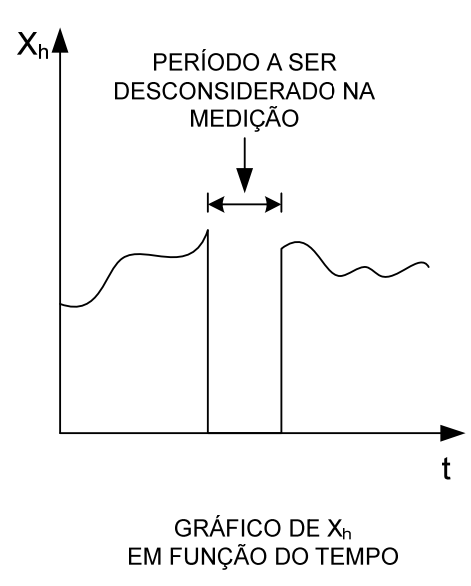

Figura 2 - Exemplo de registro com intervalo sem medição.

Também é preciso verificar se os valores amostrados estão dentro da escala correta de amplitude, multiplicando os valores por um fator de escala, quando necessário. Por exemplo, relações de TP ou TC.

Uma vez identificados os períodos com registros perdidos ou afetados por fatores externos tais como os citados anteriormente, para análises comparativas entre dois ou mais registros de medidores, recomenda-se eliminar da análise os registros de todos os medidores que coincidam com os mesmos períodos identificados em que ocorreram os registros perdidos ou afetados por fatores externos. Isso permite que sempre seja utilizado um mesmo número de registros válidos para as análises e comparações.

\subsubsection{Normalização Fasorial}

Antes de realizar a análise fasorial, primeiramente deve-se verificar se os ângulos de defasagem entre os sinais fundamentais de cada fase estão coerentes ou se há algum valor que foi registrado com sentido oposto, provavelmente por acoplamento invertido do TC durante a instalação. Caso os registros de uma determinada fase apresentem sentido inverso, é preciso corrigir todos os ângulos de defasagem desta 
fase, para todas as ordens harmônicas, girando-se em $180^{\circ} \mathrm{o}$ valor do ângulo de defasagem medido para que se tenha os registros das correntes no sentido correto.

Durante a medição, podem ter ocorrido momentos em que os sinais de sincronização foram perdidos e o medidor permaneceu em funcionamento através de seu relógio interno. Nestes casos, deve-se considerar que o sincronismo dos registros foi perdido em todas as frequências, tanto na fundamental quanto para as frequências harmônicas. Os erros nos ângulos de fase serão tão maiores quanto maior for a frequência da ordem harmônica a ser analisada, tornando impossível a realização da análise fasorial.

Quando os medidores realizam o disparo do registro tendo como referência o seu relógio interno, geralmente também é registrado um indicador para informar que este registro foi feito sem o sincronismo de tempo (para verificar a existência deste indicador, deve-se fazer a leitura do manual do equipamento de medição utilizado). Isso permite que se possa decidir posteriormente se estes valores serão utilizados ou descartados das análises, dependendo da aplicação. Para análise fasorial harmônica, é recomendável que estes registros sejam desconsiderados.

Uma vez que todos os ângulos estejam coerentes com base nas observações anteriores deve-se, então, tomar como referência o ângulo de defasagem na frequência fundamental de uma determinada variável do sistema para normalizar todos os resultados a partir dela e permitir a observação da variação dos ângulos de defasagem dos fasores medidos durante os intervalos de medição.

A razão desta normalização é a de que os sinais são amostrados ao longo do tempo, contendo diferentes ângulos de fase com base no instante em que a amostra instantânea da senóide foi coletada pelo medidor. Assim, se for necessário comparar os registros de dois instantes diferentes de tempo, a visualização das diferenças entre eles será mais fácil se os fasores estiverem fixados em posições relativas a um referencial comum do sistema. 
De uma maneira geral, é recomendável tomar como referência uma variável com disponibilidade contínua e alta estabilidade. Assim, recomenda-se tomar como referência o ângulo de defasagem instantâneo de uma das fases da tensão na barra mais próxima do local de suprimento/geração.

Por exemplo, supondo-se que as seguintes grandezas representem os registros fasoriais em cada fase das tensões e correntes em uma barra fictícia de uma rede, chamada de " $X$ ", conforme definição apresentada na eq.(3):

$$
\begin{aligned}
& \hat{V}_{1}{ }^{X}{ }_{A}=V_{1}{ }^{X}{ }_{A} \angle \delta_{1}{ }^{X}{ }_{A} \\
& \hat{V}_{1}{ }_{B}=V_{1}{ }_{B} \angle \delta_{1}{ }_{B} \\
& \hat{V}_{1}{ }_{C}=V_{1}{ }_{C} \angle \delta_{1}{ }_{C} \\
& \hat{I}_{1}{ }^{X}{ }_{A}=I_{1}{ }^{X}{ }_{A} \angle \varphi_{1}{ }^{X}{ }_{A} \\
& \hat{I}_{1}{ }_{B}{ }_{B}=I_{1}{ }^{X}{ }_{B} \angle \varphi_{1}{ }_{B} \\
& \hat{I}_{1}{ }^{X}{ }_{C}=I_{1}{ }^{X}{ }_{C} \angle \varphi_{1}{ }_{C} \\
& \hat{I}_{h}{ }^{X}{ }_{A}=I_{h}{ }^{X} \angle \varphi_{h}{ }^{X}{ }_{A} \\
& \hat{I}_{h}{ }^{X}{ }_{B}=I_{h}{ }^{X}{ }_{B} \angle \varphi_{h}{ }^{X}{ }_{B} \\
& \hat{I}_{h}{ }^{X}{ }_{C}=I_{h}{ }^{X}{ }_{C} \angle \varphi_{h}{ }^{X}{ }_{C}
\end{aligned}
$$

Onde: $\hat{V}_{1}^{X}{ }_{A}$ é o fasor da tensão da fase $A$, na frequência fundamental, medida na barra " $X$ ";

$V_{1}{ }_{A}$ é a amplitude da tensão da fase A, na frequência fundamental, medida na barra " $X$ ";

$I_{1}^{X} A$ é a amplitude da corrente da fase A na frequência fundamental, medida na barra " $X$ ";

$I_{h}{ }^{X}$ é a amplitude da corrente da fase A na frequência harmônica $h$, medida na barra " $X$ ";

$\delta_{1}{ }_{A}$ é $O$ ângulo de defasagem da tensão da fase $A$ na frequência fundamental, medida na barra " $X$ ";

$\varphi_{1}{ }_{A}$ é $O$ ângulo de defasagem da corrente da fase $A$ na frequência fundamental, medida na barra " $X$ "; 
$\varphi_{h}{ }_{A}$ é o ângulo de defasagem da Corrente da fase $A$ na frequência harmônica $h$, medida na barra " $X$ ".

Tomando-se por referência o ângulo de defasagem da tensão na fase $A\left(\delta_{1}{ }^{X}\right)$, normalizam-se os ângulos de defasagem dos registros fasoriais trifásicos da barra "X" através do teorema de deslocamento no tempo (Mack Grady, 2001) subtraindose dos ângulos de defasagem de cada grandeza o ângulo de defasagem da tensão na fase $A$, multiplicado pela respectiva ordem harmônica. Este processo está ilustrado através das seguintes equações:

$$
\begin{aligned}
& \hat{V}_{1}{ }^{X}{ }^{\prime}=V_{1}{ }_{A}{ }_{A} \angle\left(\delta_{1}{ }^{X}{ }_{A}-\delta_{1}{ }_{A}{ }_{A}\right)=V_{1}{ }^{X} \angle 0^{\circ} \\
& \hat{V}_{1}^{X}{ }_{B}{ }^{\prime}=V_{1}{ }_{B} \angle\left(\delta_{1}{ }_{B}^{X}-\delta_{1}{ }^{X}{ }_{A}\right) \\
& \hat{V}_{1}^{X}{ }^{X}{ }^{\prime}=V_{1}{ }^{X} C \angle\left(\delta_{1}{ }^{X}{ }_{C}-\delta_{1}{ }^{X}{ }_{A}\right) \\
& \hat{I}_{1}{ }^{X}{ }^{A}=I_{1}{ }_{A}{ }_{A} \angle\left(\varphi_{1}{ }^{X}{ }_{A}-\delta_{1}{ }^{X}{ }_{A}\right) \\
& \hat{I}_{1}{ }_{B}{ }^{\prime}=I_{1}{ }^{X}{ }_{B} \angle\left(\varphi_{1}{ }_{B}{ }_{B}-\delta_{1}{ }^{X}{ }_{A}\right) \\
& \hat{I}_{1}{ }^{X} C^{\prime}=I_{1}{ }^{X}{ }_{C} \angle\left(\varphi_{1}{ }^{X}{ }_{C}-\delta_{1}{ }^{X}{ }_{A}\right) \\
& \hat{I}_{h}{ }^{X} A^{\prime}=I_{h}{ }^{X}{ }_{A} \angle\left\{\varphi_{h}{ }^{X}{ }_{A}-\left(h * \delta_{1}{ }^{X}{ }_{A}\right)\right\} \\
& \hat{I}_{h}{ }^{X}{ }_{B}{ }^{\prime}=I_{h}{ }^{X}{ }_{B} \angle\left\{\varphi_{h}{ }^{X}{ }_{B}-\left(h * \delta_{1}{ }^{X}{ }_{A}\right)\right\} \\
& \hat{I}_{h}{ }^{X} C^{\prime}=I_{h}{ }^{X} C \angle\left\{\varphi_{h}{ }^{X}{ }_{C}-\left(h * \delta_{1}{ }^{X}{ }_{A}\right)\right\}
\end{aligned}
$$

Onde: $\hat{V}_{1}^{X}{ }_{A^{\prime}}$ é o fasor normalizado da tensão da fase $A$, na frequência fundamental, medida na barra $X$.

Esta correção deve ser realizada sobre os registros de todas as barras do sistema em estudo, utilizando-se sempre o mesmo ângulo de referência escolhido, da barra de referência adotada. Com isto, todos os fasores medidos em diferentes instantes tornam-se comparáveis. 


\subsection{Análise Estatística por Correlação}

Através de uma análise por correlação dos registros de correntes de dois locais distintos é possível verificar a existência ou não de uma relação entre as variações dos valores de correntes ao longo do tempo. É importante notar, contudo, que a identificação desta relação não implica em uma relação do tipo causa-efeito, mas apenas que há algum tipo de relação entre o comportamento das duas correntes analisadas.

São requisitos fundamentais para esta análise que o número de registros de valores eficazes seja igual para ambos os locais em comparação, e também que estes registros tenham sido realizados fazendo o uso de sincronismo de tempo.

\subsubsection{Diagrama de Dispersão}

Para a análise de dispersão, segundo Crespo (2004), constrói-se um diagrama de dispersão cartesiano cujos eixos são compostos pelos valores eficazes das correntes em uma determinada ordem harmônica, registradas em dois locais distintos. Cada ponto no diagrama representará uma amplitude em função da outra, ambas ocorridas em um mesmo instante de tempo e registradas com sincronismo por ambos os medidores. O formato da nuvem de pontos composta por todos os pares de registros indicará se existe alguma relação entre as correntes dos dois locais e qual é o seu tipo.

Para exemplificar, tomem-se os registros de valores eficazes das correntes de uma determinada ordem harmônica $h$ de dois locais distintos " $X$ " e " $Y$ ". Monta-se um diagrama de dispersão de $X_{h}$ e $Y_{h}$ e, para cada instante de tempo $t_{i}$ em que ocorreu amostragem simultânea das correntes, é montado um ponto característico no diagrama de dispersão, conforme exemplificado na Figura 3. Cada ponto no 
diagrama de dispersão corresponderá ao estado de cada uma das duas correntes harmônicas em um dado instante de tempo.
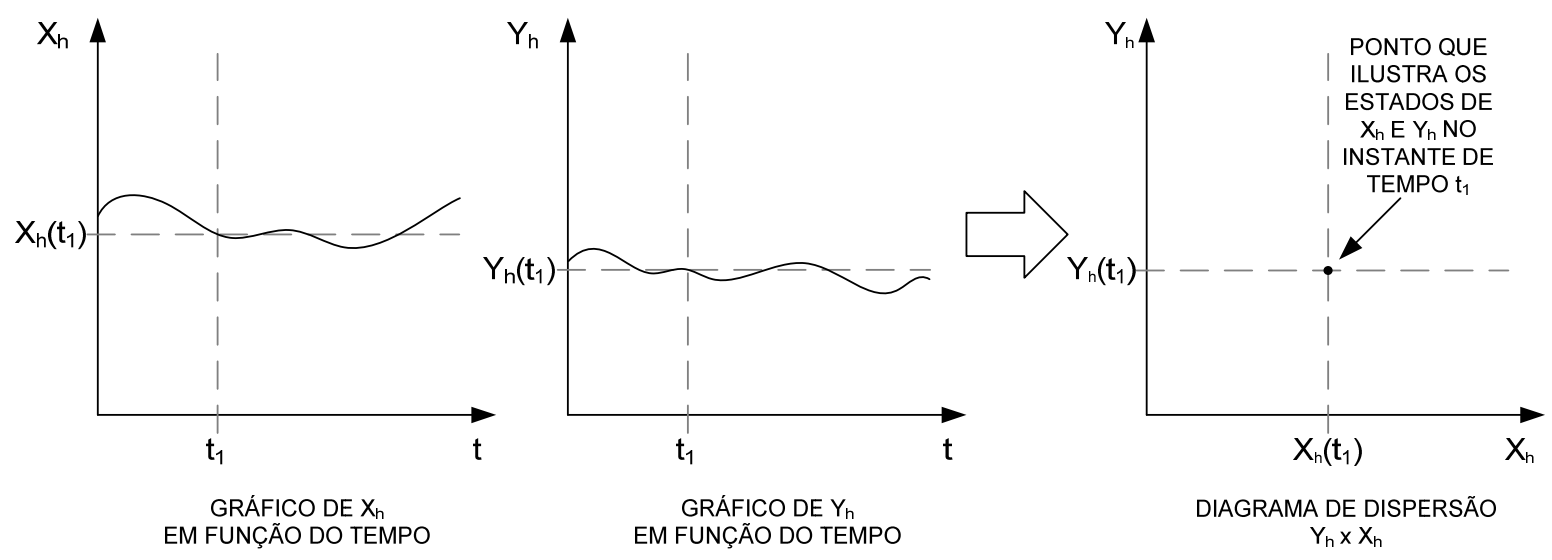

Figura 3 - Exemplo de montagem de um diagrama de dispersão.

Uma vez que todos os pontos do intervalo tenham sido dispostos no gráfico de dispersão, por inspeção gráfica pode-se avaliar o grau de correlação (Crespo, 2004) conforme ilustra a Figura 4. 


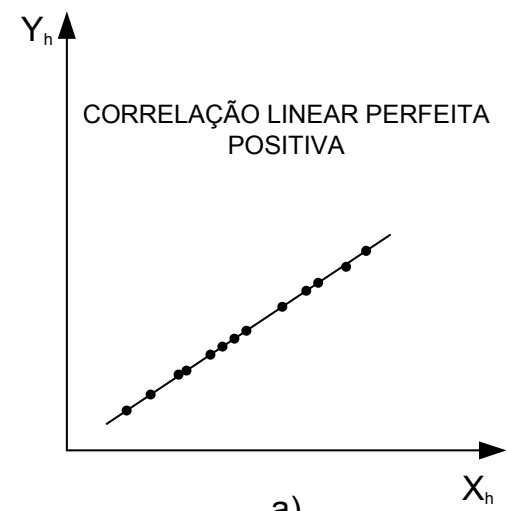

a)

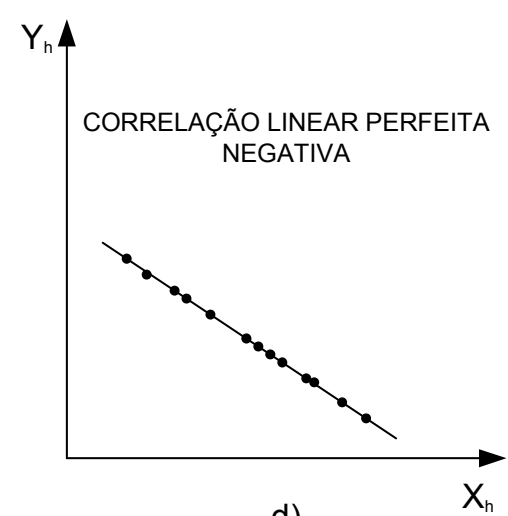

d)

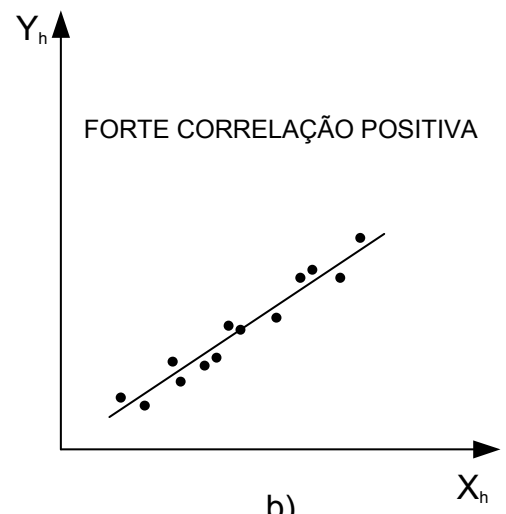

b)

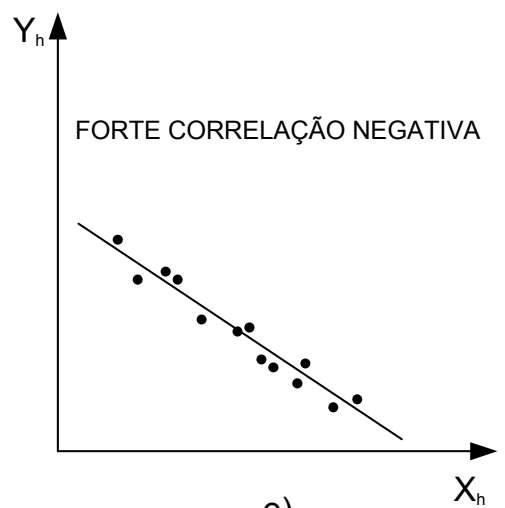

e)
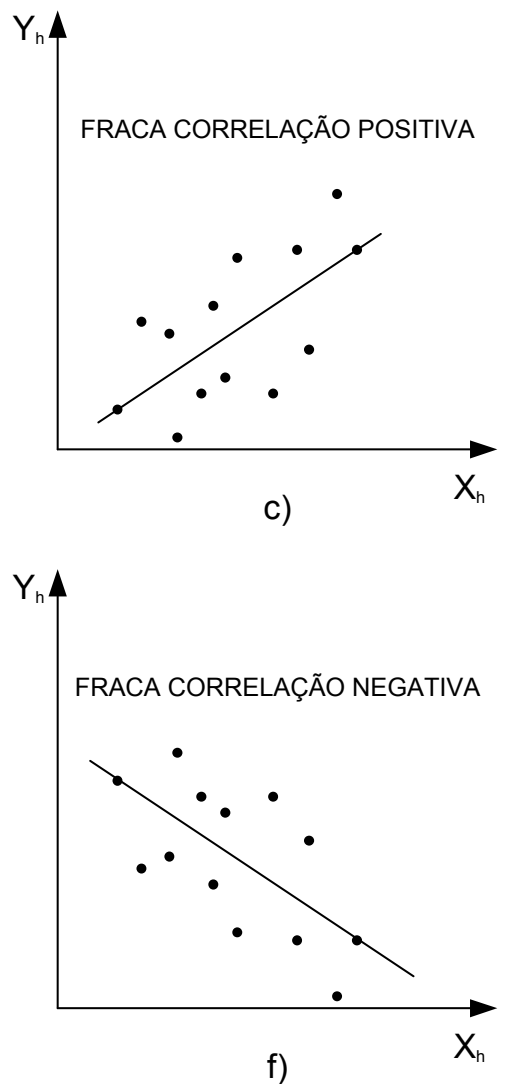

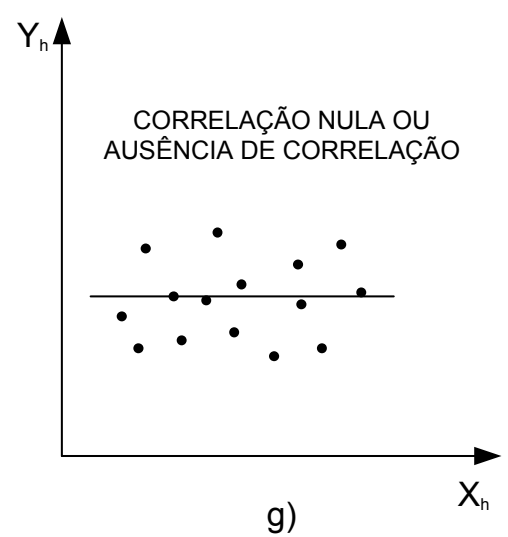

g)

Figura 4 - Exemplos gráficos de diferentes graus de correlação.

A forma matemática de se averiguar o grau de correlação em um gráfico é através da determinação do coeficiente de correlação linear. 


\subsubsection{Coeficiente de Correlação Linear}

Uma vez que todos os pontos do período que se deseja avaliar estejam representados no diagrama de dispersão, pode-se avaliar o grau de correlação entre as duas grandezas quaisquer $X_{h}$ e $Y_{h}$ através do coeficiente de correlação linear populacional de Pearson, conforme Crespo (2004) e Figueiredo Filho (2009), definido pela eq.(26).

$$
\rho_{X, Y, \mathrm{~h}}=\frac{\sum_{i=1}^{n}\left(X_{\mathrm{h}, i} * Y_{\mathrm{h}, i}\right)-\frac{1}{n} * \sum_{i=1}^{n} X_{\mathrm{h}, i} * \sum_{i=1}^{n} Y_{\mathrm{h}, i}}{\sqrt{\left[\sum_{i=1}^{n} X_{\mathrm{h}, i}{ }^{2}-\frac{1}{n} *\left(\sum_{i=1}^{n} X_{\mathrm{h}, i}\right)^{2}\right] *\left[\sum_{i=1}^{n} Y_{\mathrm{h}, i}{ }^{2}-\frac{1}{n} *\left(\sum_{i=1}^{n} Y_{\mathrm{h}, i}\right)^{2}\right]}}
$$

Onde: $\rho_{X, Y, h}$ representa o coeficiente de correlação linear populacional de Pearson entre $X$ e $Y$ para uma determinada ordem harmônica $h$;

$n$ é o número total de amostras para a análise, que é igual ao número total de amostras de $X_{h}$ ou de $Y_{h}$;

$X_{h, i}$ representa 0 valor da amostra $i$ de $X$ para uma determinada ordem harmônica $h$;

$Y_{h, i}$ representa $o$ valor da amostra $i$ de $Y$ para uma determinada ordem harmônica $h$.

O coeficiente de correlação linear populacional $\rho_{X, Y, h}$ é um número real que varia no intervalo de -1 a +1 , e sua interpretação está vinculada às seguintes regras:

- se $\rho_{X, Y, h}$ é negativo, a correlação é negativa;

- se $\rho_{X, Y, h}$ é positivo, a correlação é positiva;

- se $\rho_{X, Y, h}$ é igual a -1 ou +1 , a correlação é perfeita;

- se $\rho_{X, Y, h}$ está entre $-0,7$ e - 1 ou +0,7 e +1, a correlação é forte;

- se $\rho_{X, Y, h}$ está entre $-0,4$ e $-0,7$ ou $+0,4$ e +0,7, a correlação é moderada;

- se $\rho_{X, Y, h}$ está entre $-0,2$ e - 0,4 ou +0,2 e +0,4, a correlação é fraca;

- se $\rho_{X, Y, h}$ está entre $-0,2$ e $+0,2$, a correlação é nula. 
Deve-se lembrar que a análise por correlação não determina uma relação de causaefeito, mas apenas a existência de uma relação entre as duas variáveis em estudo. Entretanto, pode-se afirmar que duas variáveis que possuem relação de causa-efeito estarão obrigatoriamente correlacionadas.

\subsubsection{Análise por Patamares de Carga}

O comportamento da carga influencia as correntes harmônicas que circulam no sistema, pois a rotina dos consumidores dita a composição de equipamentos que estão ligados ao sistema elétrico em um determinado período do dia.

Tipicamente em dias úteis da semana, das 7 horas às 17 horas o comportamento principal das cargas é diretamente influenciado pelas cargas dos setores industrial e comercial. Das 17 horas às 22 horas, adicionalmente ao comportamento industrial há cargas residenciais como chuveiros e aparelhos eletrônicos domésticos. Das 22 horas às 7 horas, a carga é muito baixa, resultado de equipamentos eletrônicos em stand-by e outras cargas mais dispersas em uso.

Nos sábados e domingos, a carga também possui comportamento diferenciado, naturalmente ditado pela forma como os consumidores utilizam a energia elétrica nos fins de semana.

Dada a diferença nos tipos de equipamentos ligados em cada patamar de carga, a análise dos registros torna-se mais simples se os registros de medição forem divididos de forma a isolar os comportamentos de cada patamar de carga.

Por exemplo, considerando um registro fictício de uma semana de um local " $X$ ", representativo de uma corrente de ordem harmônica $h$, apresentado na Figura 5. 


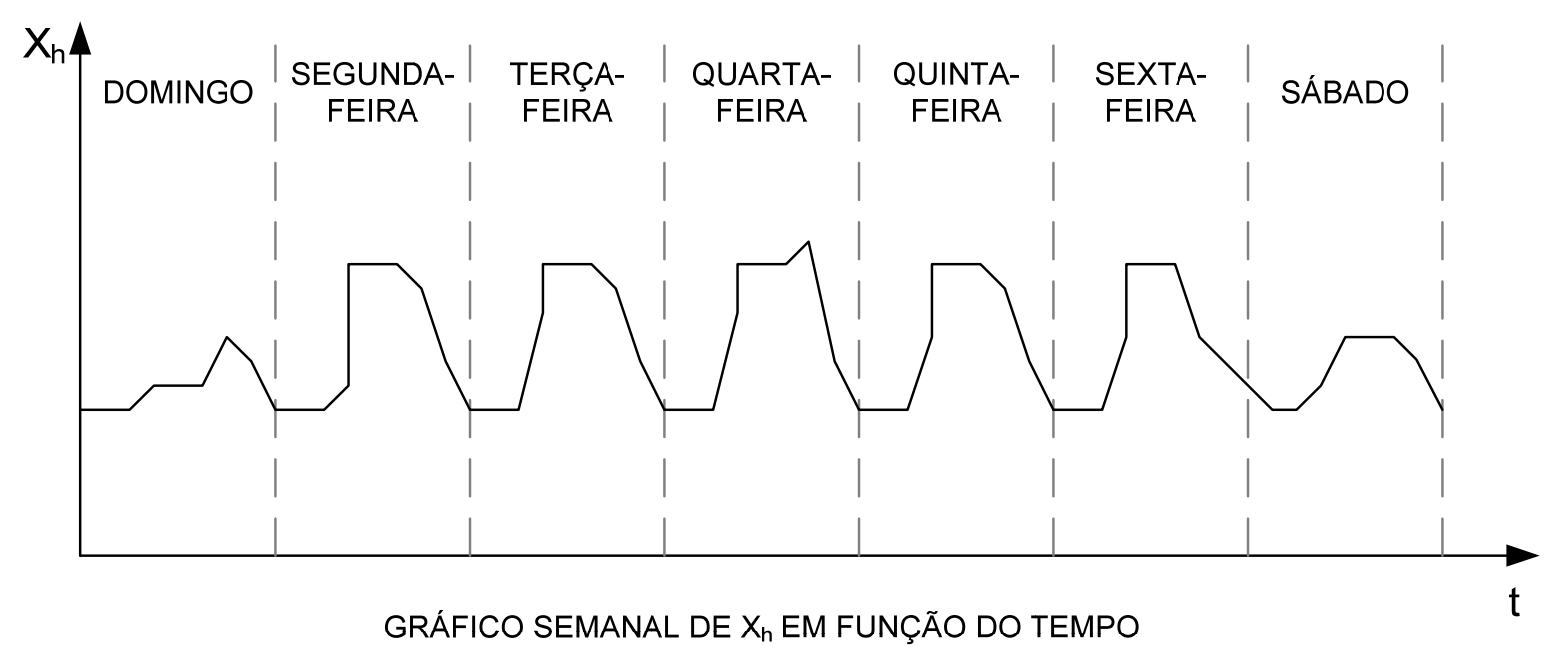

Figura 5 - Exemplo de gráfico semanal do valor eficaz da corrente harmônica $h$ de um local $X$.

Supondo-se que se realize uma análise por correlação destes registros com um segundo conjunto de registros de um local " $Y$ " qualquer, com registros de valores eficazes semelhantes da mesma semana em que ocorreram os registros do local " $X$ ', o diagrama de dispersão obtido pode resultar em uma fraca correlação, conforme ilustra a Figura 6.

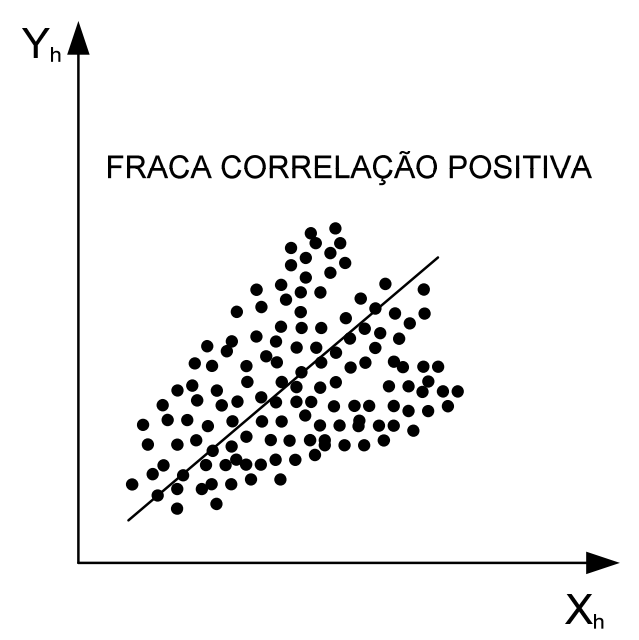

Figura 6 - Exemplo de diagrama de dispersão dos valores eficazes da corrente harmônica $h$ dos locais $X$ e $Y$. 
A variação dos equipamentos ligados à rede elétrica ao longo do dia pode alterar o a correlação de fluxos entre as linhas que estão sendo analisadas. O mesmo pode ser afirmado para diferentes dias da semana, como fins de semana e dias úteis. Se estas diferentes formas de correlação de fluxos forem avaliadas juntas, a nuvem de pontos no diagrama de dispersão será muito dispersa, levando sua análise a concluir que a correlação entre estas duas linhas é fraca.

Se estes registros forem divididos de acordo com o comportamento de carga particular desta semana, obtemos a discriminação apresentada na Figura 7.

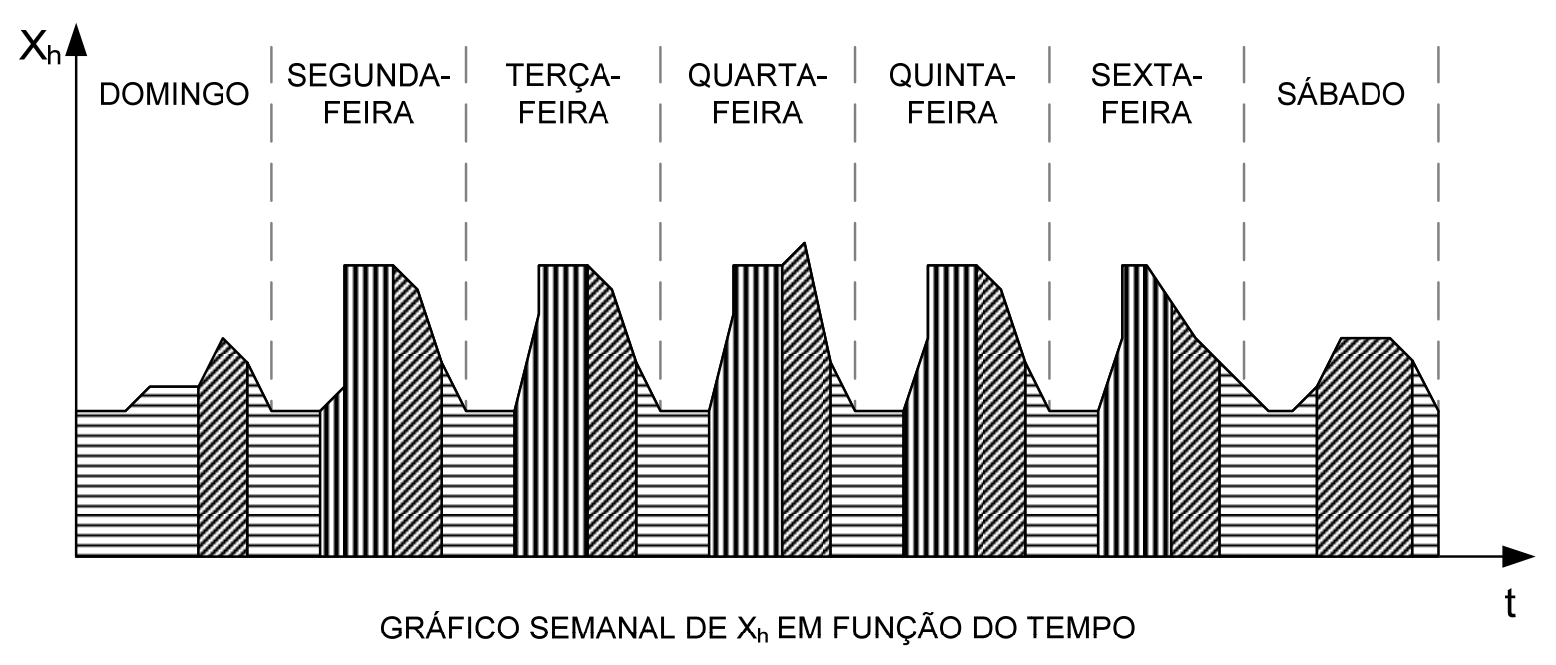

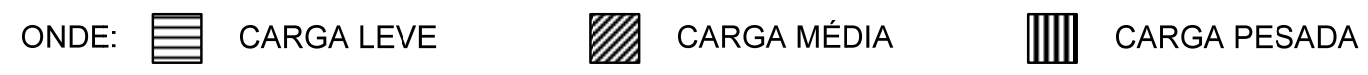

Figura 7 - Exemplo de divisão por patamares de carga do gráfico de valor eficaz da corrente harmônica $h$ do local $X$.

Separando-se os registros de acordo com o tipo de carga (leve, média ou pesada), têm-se os seguintes agrupamentos de registros de valores eficazes para serem analisados separadamente, conforme indicado na Figura 8. 

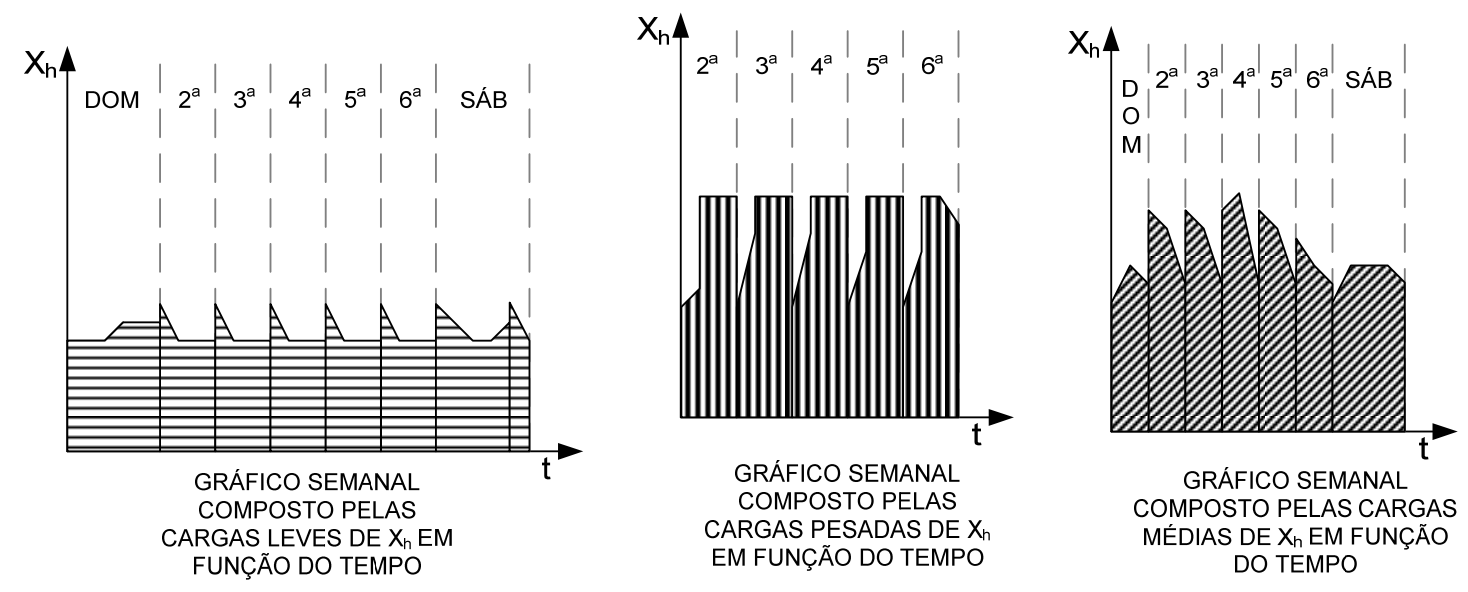

Figura 8 - Agrupamento dos registros por patamar de carga.

Realizando-se o mesmo procedimento para o local $Y$, o resultado das correlações para patamares de carga independentes entre $X$ e $Y$ pode ser ilustrado pela Figura 9.
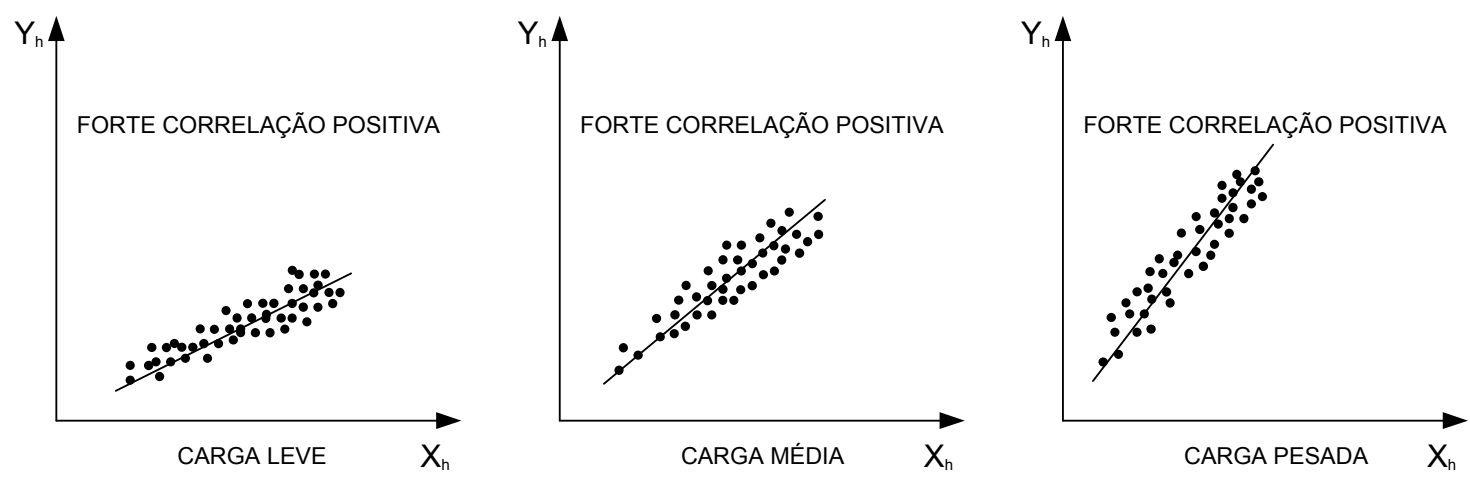

Figura 9 - Diagramas de dispersão da corrente harmônica $h$ entre os locais $X$ e $Y$, divididos por patamar de carga.

Nota-se que ao agrupar os registros por patamares de carga o comportamento se torna mais constante e coerente. Isso resulta em diagramas de dispersão mais "limpos" e o coeficiente de correlação linear de cada gráfico apresentará um valor mais consistente. 


\subsection{Análise Fasorial}

Definindo o foco em uma determinada barra do sistema elétrico em estudo, contendo medições fasoriais sincronizadas em todas as linhas conectadas a esta barra, pode-se realizar uma análise fasorial das correntes que passam pela barra para determinar o fluxo de corrente harmônica de suas linhas.

Partindo do princípio que todas as correntes fasoriais foram tratadas conforme descrito no item 2.3, é fixado um sentido de fluxo de corrente como "positivo". Por exemplo, o sentido de corrente é positivo quando a corrente flui do extremo oposto da linha até a barra.

Por definição, para cada uma das fases de uma barra, em um dado instante de tempo, a somatória dos fasores das correntes de uma determinada ordem harmônica resultará em zero.

Vale comentar que, quando são utilizados fasores obtidos de medições reais, nem sempre esta definição poderá ser verificada, pois o resultado da somatória dependerá dos erros de precisão dos diversos equipamentos que fazem a interface entre a rede elétrica e o medidor, principalmente para ordens harmônicas mais elevadas, visto que se torna mais complexa e custosa a obtenção de equipamentos calibrados nestas frequências.

A análise fasorial por inspeção consiste em reproduzir em diagramas fasoriais individuais os fasores das componentes fundamentais e das componentes harmônicas das correntes de cada linha, para cada ordem harmônica, visando determinar as seguintes características:

- o caminho do fluxo de corrente na frequência fundamental, consistindo na determinação das linhas que contém as cargas e das linhas que possuem os 
suprimentos das correntes que passam pela barra naquele dado instante de tempo, como ilustrado no exemplo da Figura 10;

- para o mesmo instante de tempo, sobre o diagrama dos fasores de ordem harmônica, define-se quais fasores pertencem às cargas e aos suprimentos definidos com base na análise de fasores na frequência fundamental, como ilustrado no exemplo da Figura 11;

- através da análise angular da posição dos fasores, determinar quais são as composições de correntes que possuem sentidos opostos uma às outras, para definir os caminhos de maior fluxo das correntes harmônicas.
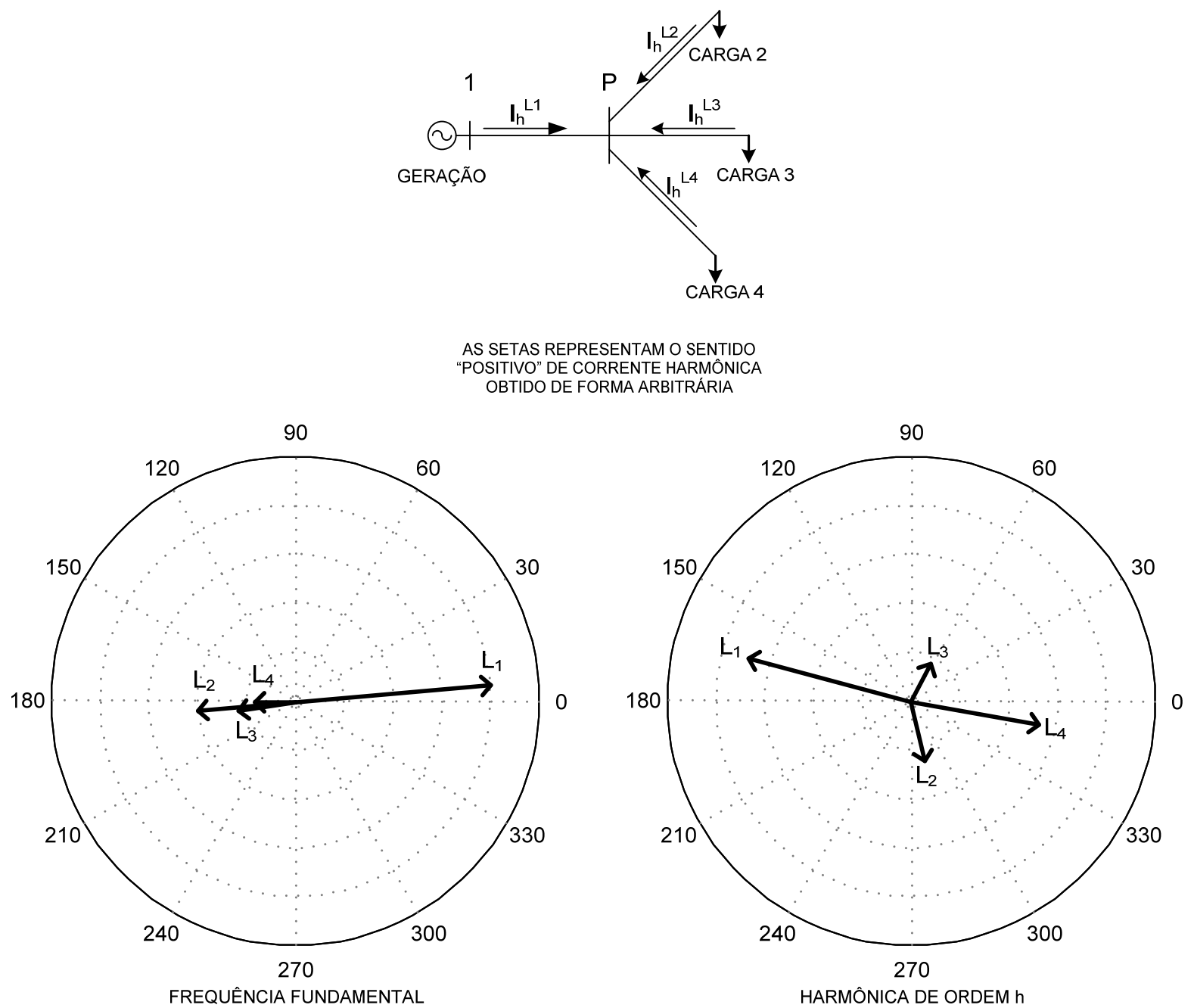

Figura 10 - Diagramas fasoriais das correntes fundamental e harmônica de ordem $h$ das linhas conectadas a uma barra fictícia $P$. 


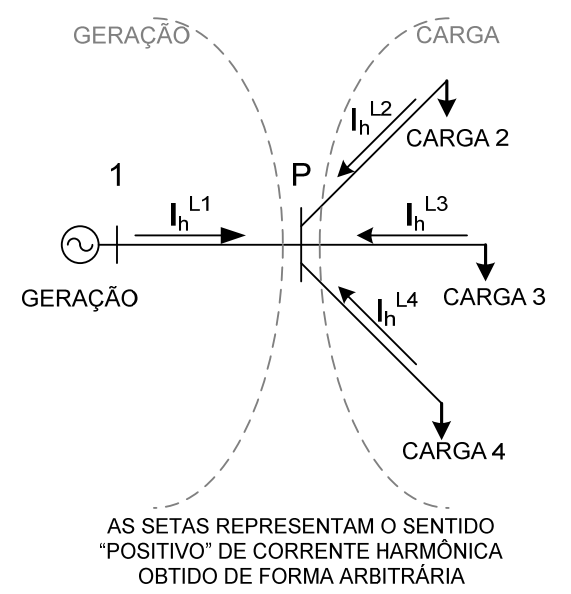

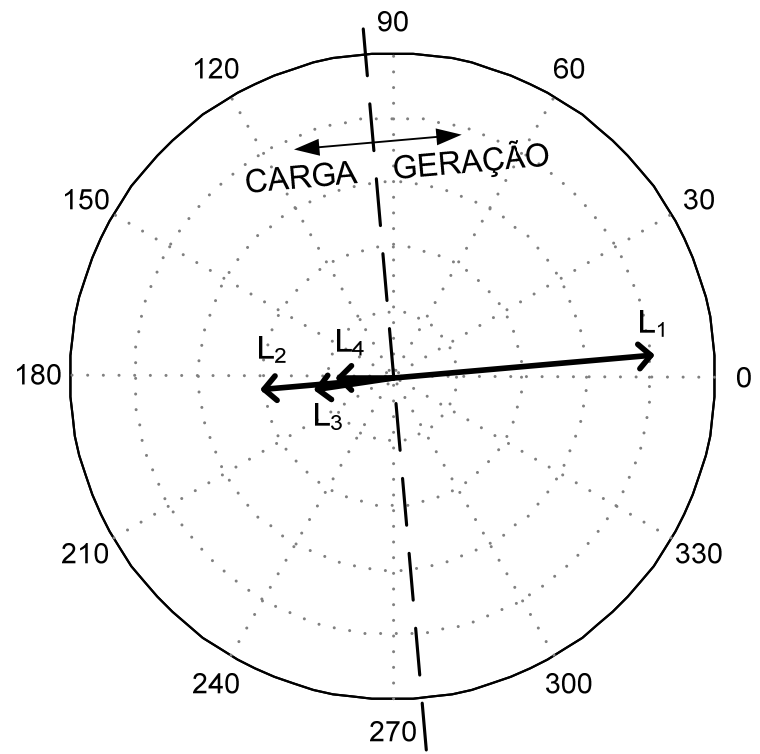

FREQUÊNCIA FUNDAMENTAL

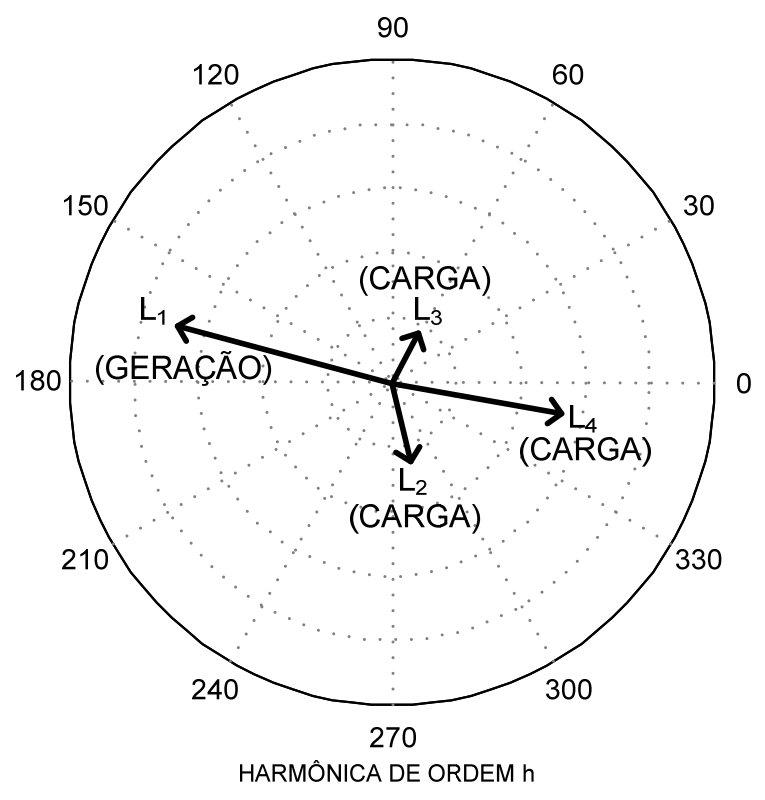

Figura 11 - Classificação de fasores das linhas de carga e das linhas de geração.

Para ilustrar, através de uma análise dos fasores de ordem harmônica $h$ apresentados no diagrama fasorial da Figura 11, o principal fluxo harmônico vai da carga na linha $L_{4}$ para a linha do suprimento. As correntes das linhas $L_{2}$ e $L_{3}$ também contribuem, mas o ângulo de defasagem entre elas faz com que ambas se cancelem parcialmente, resultando em uma componente equivalente de menor amplitude, conforme ilustra a Figura 12. 


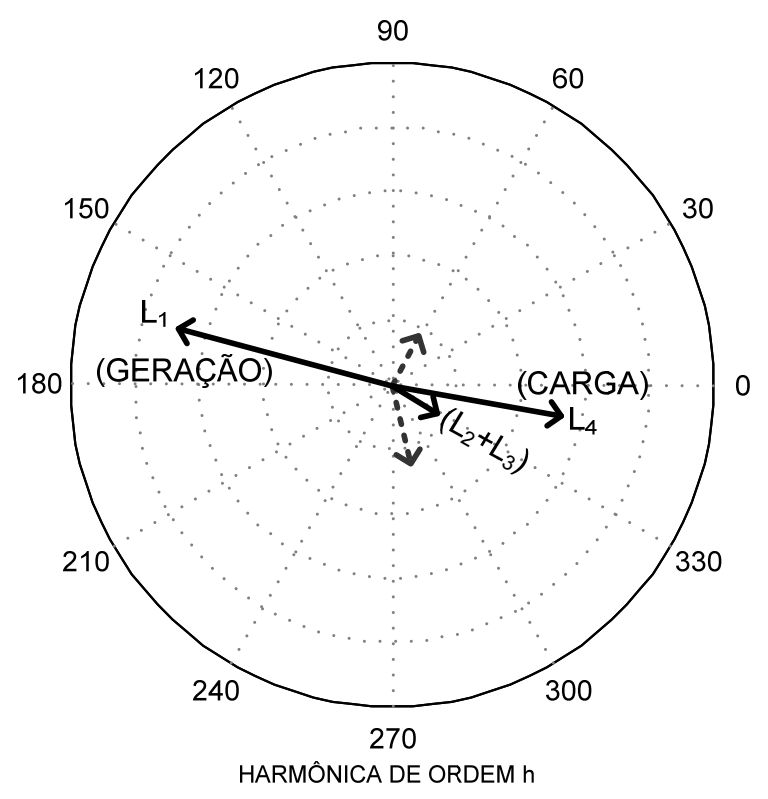

Figura 12 - Exemplo de cancelamento parcial das parcelas das linhas $L_{2}$ e $L_{3}$.

Durante a análise fasorial, deve-se lembrar que os fluxos de correntes harmônicas incidentes em uma barra podem possuir as seguintes características:

- todas as correntes harmônicas se originam nas linhas das cargas e fluem para as linhas de suprimento, conforme ilustra a Figura 13;

- algumas correntes harmônicas se originam nas linhas das cargas e fluem para as linhas de suprimento, enquanto outras fluem entre duas ou mais cargas. Estas últimas se verificam no cancelamento de suas correntes ao se fazer a somatória, conforme ilustra a Figura 14;

- todas as correntes harmônicas fluem somente nas linhas das cargas com quase nenhuma corrente resultante nas linhas de suprimento, conforme ilustra a Figura 15. 


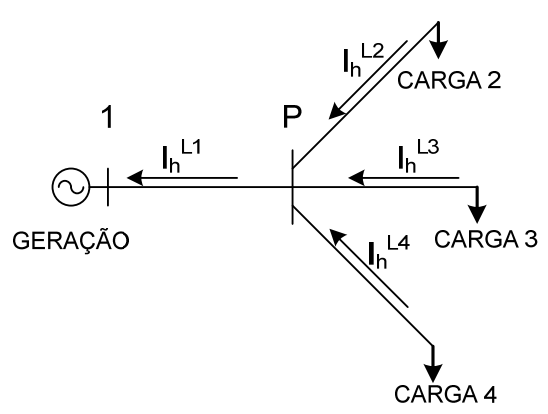

AS SETAS REPRESENTAM O SENTIDO DOS FLUXOS DE CORRENTE HARMÔNICA

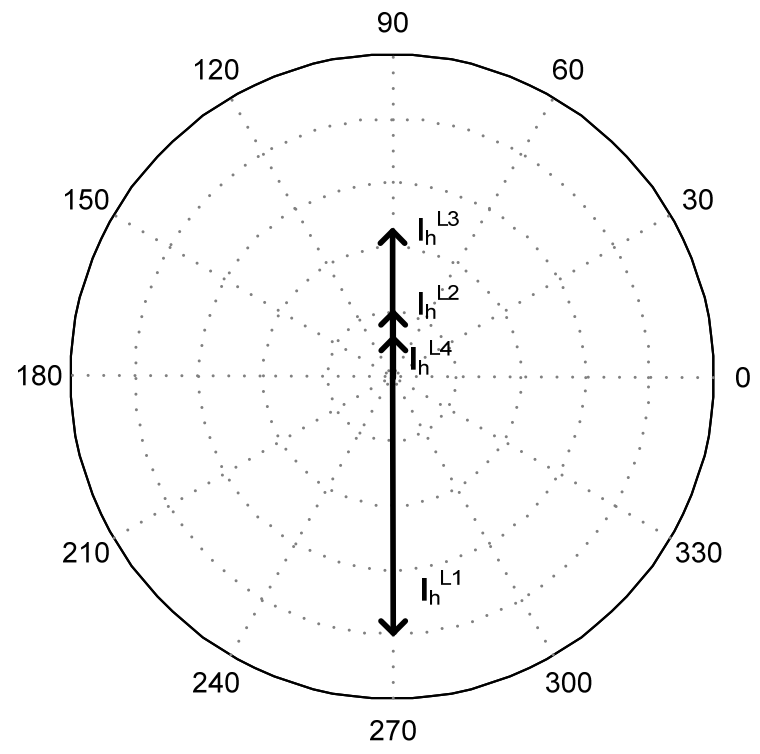

Figura 13 - Exemplo das correntes harmônicas medidas na barra $P$, se originando nas cargas e fluindo para as linhas de suprimento.
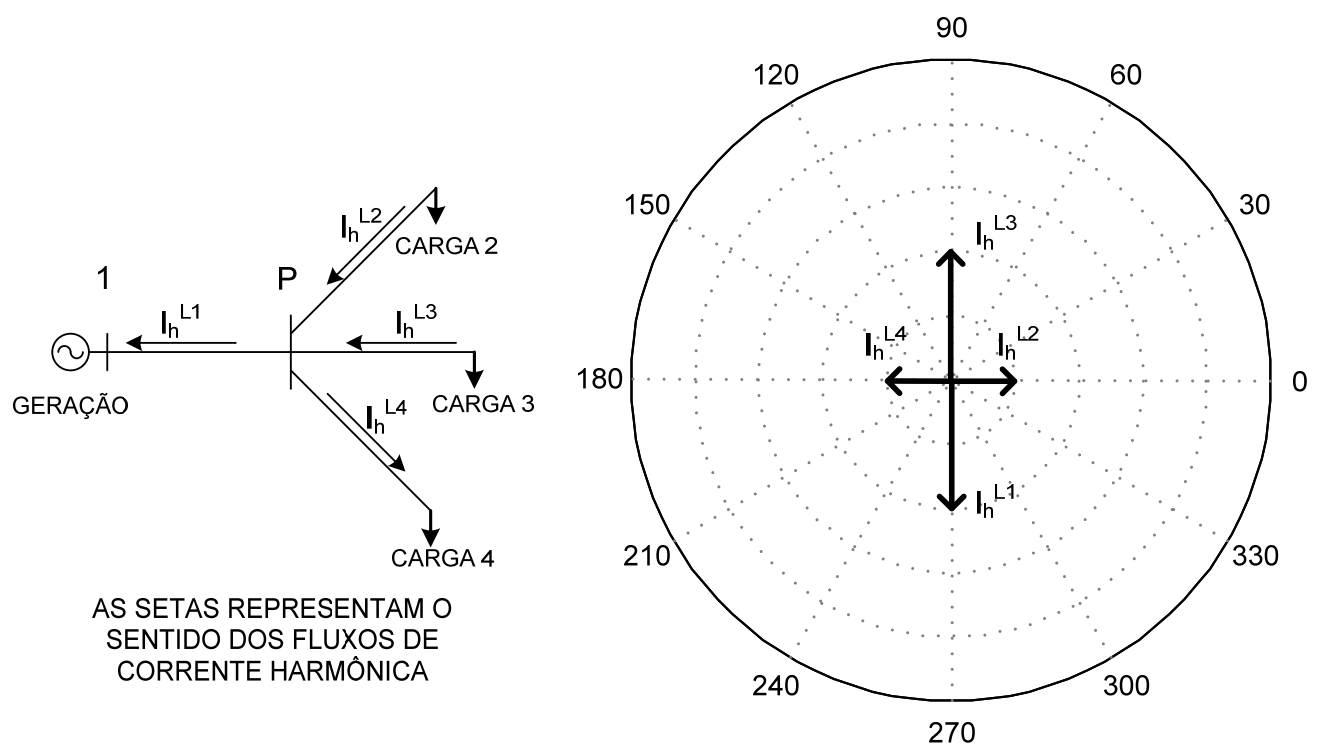

Figura 14 - Exemplo de correntes harmônicas medidas na barra $P$, com cancelamento de correntes entre as cargas 2 e 4. 

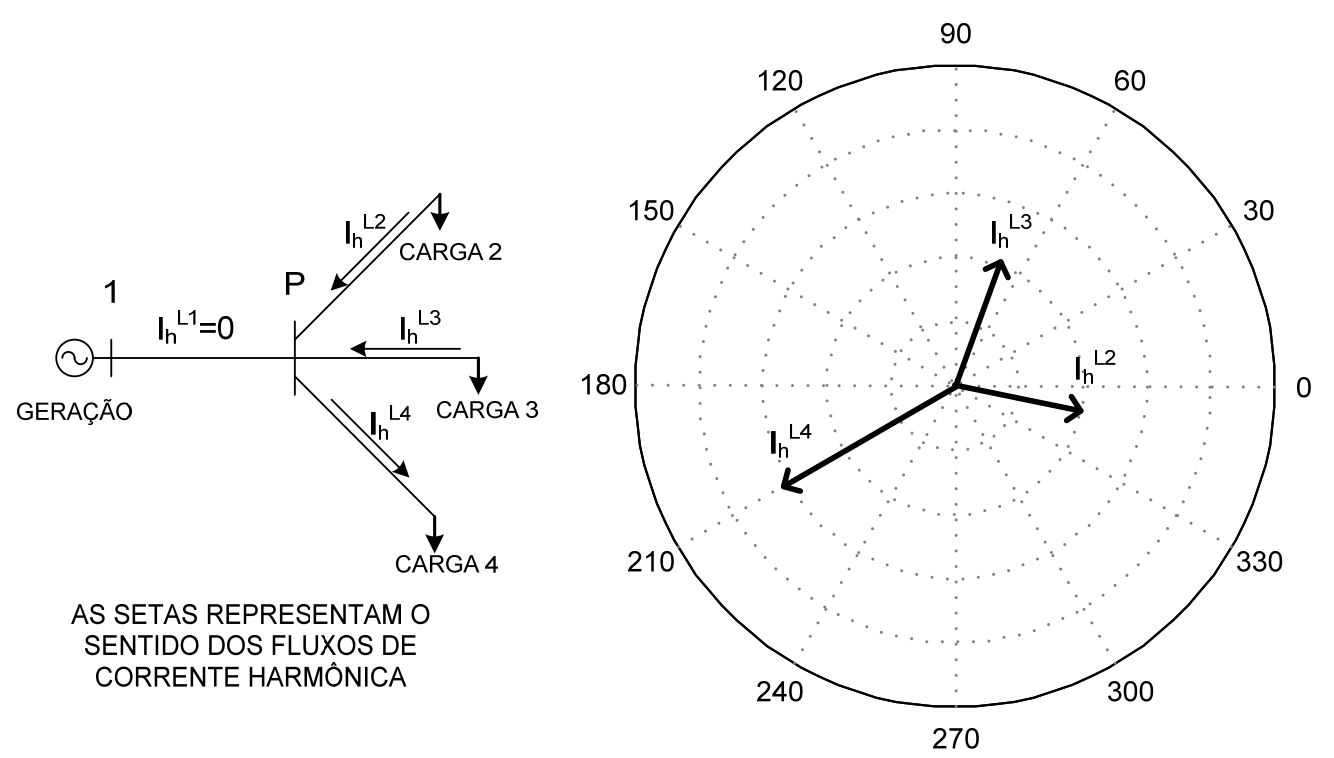

Figura 15 - Exemplo de correntes harmônicas medidas na barra $P$, com cancelamento total das corrente apenas nas linhas das cargas, sem corrente resultante para as linhas de suprimento $\left(\mathrm{l}_{\mathrm{h}}{ }^{\mathrm{L}}=0\right)$.

É importante ressaltar que nem sempre o maior fluxo de correntes harmônicas será das cargas até os suprimentos. Se houver a presença de sorvedouros de corrente com alta capacidade de absorção como, por exemplo, filtros de harmônicos instalados ao longo do sistema, as correntes harmônicas podem ser dirigidas para as linhas que levem a estes sorvedouros.

Através desta análise fasorial quantitativa pode-se determinar quais linhas possuem maior contribuição direta para as correntes harmônicas que circulam pela linha da geração e, portanto, qual é o caminho principal do fluxo de corrente harmônica. 


\section{DESCRIÇÃO DA CAMPANHA DE MEDIÇÕES}

Para demonstrar a aplicação dos métodos discutidos neste trabalho, serão apresentados os resultados de uma campanha de estudos de correntes harmônicas realizada nos anos de 2007 e 2008 pelo Operador Nacional do Sistema (ONS) e pela Universidade de São Paulo (USP). O objetivo desta campanha foi determinar as causas de sobrecarga de correntes nos Filtros de harmônicos para o link de conversão DC-AC da Subestação (SE) Ibiúna.

A minha participação nesta campanha de estudos de correntes harmônicas foi a de envolvimento em todas as etapas do estudo. Participei ativamente das instalações dos equipamentos nas SEs, da coleta de dados dos medidores, realizei o tratamento dos dados coletados e participei da análise dos resultados pelos profissionais da USP e do ONS envolvidos no estudo.

O bloco do sistema de transmissão em estudo está ilustrado na Figura 16, compreendendo as principais linhas de transmissão ligadas a SE Ibiúna. 


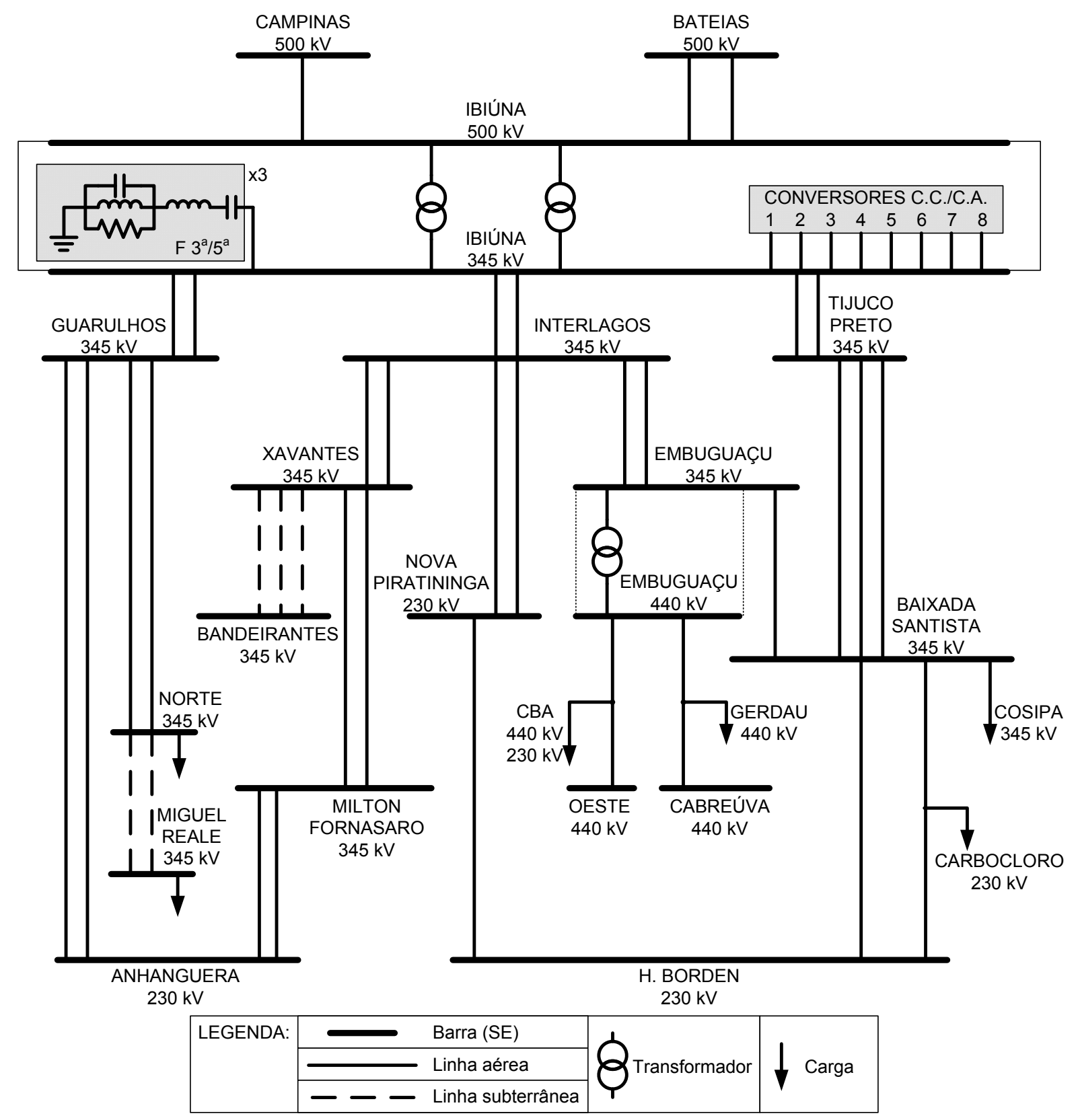

Figura 16 - Bloco do Sistema de Transmissão em estudo.

Devido ao elevado número de locais a se avaliar e a quantidade limitada de medidores, uma estratégia de medição foi executada de modo que alguns locais tiveram medição em semanas não coincidentes com outros, mas sempre com um determinado conjunto de medidores fixados, conforme apresentado nas Tabelas $1 \mathrm{e}$ 2. 
Tabela 1 - Diagrama de Medições Realizadas ao longo da Campanha (parte 1).

\begin{tabular}{|c|c|c|c|c|c|c|c|c|c|c|c|c|c|c|c|c|c|c|c|c|c|c|c|c|c|c|}
\hline \multicolumn{3}{|c|}{ Medição } & \multicolumn{24}{|c|}{ Semana } \\
\hline $\begin{array}{c}\text { Tipo de } \\
\text { Elemento } \\
\text { Avaliado } \\
\end{array}$ & \begin{tabular}{|c|}
$\begin{array}{c}\text { Local de } \\
\text { Instalação do } \\
\text { Medidor }\end{array}$ \\
\end{tabular} & $\begin{array}{l}\text { Elemento } \\
\text { Observado }\end{array}$ & 01 & 02 & 03 & 04 & 05 & 06 & 07 & 08 & 09 & 10 & 11 & 12 & 13 & 14 & 15 & 16 & 17 & 18 & 19 & 20 & 21 & 22 & 23 & 24 \\
\hline \multirow{3}{*}{ Filtro } & \multirow{3}{*}{ SE Ibiúna } & Elemento série & $\mathrm{M}$ & M & $\mathrm{M}$ & M & M & $\mathrm{M}$ & M & M & $M$ & M & M & M & M & M & $M$ & $M$ & M & M & M & $M$ & $M$ & M & $M$ & $M$ \\
\hline & & $\begin{array}{c}\text { Capacitor } \\
\text { paralelo }\end{array}$ & $\mathrm{M}$ & M & M & $\mathrm{M}$ & M & M & M & M & M & M & M & M & $\mathrm{M}$ & M & $\mathrm{M}$ & M & M & $\mathrm{M}$ & M & M & M & $\mathrm{M}$ & $\mathrm{M}$ & M \\
\hline & & $\begin{array}{l}\text { Reator } \\
\text { paralelo }\end{array}$ & $\mathrm{M}$ & M & $\mathrm{M}$ & $M$ & M & $\mathrm{M}$ & $\mathrm{M}$ & M & M & M & M & M & $\mathrm{M}$ & M & $\mathrm{M}$ & M & $\mathrm{M}$ & $\mathrm{M}$ & M & $\mathrm{M}$ & $M$ & $\mathrm{M}$ & $\mathrm{M}$ & $\mathrm{M}$ \\
\hline \multirow{11}{*}{$\begin{array}{l}\text { Linhas de } \\
\text { Transmissão }\end{array}$} & \multirow{5}{*}{ SE Ibiúna } & $\begin{array}{l}\text { Ibiúna - } \\
\text { Bateias }\end{array}$ & $\mathrm{M}$ & M & M & $\mathrm{M}$ & M & $\mathrm{M}$ & $\mathrm{M}$ & M & M & M & M & M & $\mathrm{M}$ & M & $\mathrm{M}$ & M & M & $\mathrm{M}$ & M & M & M & M & $\mathrm{M}$ & M \\
\hline & & $\begin{array}{l}\text { Ibiúna - } \\
\text { Interlagos }\end{array}$ & M & M & $\mathrm{M}$ & $\mathrm{M}$ & M & $M$ & M & M & M & M & M & M & $\mathrm{M}$ & M & $\mathrm{M}$ & M & M & $\mathrm{M}$ & M & M & M & M & $\mathrm{M}$ & M \\
\hline & & $\begin{array}{c}\text { Ibiúna - } \\
\text { Campinas }\end{array}$ & $\mathrm{M}$ & M & $\mathrm{M}$ & $M$ & $M$ & $\mathrm{M}$ & $M$ & $M$ & M & & & & & & & & & & & & & & & \\
\hline & & $\begin{array}{l}\text { Ibiúna - } \\
\text { Guarulhos }\end{array}$ & M & M & $\mathrm{M}$ & $\mathrm{M}$ & M & M & $M$ & $M$ & M & $M$ & & & & & & & & & & & & & & \\
\hline & & \begin{tabular}{|c|} 
Ibiúna - Tijuco \\
Preto \\
\end{tabular} & M & M & M & $\mathrm{M}$ & M & M & M & $\mathrm{M}$ & M & & & & & & & & & & & & & & & \\
\hline & $\begin{array}{l}\text { SE Tijuco } \\
\text { Preto }\end{array}$ & \begin{tabular}{|c|} 
Ibiúna - Tijuco \\
Preto
\end{tabular} & & M & $\mathrm{M}$ & $M$ & M & $\mathrm{M}$ & $\mathrm{M}$ & M & M & M & M & M & $\mathrm{M}$ & M & $\mathrm{M}$ & M & & & & & & & & \\
\hline & SE Guarulhos & $\begin{array}{c}\text { Ibiúna - } \\
\text { Guarulhos }\end{array}$ & & & $\mathrm{M}$ & $M$ & $\mathrm{M}$ & $M$ & $\mathrm{M}$ & $\mathrm{M}$ & $M$ & M & M & $M$ & M & M & $\mathrm{M}$ & $M$ & $\mathrm{M}$ & $M$ & M & $\mathrm{M}$ & M & $\mathrm{M}$ & $\mathrm{M}$ & $\mathrm{M}$ \\
\hline & SE Interlagos & $\begin{array}{c}\text { Ibiúna - } \\
\text { Interlagos }\end{array}$ & & & & $\mathrm{M}$ & M & M & $\mathrm{M}$ & M & M & M & M & M & $\mathrm{M}$ & & & & & & & & & & & \\
\hline & SE Xavantes & $\begin{array}{l}\text { Interlagos - } \\
\text { Xavantes }\end{array}$ & & & & & & & & & & M & M & M & $\mathrm{M}$ & M & $\mathrm{M}$ & M & M & $\mathrm{M}$ & M & M & M & $\mathrm{M}$ & $\mathrm{M}$ & M \\
\hline & \begin{tabular}{|c|}
$\mathrm{SE}$ \\
Bandeirantes \\
\end{tabular} & $\begin{array}{c}\text { Xavantes - } \\
\text { Bandeirantes } \\
\end{array}$ & & & & & & & & & & $\mathrm{M}$ & M & M & $\mathrm{M}$ & M & $\mathrm{M}$ & M & M & $\mathrm{M}$ & $M$ & M & M & $\mathrm{M}$ & $\mathrm{M}$ & M \\
\hline & SE Interlagos & $\begin{array}{l}\text { Interlagos - } \\
\text { Embuguaçú }\end{array}$ & & & & & & & & & & & M & M & $M$ & M & $\mathrm{M}$ & M & $\mathrm{M}$ & $M$ & M & M & M & $\mathrm{M}$ & $\mathrm{M}$ & M \\
\hline \multirow{5}{*}{$\begin{array}{l}\text { Cargas } \\
\text { Industriais }\end{array}$} & Gerdau & P.A.C. & & & & & & & & & & & & & & & & & $\mathrm{M}$ & $\mathrm{M}$ & $M$ & $M$ & & & & \\
\hline & CBA & $\begin{array}{c}\text { P.A.C. Ligação } \\
440 \mathrm{kV}\end{array}$ & & & & & & & & & & & & & & & & & $\mathrm{M}$ & $\mathrm{M}$ & M & & & & & \\
\hline & CBA & $\begin{array}{c}\text { P.A.C. Ligação } \\
230 \mathrm{kV}\end{array}$ & & & & & & & & & & & & & & & & & & & & M & & & & \\
\hline & Carbocloro & P.A.C. & & & & & & & & & & & & & & & & & & & & & $\mathrm{M}$ & $\mathrm{M}$ & $\mathrm{M}$ & \\
\hline & Cosipa & P.A.C. & & & & & & & & & & & & & & & & & & & & & $M$ & $M$ & $\mathrm{M}$ & \\
\hline
\end{tabular}


Tabela 2 - Diagrama de Medições Realizadas ao longo da Campanha (parte 2).

\begin{tabular}{|c|c|c|c|c|c|c|c|c|c|c|c|c|c|}
\hline \multicolumn{3}{|c|}{ Medição } & \multicolumn{11}{|c|}{ Semana } \\
\hline $\begin{array}{c}\text { Tipo de } \\
\text { Elemento } \\
\text { Avaliado }\end{array}$ & \begin{tabular}{|c|} 
Local de \\
$\begin{array}{c}\text { Instalação do } \\
\text { Medidor }\end{array}$ \\
\end{tabular} & $\begin{array}{l}\text { Elemento } \\
\text { Observado }\end{array}$ & 25 & 26 & 27 & 28 & 29 & 30 & 31 & 32 & 33 & 34 & 35 \\
\hline Filtro & SE Ibiúna & Elemento série & $\mathrm{M}$ & $\mathrm{M}$ & $\mathrm{M}$ & $\mathrm{M}$ & $\mathrm{M}$ & $\mathrm{M}$ & $\mathrm{M}$ & $M$ & $\mathrm{M}$ & $\mathrm{M}$ & $\mathrm{M}$ \\
\hline \multirow{12}{*}{$\begin{array}{c}\text { Linhas de } \\
\text { Transmissão }\end{array}$} & \multirow{4}{*}{ SE Ibiúna } & $\begin{array}{c}\text { Transformador } \\
345-500 \mathrm{kV} \\
\end{array}$ & $\mathrm{M}$ & M & M & $\mathrm{M}$ & $\mathrm{M}$ & $M$ & $\mathrm{M}$ & M & $\mathrm{M}$ & $\mathrm{M}$ & M \\
\hline & & $\begin{array}{c}\text { Ibiúna - } \\
\text { Interlagos }\end{array}$ & $\mathrm{M}$ & M & M & M & $\mathrm{M}$ & M & $\mathrm{M}$ & M & $\mathrm{M}$ & $\mathrm{M}$ & M \\
\hline & & $\begin{array}{c}\text { Ibiúna - } \\
\text { Guarulhos }\end{array}$ & $\mathrm{M}$ & M & M & M & $\mathrm{M}$ & $\mathrm{M}$ & $\mathrm{M}$ & M & $\mathrm{M}$ & $\mathrm{M}$ & $M$ \\
\hline & & $\begin{array}{c}\text { Ibiúna - Tijuco } \\
\text { Preto }\end{array}$ & $\mathrm{M}$ & M & $\mathrm{M}$ & $\mathrm{M}$ & $\mathrm{M}$ & $\mathrm{M}$ & $\mathrm{M}$ & M & $M$ & $\mathrm{M}$ & M \\
\hline & $\begin{array}{c}\text { SE } \\
\text { Anhanguera }\end{array}$ & $\begin{array}{l}\text { Guarulhos- } \\
\text { Anhanguera }\end{array}$ & & M & $\mathrm{M}$ & $\mathrm{M}$ & M & & & & & & \\
\hline & $\begin{array}{c}\text { SE } \\
\text { Anhanguera }\end{array}$ & $\begin{array}{c}\text { Anhanguera- } \\
\text { Milton } \\
\text { Fornasaro }\end{array}$ & & M & $\mathrm{M}$ & $\mathrm{M}$ & M & & & & & & \\
\hline & SE Xavantes & $\begin{array}{l}\text { Interlagos- } \\
\text { Xavantes }\end{array}$ & & M & M & M & $\mathrm{M}$ & & & & & & \\
\hline & SE Xavantes & $\begin{array}{c}\text { Xavantes- } \\
\text { Bandeirantes }\end{array}$ & & M & $\mathrm{M}$ & M & M & & & & & & \\
\hline & SE Xavantes & $\begin{array}{l}\text { Xavantes-Milton } \\
\text { Fornasaro }\end{array}$ & & M & $\mathrm{M}$ & $\mathrm{M}$ & M & & & & & & \\
\hline & SE Norte & $\begin{array}{l}\text { Guarulhos- } \\
\text { Norte }\end{array}$ & & & & & & & & & $\mathrm{M}$ & $\mathrm{M}$ & M \\
\hline & SE Norte & $\begin{array}{l}\text { Norte-Miguel } \\
\text { Reale }\end{array}$ & & & & & & & & & $M$ & $\mathrm{M}$ & $M$ \\
\hline & $\begin{array}{l}\text { SE Miguel } \\
\text { Reale }\end{array}$ & $\begin{array}{l}\text { Norte-Miguel } \\
\text { Reale }\end{array}$ & & & & & & & & & $M$ & $\mathrm{M}$ & $M$ \\
\hline
\end{tabular}

\subsection{Objetivos da Campanha de Medições}

A campanha de medição teve por objetivo determinar as origens das correntes harmônicas que têm sobrecarregado os Filtros de $3^{\mathrm{a}}$ e $5^{\mathrm{a}}$ harmônicas instalados na SE Ibiúna.

\subsection{Descrição de Equipamentos Utilizados}

Foram utilizados onze medidores de qualidade de energia elétrica da marca Arbiter $\AA$, modelo Power Sentinel 1133A, utilizando-se de recursos de sincronismo no tempo por intermédio de antenas de GPS. 
Para realizar os registros, foram utilizados os TPs e TCs de medição das próprias subestações, levando-se em conta que esses elementos foram concebidos para medir com precisão os sinais na frequência fundamental e podem introduzir variações nas amplitudes e ângulos de defasagem dos sinais de maior frequência.

Conforme citado no item 2.1.4, por medida de segurança da operação não é permitido abrir os secundários dos TCs para a conexão de equipamento. Por conta disto, foram utilizados onze espelhos de corrente desenvolvidos por Saraiva (2007) para envolver os secundários dos TCs.

\subsection{Instalação: Dificuldades Encontradas e Soluções}

\subsubsection{Antenas de GPS}

Algumas das principais dificuldades encontradas na instalação dos equipamentos estão ligadas à instalação da antena de sinal GPS. Para que as antenas possam captar os sinais dos satélites e realizar o sincronismo de tempo, é preciso que as antenas estejam posicionadas em local aberto e expostas ao tempo.

Uma primeira dificuldade foi a de encontrar um local para a instalação da antena na parte externa dos edifícios. Além do mais, a conexão da antena ao medidor é realizada através de cabo coaxial de $75 \Omega$, o que leva à necessidade de se manter aberta uma passagem do exterior para o interior do edifício, levando até o medidor junto às cabines de medição e controle da subestação.

A distância percorrida pelo cabo coaxial também pode ser bastante extensa e este deve obrigatoriamente ser passado pelos dutos de passagem de cabos de comunicação existentes na subestação, por medidas de segurança de operação, mesmo sendo equipamento de terceiros. Os dutos nem sempre conduzem diretamente ao local em que se encontra o medidor, e muitas vezes o acesso aos 
dutos é bastante limitado, trazendo grandes dificuldades na passagem do cabo coaxial.

\subsubsection{Sinais de Tensão e Corrente}

Há ocasiões em que os locais em que os sinais de tensão e corrente estão disponibilizados para o acoplamento do medidor nem sempre se encontravam próximos um do outro, levando ao uso de longos cabos de conexão para que fosse possível conectar um ou outro sinal.

Há também ocasiões em que o local de acoplamento permitido se encontra a céu aberto, na subestação, junto dos transformadores ou das chaves de transferência. Nestes casos, além de se manter a caixa com os secundários dos TPs e TCs da subestação aberta e exposta ao tempo, também é preciso acondicionar o medidor em invólucro adequado para protegê-lo da ação do tempo (chuva, granizo, vento, sol forte, etc.). 


\section{APRESENTAÇÃO DE RESULTADOS DE CORRELAÇÃO ESTATÍSTICA}

Serão apresentados os resultados de análises de correlação obtidos ao longo da campanha de medição, os quais visam determinar:

- as diferenças ao se realizar a medição sobre um extremo da linha de transmissão e sobre o outro extremo, para o caso de linhas de transmissão aéreas;

- as diferenças ao se realizar a medição sobre o elemento série do filtro e sobre os elementos paralelos, do ponto de vista da corrente;

- a correlação entre as correntes que fluem ao longo do sistema de transmissão e as correntes absorvidas pelo filtro, buscando determinar as suas origens;

- a correlação entre as cargas industriais do sistema e as correntes absorvidas pelo filtro, buscando determinar se há contribuição destas cargas para a sobrecarga.

Os dados registrados foram tratados através do programa Matlab®, versão para estudantes.

4.1. Resultados da Análise por Correlação

4.1.1. Avaliação dos Extremos das Linhas de Transmissão

A campanha de medição teve início verificando-se quais as diferenças ao se realizar a medição de correntes harmônicas em ambos os extremos de uma linha aérea de transmissão. 
Os Gráficos 1 e 2 apresentam os registros de valores eficazes das correntes nas frequências fundamental, de $3^{a}$ e $5^{a}$ ordens harmônicas da LT Ibiúna-Interlagos, medidas nos extremos de lbiúna e de Interlagos, respectivamente.
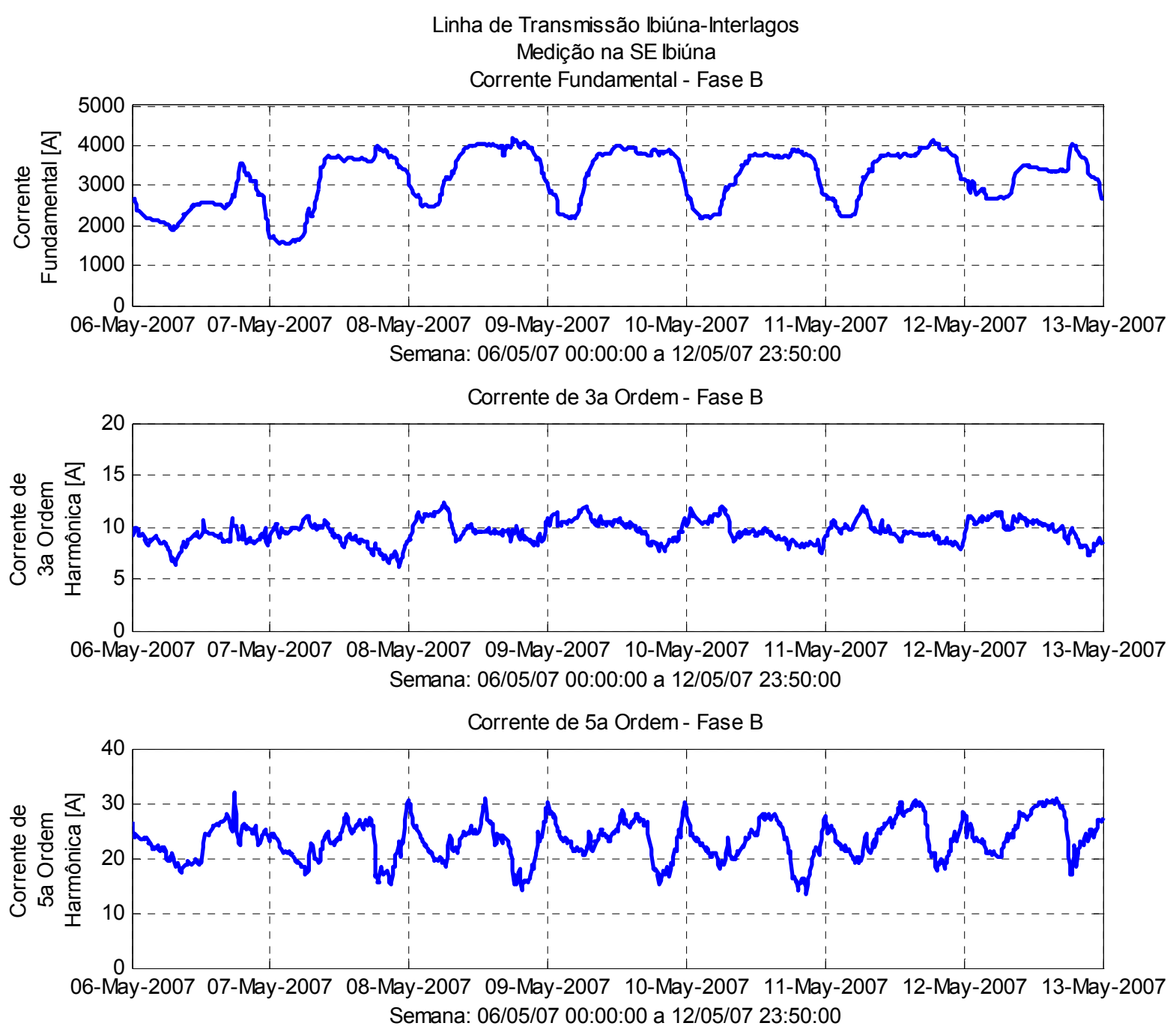

Gráfico 1 - Registro semanal dos valores eficazes das correntes da LT IbiúnaInterlagos, realizado na SE Ibiúna. 


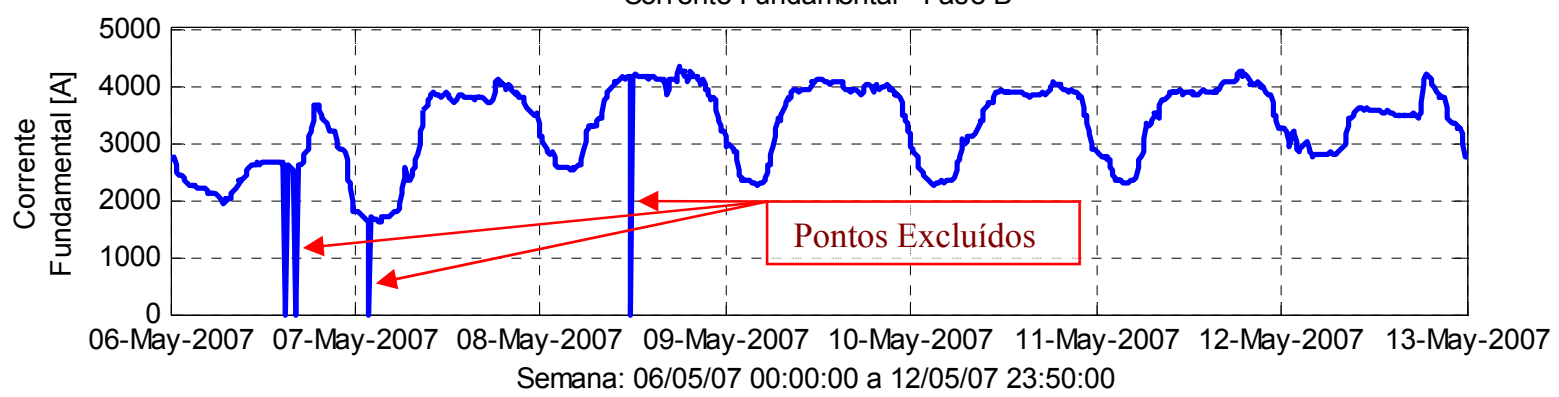

Corrente de 3 a Ordem - Fase B

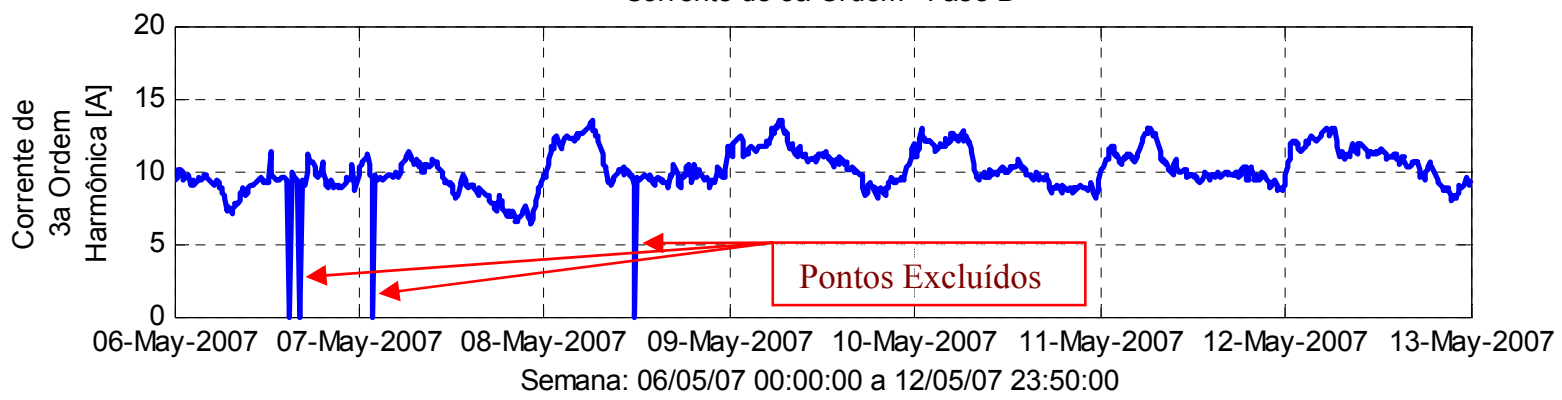

Corrente de 5a Ordem - Fase B

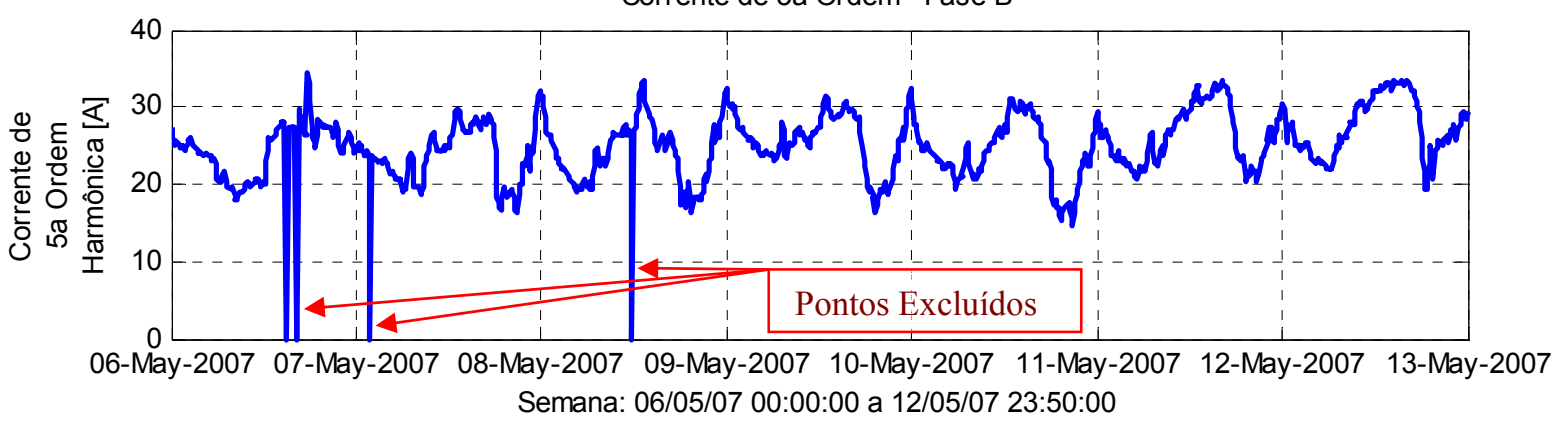

Gráfico 2 - Registro semanal dos valores eficazes das correntes da LT IbiúnaInterlagos, realizado na SE Interlagos.

Note-se no Gráfico 2 que há alguns registros que tiveram que ser excluídos da análise, apontados pelas setas vermelhas no próprio gráfico. Durante a análise de correlação entre os registros apresentados nos Gráficos 1 e 2, as amostras obtidas pelo medidor na SE Ibiúna registrados no mesmo instante em que ocorreram estes registros excluídos do medidor na SE Interlagos serão ignorados. Dessa forma se garante a correspondência de registros válidos em ambos os registros para a análise de correlação. 
Os resultados do estudo entre os extremos das LTs estão ilustrados pela análise de correlação destes registros, apresentada nos Gráficos 3, 4 e 5.

CORRELAÇÃO: Medições na SE Ibiúna versus SE Interlagos Linha de Transmissão Ibiúna-Interlagos - SEMANA: 06/05/2007 a 12/05/2007 Avaliação das Correntes Fundamentais Fase A:

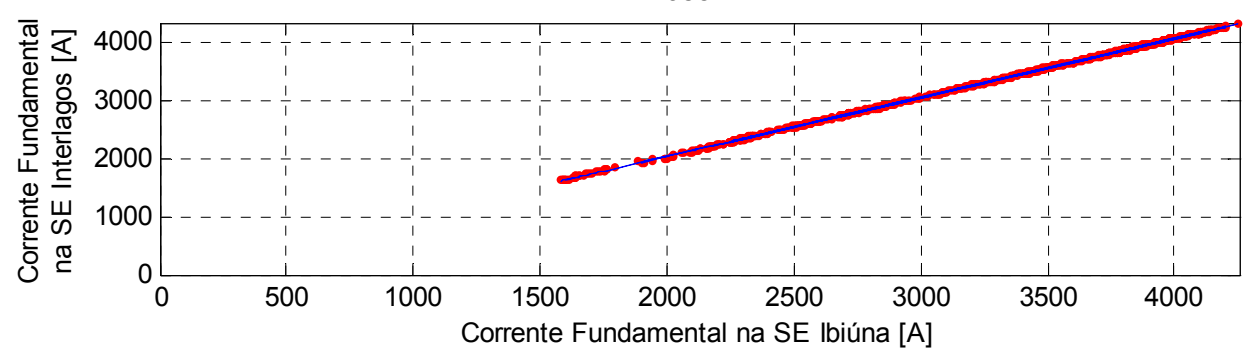

Fase B:

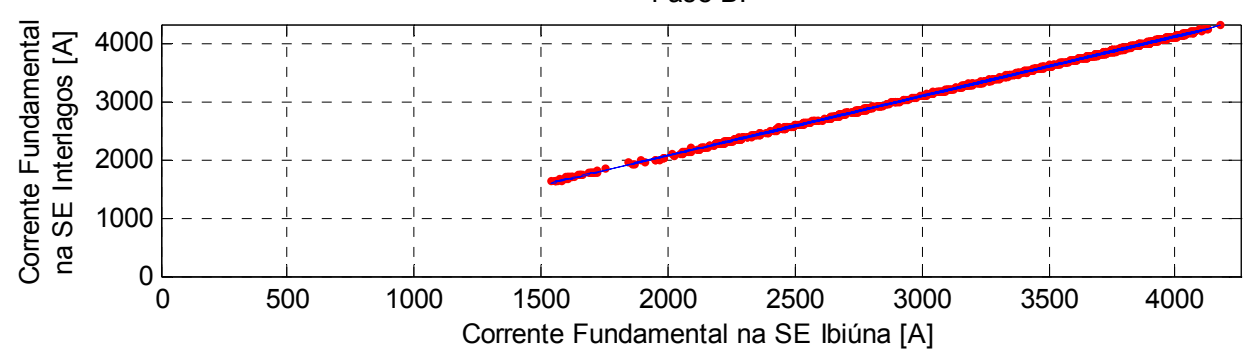

Fase C:

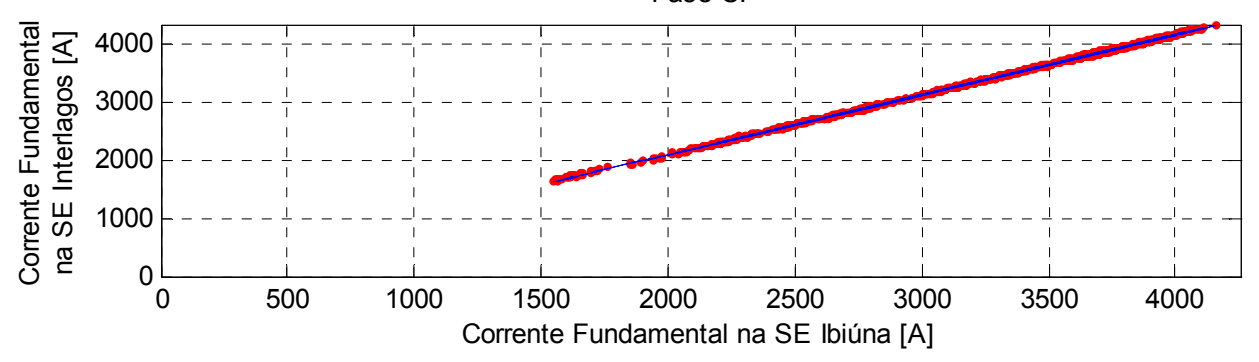

Gráfico 3 - Diagramas de dispersão das correntes fundamentais medidas no início e fim da LT Ibiúna-Interlagos.

Tabela 3 - Resultados de correlação das correntes fundamentais entre início e fim da LT Ibiúna-Interlagos.

CORRELAÇÃO: Medições na SE Ibiúna versus SE Interlagos

Linha de Transmissão Ibiúna-Interlagos - SEMANA: 06/05/2007 a 12/05/2007

Avaliação das Correntes Fundamentais

Coeficiente de Correlação Linear Populacional

\begin{tabular}{ccc}
\hline Fase A & Fase B & Fase C \\
\hline 0,99995 & 0,99993 & 0,99986 \\
\hline
\end{tabular}


O Gráfico 3 mostra uma correlação linear perfeita positiva das correntes na frequência fundamental na LT Ibiúna-Interlagos, isto é, todos os pontos estão agregados sobre uma reta perfeita. O Coeficiente de Correlação Linear Populacional ilustra este fato, estando com valores bem próximos de 1.

CORRELAÇÃO: Medições na SE Ibiúna versus SE Interlagos Linha de Transmissão Ibiúna-Interlagos - SEMANA: 06/05/2007 a 12/05/2007 Avaliação das Correntes de 3 a Ordem Harmônica
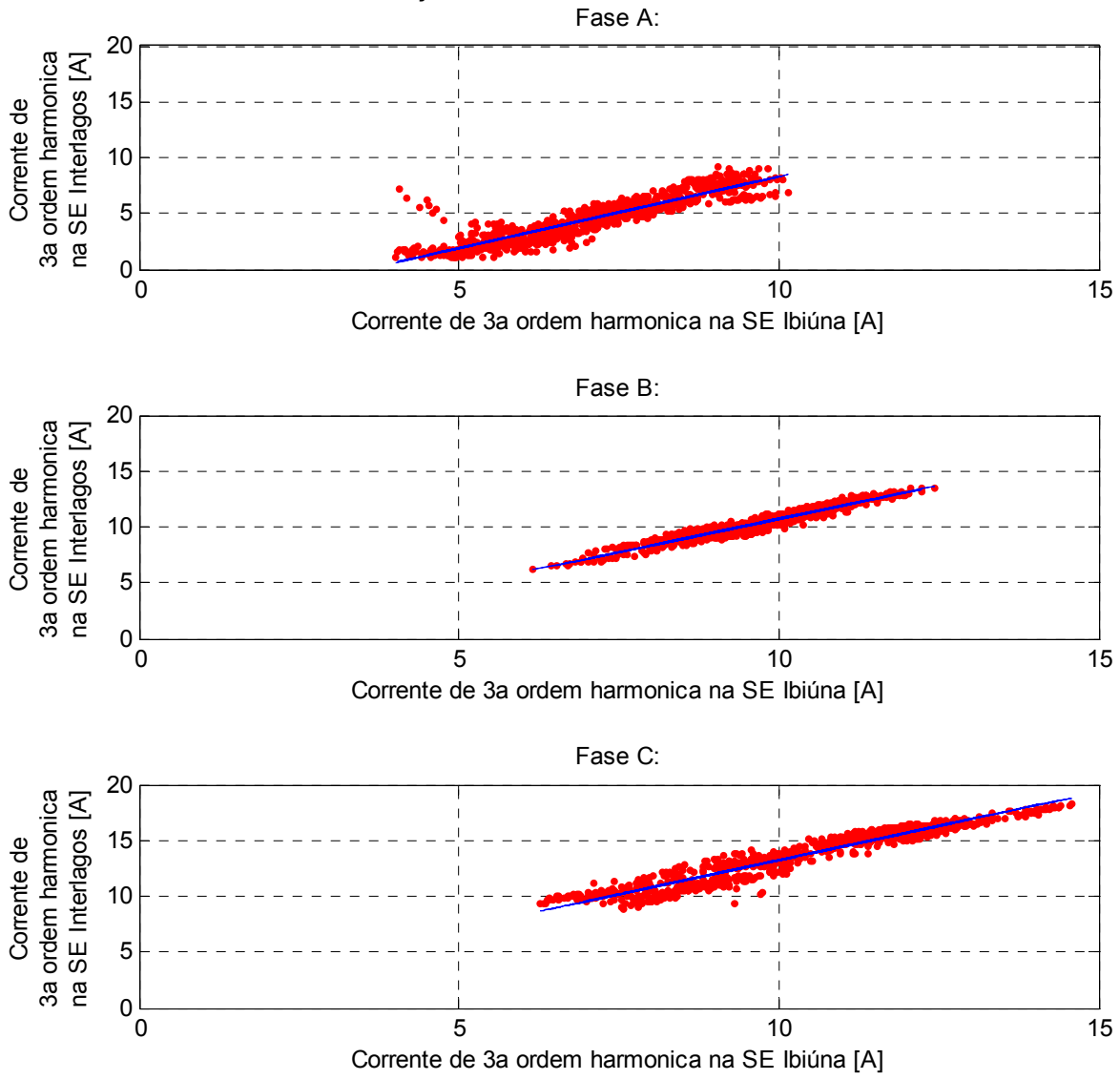

Gráfico 4 - Diagramas de dispersão das correntes de $3^{\mathrm{a}}$ ordem medidas no início e fim da LT Ibiúna-Interlagos.

Tabela 4 - Resultados de correlação das correntes de $3^{\mathrm{a}}$ ordem entre início e fim da LT Ibiúna-Interlagos.

CORRELAÇÃO: Medições na SE Ibiúna versus SE Interlagos

Linha de Transmissão Ibiúna-Interlagos - SEMANA: 06/05/2007 a 12/05/2007

Avaliação das Correntes de 3a Ordem Harmônica

Coeficiente de Correlação Linear Populacional

\begin{tabular}{ccc}
\hline Fase A & Fase B & Fase C \\
\hline 0,91637 & 0,96763 & 0,96518 \\
\hline
\end{tabular}


O Gráfico 4 mostra uma forte correlação linear positiva das correntes de $3^{\mathrm{a}}$ ordem na LT Ibiúna-Interlagos, isto é, a nuvem de pontos está agregada na região próxima a de uma reta perfeita. Este comportamento também é observado no Coeficiente de Correlação Linear Populacional, estando com valores entre 0,7 e 1.
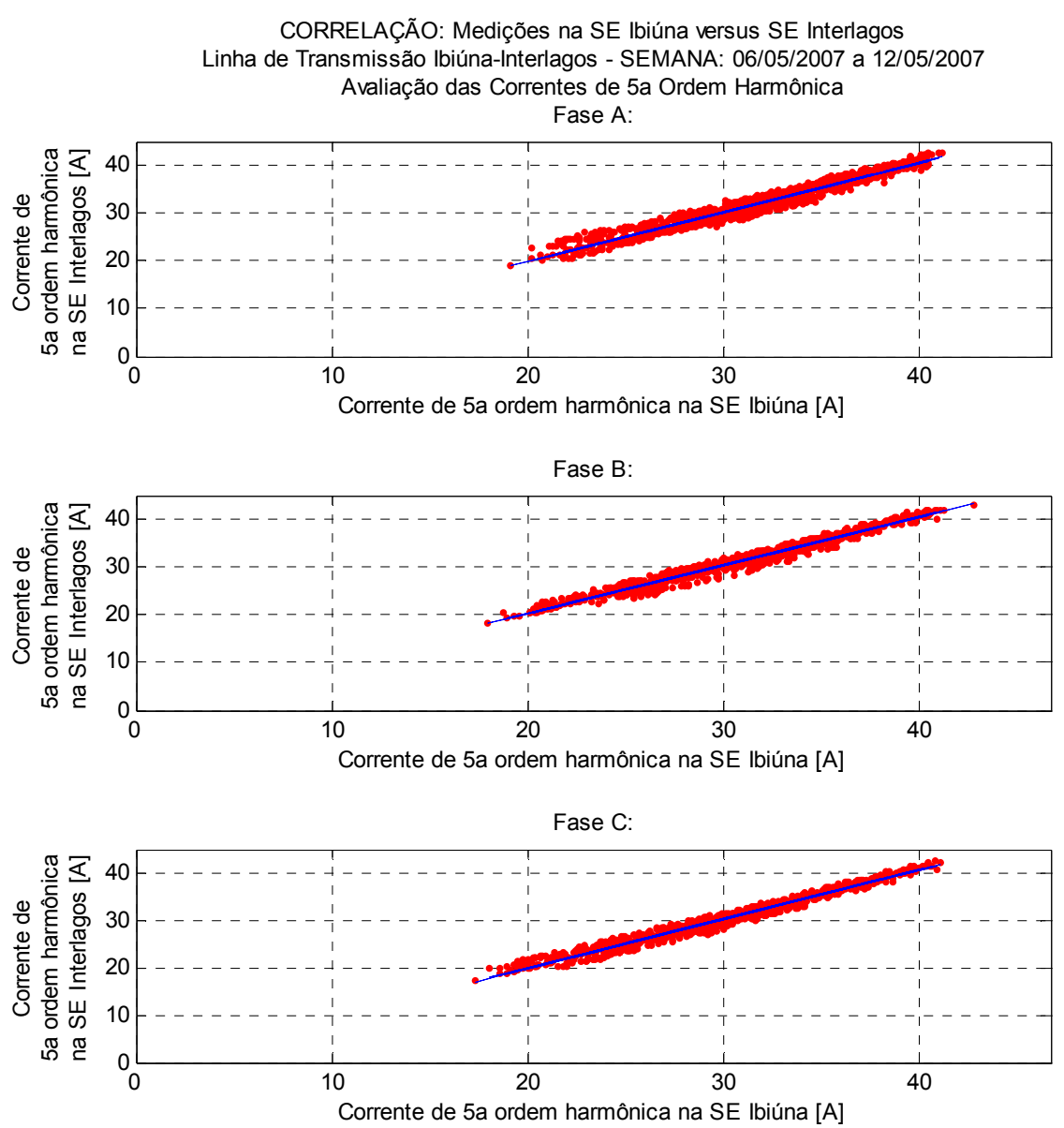

Gráfico 5 - Diagramas de dispersão das correntes de $5^{\text {a }}$ ordem medidas no início e fim da LT Ibiúna-Interlagos.

Tabela 5 - Resultados de correlação das correntes de $5^{\text {a }}$ ordem entre início e fim da LT Ibiúna-Interlagos.

CORRELAÇÃO: Medições na SE Ibiúna versus SE Interlagos Linha de Transmissão Ibiúna-Interlagos - SEMANA: 06/05/2007 a 12/05/2007

Avaliação das Correntes de 5a Ordem Harmônica

Coeficiente de Correlação Linear Populacional

\begin{tabular}{ccc}
\hline Fase A & Fase B & Fase C \\
\hline 0,97339 & 0,98608 & 0,98766 \\
\hline
\end{tabular}


O Gráfico 5 mostra que há, também, uma forte correlação linear positiva das correntes de $5^{a}$ ordem na LT Ibiúna-Interlagos. Novamente, o Coeficiente de Correlação Populacional também confirma este resultado.

Todos os resultados apresentaram uma correlação muito forte das correntes medidas no início e final da LT, demonstrando que não há diferença em se realizar medições em um extremo ou outro para LTs aéreas curtas, na frequência de $5^{a}$ ordem harmônica.

\subsubsection{Avaliação das Correntes Sobre o Filtro em Ibiúna}

Foi realizada também uma análise sobre as correntes harmônicas presentes nos elementos do conjunto de Filtros de $3^{a}$ e $5^{a}$ harmônicas instalado em Ibiúna. Foram avaliadas as correntes no ramo série do filtro e nos elementos em paralelo.

Tabela 6 - Resultados de correlação das correntes de $5^{\mathrm{a}}$ ordem medidas no elemento série e no reator paralelo dos Filtros de $3^{\mathrm{a}}$ e $5^{\mathrm{a}}$ harmônicas.

CORRELAÇÃO: Medições no Elemento Série versus Reator Paralelo

Filtro $3^{\mathrm{a}} / 5^{\mathrm{a}}$ Ordens - SEMANA: 06/05/2007 a 12/05/2007

Avaliação das Correntes de 5a Ordem Harmônica

Coeficiente de Correlação Linear Populacional

\begin{tabular}{ccc}
\hline Fase A & Fase B & Fase C \\
\hline 0,97930 & 0,98739 & 0,91121 \\
\hline
\end{tabular}

Tabela 7 - Resultados de correlação das correntes de $5^{\mathrm{a}}$ ordem medidas no elemento série e no capacitor paralelo dos Filtros de $3^{\mathrm{a}}$ e $5^{\mathrm{a}}$ harmônicas.

CORRELAÇÃO: Medições no Elemento Série versus Capacitor Paralelo

Filtro 3a/5a Ordens - SEMANA: 06/05/2007 a 12/05/2007

Avaliação das Correntes de 5a Ordem Harmônica

Coeficiente de Correlação Linear Populacional

\begin{tabular}{ccc}
\hline Fase A & Fase B & Fase C \\
\hline 0,99582 & 0,99854 & 0,99745 \\
\hline
\end{tabular}


Através da análise por correlação, determinou-se que não há diferença em se medir a corrente harmônica sobre qualquer elemento do filtro para fins de correlação. A corrente no elemento série é a corrente efetivamente drenada pelo filtro, enquanto que as correntes nos elementos paralelos possuem, além da corrente drenada, uma circulação própria de correntes harmônicas, tornando os valores medidos diferentes do drenado pelo filtro.

\subsubsection{Correlações das Linhas de Transmissão da SE Ibiúna}

Inicialmente se realizou uma análise por correlações das correntes de $5^{\mathrm{a}}$ ordem harmônica entre as linhas de transmissão que estão ligadas a SE Ibiúna e as correntes drenadas por um dos três filtros que estavam em operação em Ibiúna.

Neste caso, as análises de correlação foram divididas em patamares de carga, os quais foram indicados pelo ONS conforme definição a seguir:

- Domingo (Carga Leve): Das 0 às 17 horas e das 22 às 24 horas;

- Domingo (Carga Média): Das 17 às 22 horas;

- Segunda a Sexta (Carga Leve): Das 0 às 7 horas;

- Segunda a Sexta (Carga Média): Das 7 às 17 horas e das 22 às 24 horas;

- Segunda a Sexta (Carga Pesada): Das 17 às 22 horas.

Analisando a LT Ibiúna-Interlagos, esta LT possui em média 25 Ampères de corrente de $5^{a}$ ordem, enquanto que os filtros de Ibiúna absorvem em torno de 70 Ampères. Dividindo-se os períodos semanais em patamares de carga, obtêm-se os resultados apresentados na Tabela 8, com a apresentação dos gráficos de correlação nos Gráficos 6 e 7 para ilustrar os resultados: 

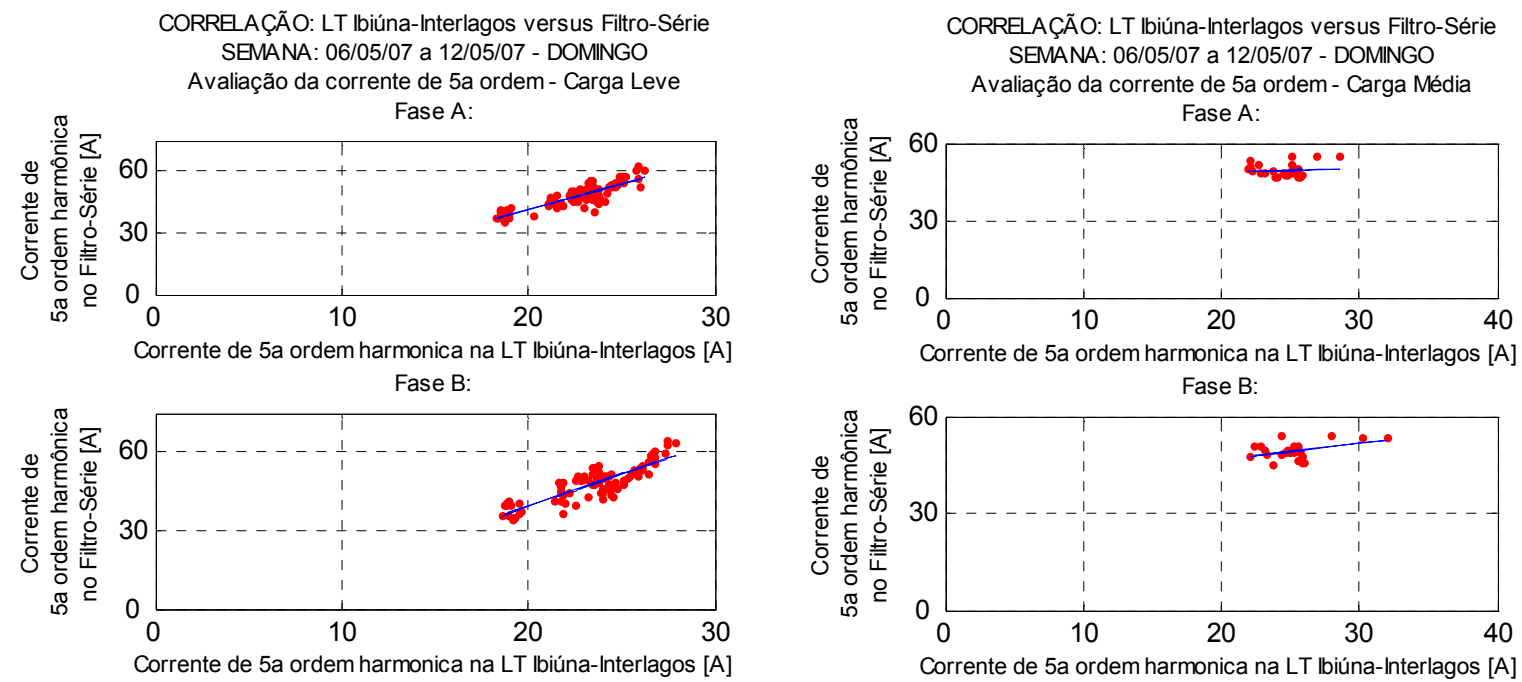
Fase C:
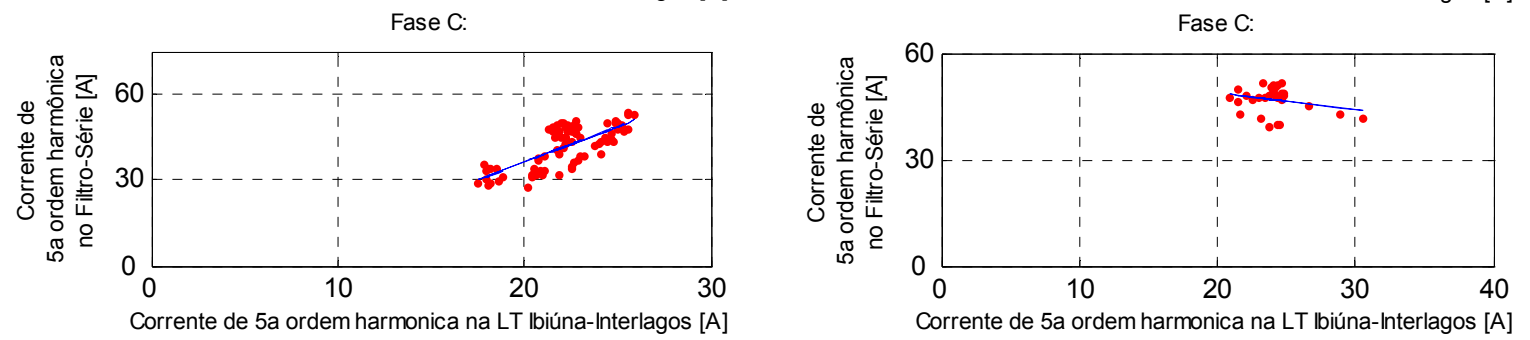

Corrente de 5 a ordem harmonica na LT Ibiúna-Interlagos $[A]$

Gráfico 6 - Diagramas de dispersão das correntes de $5^{\mathrm{a}}$ ordem entre a LT IbiúnaInterlagos e um dos Filtros de $3^{a}$ e $5^{a}$ harmônicas (Domingo). 


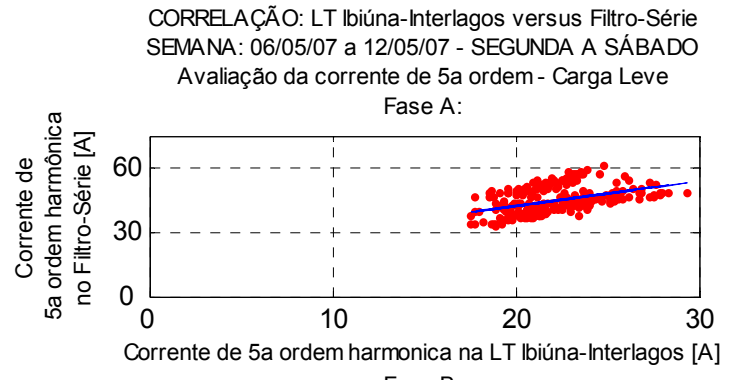

Fase B:

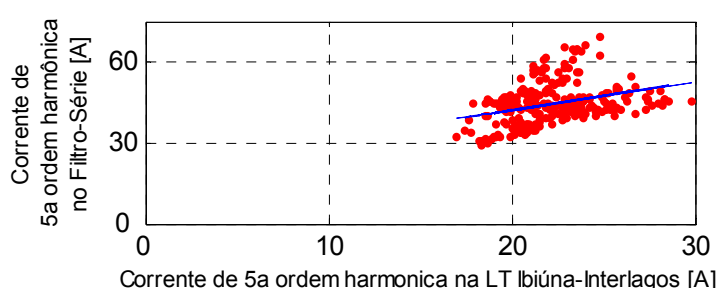

Fase C:

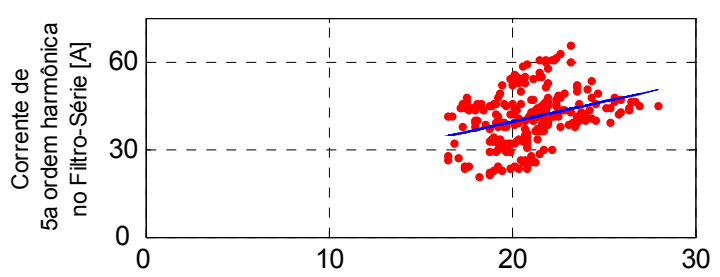

Corrente de 5 a ordem harmonica na LT lbiúna-Interlagos $[A]$
CORRELAÇÃO: LT Ibiúna-Interlagos versus Filtro-Série SEMANA: 06/05/07 a 12/05/07 - SEGUNDA A SÁBADO Avaliação da corrente de $5 a$ ordem - Carga Média

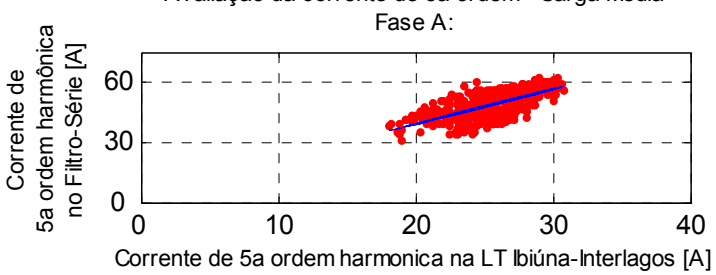
Fase B:

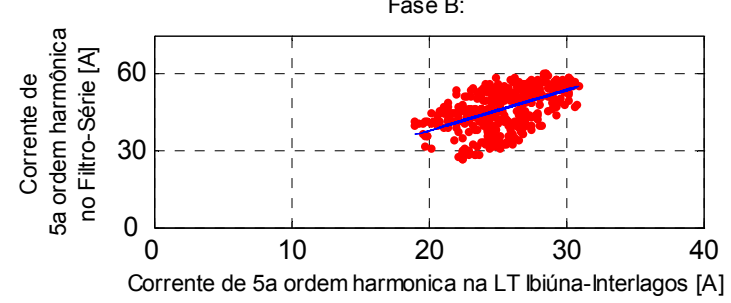
Fase C:

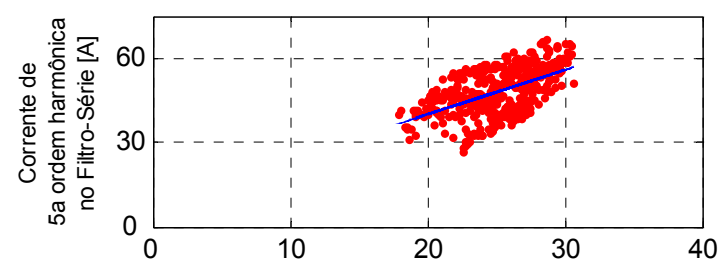

Corrente de 5 a ordem harmonica na LT Ibiúna-Interlagos $[\mathrm{A}]$
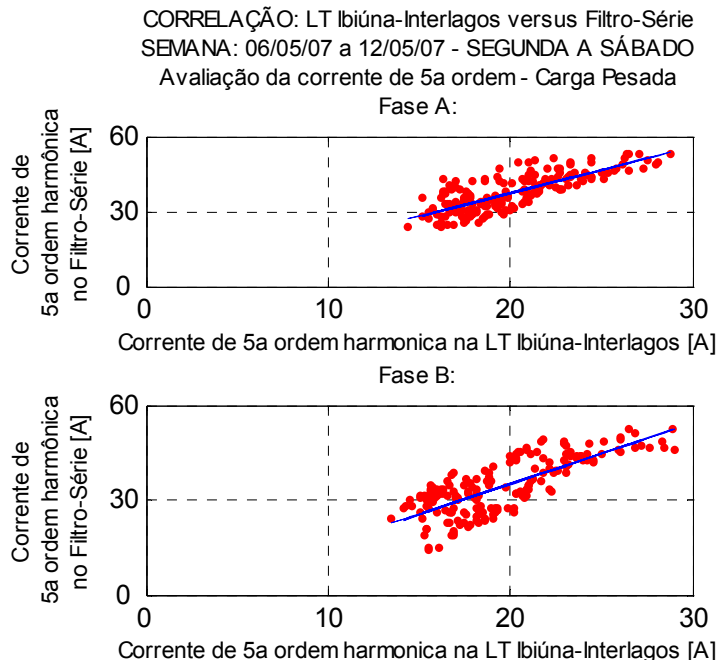

Fase C:

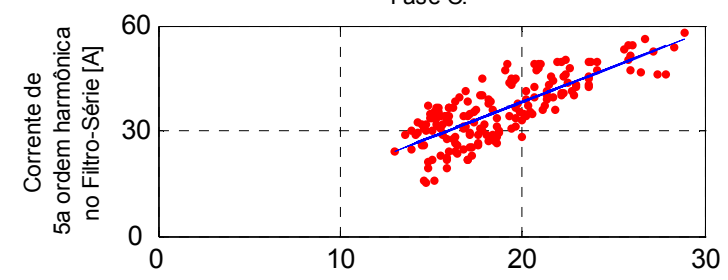

Corrente de 5 a ordem harmonica na LT Ibiúna-Interlagos $[\mathrm{A}]$

Gráfico 7 - Diagramas de dispersão das correntes de $5^{a}$ ordem entre a LT IbiúnaInterlagos e um dos Filtros de $3^{a}$ e $5^{a}$ harmônicas (Segunda a Sexta). 
Tabela 8 - Resultados de correlação das correntes de $5^{\mathrm{a}}$ ordem medidas na LT Ibiúna-Interlagos e em um dos Filtros de $3^{\mathrm{a}}$ e $5^{\mathrm{a}}$ harmônicas.

\begin{tabular}{ccccc}
\hline \multicolumn{5}{c}{$\begin{array}{c}\text { CORRELAÇÃO: LT Ibiúna-Interlagos versus Filtro-Série } \\
\text { Avaliação das Correntes de 5a Ordem Harmônica } \\
\text { Coeficiente de Correlação Linear Populacional }\end{array}$} \\
\hline Período da Semana & Patamar de carga & Fase A & Fase B & Fase C \\
\hline Domingo & Carga Leve & 0,8686 & 0,8632 & 0,7533 \\
Domingo & Carga Média & 0,1250 & 0,4394 & $-0,2548$ \\
Segunda a Sábado & Carga Leve & 0,4494 & 0,3455 & 0,3282 \\
Segunda a Sábado & Carga Média & 0,6846 & 0,5504 & 0,5511 \\
Segunda a Sábado & Carga Pesada & 0,7928 & 0,7720 & 0,7796 \\
\hline
\end{tabular}

A diferença de correlação entre as fases medidas são causadas devido às diferentes configurações de carregamento de cargas monofásicas do sistema e da forma como suas contribuições de correntes harmônicas circulam no SIN.

A correlação da LT Ibiúna-Interlagos com o elemento série do filtro determinou que há uma forte correlação positiva durante a carga leve de domingo e a carga pesada de segunda a sábado. Durante a carga média de segunda a sábado a correlação foi moderada, mas ainda assim relevante. Isso mostra que a corrente harmônica da LT Ibiúna-Interlagos possui, também, comportamento semelhante ao da corrente harmônica do filtro. Nos demais períodos a correlação pode ser considerada fraca ou nula.

A LT Ibiúna-Guarulhos possui em média 23 Ampères de corrente de $5^{\mathrm{a}}$ ordem, enquanto que os filtros de Ibiúna absorvem em torno de 70 Ampères. A Tabela 9 apresenta os resultados da análise por correlação da LT Ibiúna-Guarulhos: 
Tabela 9 - Resultados de correlação das correntes de $5^{\text {a }}$ ordem medidas na LT Ibiúna-Guarulhos e em um dos Filtros de $3^{\text {a }}$ e $5^{\text {a }}$ harmônicas.

\begin{tabular}{ccccc}
\hline \multicolumn{4}{c}{$\begin{array}{c}\text { CORRELAÇÃO: LT Ibiúna-Guarulhos versus Filtro-Série } \\
\text { Avaliação das Correntes de 5a Ordem Harmônica } \\
\text { Coeficiente de Correlação Linear Populacional }\end{array}$} \\
\hline Período da Semana & Patamar de carga & Fase A & Fase B & Fase C \\
\hline Domingo & Carga Leve & 0,4294 & 0,4090 & 0,1197 \\
Domingo & Carga Média & 0,3750 & 0,3545 & $-0,8267$ \\
Segunda a Sábado & Carga Leve & 0,2327 & 0,0561 & 0,0672 \\
Segunda a Sábado & Carga Média & 0,6351 & 0,6962 & 0,6167 \\
Segunda a Sábado & Carga Pesada & 0,7354 & 0,7888 & 0,7019 \\
\hline
\end{tabular}

A correlação da LT Ibiúna-Guarulhos com o elemento série do filtro determinou que há uma correlação positiva moderada durante a carga leve de domingo, mas durante as cargas média e pesada de segunda a sábado a correlação obtida foi de moderada a forte. Nestes períodos, a corrente harmônica da LT Ibiúna-Guarulhos possui um comportamento semelhante com a corrente harmônica do filtro. Nos demais períodos a correlação pode ser considerada fraca ou nula.

A LT Ibiúna-Tijuco Preto possui em média 7 Ampères de corrente de $5^{a}$ ordem, enquanto que os filtros de lbiúna absorvem em torno de 70 Ampères. Os resultados da análise da LT Ibiúna-Tijuco Preto são apresentados na Tabela 10:

Tabela 10 - Resultados de correlação das correntes de $5^{\mathrm{a}}$ ordem medidas na LT Ibiúna-Tijuco Preto e em um dos Filtros de $3^{\mathrm{a}}$ e $5^{\mathrm{a}}$ harmônicas.

\begin{tabular}{ccccc}
\hline \multicolumn{5}{c}{$\begin{array}{c}\text { CORRELAÇÃO: LT Ibiúna-Tijuco Preto versus Filtro-Série } \\
\text { Avaliação das Correntes de 5a Ordem Harmônica } \\
\text { Coeficiente de Correlação Linear Populacional }\end{array}$} \\
\hline Período da Semana & Patamar de carga & Fase A & Fase B & Fase C \\
\hline Domingo & Carga Leve & 0,2581 & 0,1895 & $-0,3260$ \\
Domingo & Carga Média & 0,4514 & $-0,1356$ & 0,3536 \\
Segunda a Sábado & Carga Leve & 0,5653 & 0,6379 & 0,4151 \\
Segunda a Sábado & Carga Média & 0,3928 & 0,0380 & 0,2928 \\
Segunda a Sábado & Carga Pesada & 0,3015 & 0,1156 & 0,2586 \\
\hline
\end{tabular}


A correlação da LT Ibiúna-Tijuco Preto com o elemento série do filtro determinou que há apenas uma correlação positiva moderada durante as cargas médias e carga leve de segunda a sábado. Nos demais períodos a correlação é fraca ou nula.

A LT Ibiúna-Bateias possui em média 14 Ampères de corrente de $5^{\mathrm{a}}$ ordem, enquanto que os filtros de Ibiúna absorvem em torno de 70 Ampères. Os resultados da LT Ibiúna-Bateias estão apresentados na Tabela 11.

Tabela 11 - Resultados de correlação das correntes de $5^{\mathrm{a}}$ ordem medidas na LT Ibiúna-Bateias e em um dos Filtros de $3^{\mathrm{a}}$ e $5^{\mathrm{a}}$ harmônicas.

\begin{tabular}{ccccc}
\hline \multicolumn{4}{c}{ CORRELAÇÃO: LT Ibiúna-Bateias versus Filtro-Série } \\
\multicolumn{4}{c}{$\begin{array}{c}\text { Avaliação das Correntes de 5a Ordem Harmônica } \\
\text { Coeficiente de Correlação Linear Populacional }\end{array}$} \\
\hline Período da Semana & Patamar de carga & Fase A & Fase B & Fase C \\
\hline Domingo & Carga Leve & $-0,7564$ & $-0,6260$ & $-0,5511$ \\
Domingo & Carga Média & $-0,3535$ & $-0,1826$ & 0,2576 \\
Segunda a Sábado & Carga Leve & $-0,3890$ & $-0,2104$ & 0,5619 \\
Segunda a Sábado & Carga Média & $-0,0283$ & $-0,1817$ & $-0,2061$ \\
Segunda a Sábado & Carga Pesada & $-0,0249$ & $-0,2227$ & $-0,2415$ \\
\hline
\end{tabular}

A correlação da LT Ibiúna-Bateias com o elemento série do filtro determinou que há uma correlação negativa moderada durante a carga leve dos domingos e fraca correlação negativa durante a carga leve de segunda a sábado. Nos demais períodos a correlação pode ser considerada praticamente nula.

A LT Ibiúna-Campinas possui em média 10 Ampères de corrente de $5^{\mathrm{a}}$ ordem, enquanto que os filtros de Ibiúna absorvem em torno de 70 Ampères. Os resultados da análise da LT Ibiúna-Campinas são apresentados na Tabela 12. 
Tabela 12 - Resultados de correlação das correntes de $5^{\mathrm{a}}$ ordem medidas na LT Ibiúna-Campinas e em um dos Filtros de $3^{\mathrm{a}}$ e $5^{\mathrm{a}}$ harmônicas.

\begin{tabular}{ccccc}
\hline \multicolumn{5}{c}{$\begin{array}{c}\text { CORRELAÇÃO: LT Ibiúna-Campinas versus Filtro-Série } \\
\text { Avaliação das Correntes de 5a Ordem Harmônica } \\
\text { Coeficiente de Correlação Linear Populacional }\end{array}$} \\
\hline Período da Semana & Patamar de carga & Fase A & Fase B & Fase C \\
\hline Domingo & Carga Leve & 0,4955 & 0,3940 & 0,0741 \\
Domingo & Carga Média & $-0,3797$ & $-0,2533$ & $-0,2053$ \\
Segunda a Sábado & Carga Leve & 0,5825 & 0,5269 & 0,5923 \\
Segunda a Sábado & Carga Média & 0,4211 & 0,4437 & 0,4738 \\
Segunda a Sábado & Carga Pesada & 0,2166 & 0,0199 & 0,1935 \\
\hline
\end{tabular}

A correlação da LT Ibiúna-Campinas com o elemento série do filtro determinou que há uma correlação positiva moderada durante as cargas leves e durante a carga média de segunda a sábado. Nos demais períodos a correlação pode ser considerada fraca ou nula.

Tabela 13 - Resultados de correlação das correntes de $5^{\mathrm{a}}$ ordem medidas nas LTs da SE Ibiúna com as correntes dos Filtros de $3^{\mathrm{a}}$ e $5^{\mathrm{a}}$ harmônicas.

\begin{tabular}{ccccccc}
\hline \multicolumn{7}{c}{ CORRELAÇÃO: LTs de Ibiúna versus Filtro-série } \\
\multicolumn{7}{c}{$\begin{array}{c}\text { Avaliação das Correntes de 5a Ordem Harmônica } \\
\text { Coeficiente de Correlação Linear Populacional }\end{array}$} \\
\hline $\begin{array}{c}\text { Período da } \\
\text { Semana }\end{array}$ & $\begin{array}{c}\text { Patamar de } \\
\text { carga }\end{array}$ & $\begin{array}{c}\text { Ibiúna- } \\
\text { Bateias }\end{array}$ & $\begin{array}{c}\text { Ibiúna- } \\
\text { Campinas }\end{array}$ & $\begin{array}{c}\text { Ibiúna- } \\
\text { Guarulhos }\end{array}$ & $\begin{array}{c}\text { Ibiúna- } \\
\text { Interlagos }\end{array}$ & $\begin{array}{c}\text { Ibiúna- } \\
\text { Tijuco Preto }\end{array}$ \\
\hline Domingo & Carga Leve & $-0,6445$ & 0,3212 & 0,3194 & 0,8284 & 0,0405 \\
Domingo & Carga Média & $-0,0928$ & $-0,2794$ & $-0,0324$ & 0,1032 & 0,2231 \\
Seg. a Sab. & Carga Leve & $-0,0125$ & 0,5672 & 0,1187 & 0,3744 & 0,5394 \\
Seg. a Sab. & Carga Média & $-0,1387$ & 0,4462 & 0,6493 & 0,5954 & 0,2412 \\
Seg. a Sab. & Carga Pesada & $-0,1630$ & 0,1433 & 0,7420 & 0,7815 & 0,2252 \\
\hline
\end{tabular}

Através dos resultados obtidos apresentados na Tabela 13, determinou-se que a corrente harmônica na LT Ibiúna-Interlagos possui a maior correlação com a corrente harmônica absorvida pelo filtro durante a maior parte do tempo, de modo que o estudo priorizou a investigação desta LT. 


\subsubsection{Correlações das Linhas da SE Interlagos}

Foram avaliadas as correlações das correntes de $5^{\text {a }}$ ordem harmônica nas LTs Interlagos-Embuguaçú e Interlagos-Xavantes, com relação às correntes da LT Ibiúna-Interlagos. As correntes na LT Interlagos-Nova Piratininga não foram medidas nesta campanha de medição.

A LT Interlagos-Embuguaçú possui em média 8 Ampères de corrente de $5^{\mathrm{a}}$ ordem, enquanto que a LT Ibiúna-Interlagos possui em média 25 Ampères.

Tabela 14 - Resultados de correlação das correntes de $5^{\mathrm{a}}$ ordem medidas na LT Ibiúna-Interlagos e na LT Interlagos-Embuguaçú.

\begin{tabular}{ccccc}
\hline $\begin{array}{c}\text { CORRELAÇÃO: LT Ibiúna-Interlagos versus LT Interlagos-Embuguaçú } \\
\text { Avaliação das Correntes de 5a Ordem Harmônica } \\
\text { Coeficiente de Correlação Linear Populacional }\end{array}$ \\
\hline Período da Semana & Patamar de carga & Fase A & Fase B & Fase C \\
\hline Domingo & Carga Leve & 0,5189 & 0,4487 & 0,5292 \\
Domingo & Carga Média & 0,9090 & 0,9136 & 0,7555 \\
Segunda a Sábado & Carga Leve & 0,3918 & 0,3524 & 0,2563 \\
Segunda a Sábado & Carga Média & $-0,1843$ & $-0,1276$ & $-0,2235$ \\
Segunda a Sábado & Carga Pesada & 0,4161 & 0,3680 & 0,2807 \\
\hline
\end{tabular}

Somente nos domingos, durante a carga média a correlação é forte, e durante a carga leve a correlação é moderada. No período de segunda a sábado, a correlação desta LT com a LT Ibiúna-Interlagos é fraca ou nula.

A LT Interlagos-Xavantes possui em média 25 Ampères de corrente de $5^{\text {a }}$ ordem, enquanto que a LT Ibiúna-Interlagos possui em média 25 Ampères. 
Tabela 15 - Resultados de correlação das correntes de $5^{\mathrm{a}}$ ordem medidas na LT Ibiúna-Interlagos e na LT Interlagos-Xavantes.

\begin{tabular}{ccccc}
\hline $\begin{array}{c}\text { CORRELAÇÃO: LT Ibiúna-Interlagos versus LT Interlagos-Xavantes } \\
\text { Avaliação das Correntes de 5a Ordem Harmônica } \\
\text { Coeficiente de Correlação Linear Populacional }\end{array}$ \\
\hline Período da Semana & Patamar de carga & Fase A & Fase B & Fase C \\
\hline Domingo & Carga Leve & 0,9843 & 0,9880 & 0,9848 \\
Domingo & Carga Média & 0,5518 & 0,7592 & 0,8209 \\
Segunda a Sábado & Carga Leve & 0,6965 & 0,7122 & 0,7361 \\
Segunda a Sábado & Carga Média & 0,7250 & 0,7104 & 0,7553 \\
Segunda a Sábado & Carga Pesada & 0,8830 & 0,8877 & 0,8772 \\
\hline
\end{tabular}

Durante todos os períodos de carga, a correlação desta LT com a LT IbiúnaInterlagos é forte. Também pode ser avaliada a ordem de grandeza das correntes, que indicam que a LT Interlagos-Xavantes possui praticamente a mesma corrente de $5^{a}$ ordem harmônica que passa pela LT Ibiúna-Interlagos.

Tabela 16 - Resultados de correlação das correntes de $5^{\mathrm{a}}$ ordem medidas nas LTs de Interlagos com as correntes na LT Ibiúna-Interlagos.

\begin{tabular}{|c|c|c|c|}
\hline \multicolumn{4}{|c|}{$\begin{array}{l}\text { CORRELAÇÃO: LTs de Interlagos com LT Ibiúna-Interlagos } \\
\text { Avaliação das Correntes de 5a Ordem Harmônica } \\
\text { Coeficiente de Correlação Linear Populacional }\end{array}$} \\
\hline $\begin{array}{l}\text { Período da } \\
\text { Semana }\end{array}$ & $\begin{array}{l}\text { Patamar } \\
\text { de carga }\end{array}$ & $\begin{array}{l}\text { Interlagos- } \\
\text { Embuguaçú }\end{array}$ & $\begin{array}{c}\text { Interlagos- } \\
\text { Xavantes }\end{array}$ \\
\hline Domingo & Carga Leve & 0,4989 & 0,9857 \\
\hline Domingo & Carga Média & 0,8594 & 0,7106 \\
\hline Segunda a Sábado & Carga Leve & 0,3335 & 0,7149 \\
\hline Segunda a Sábado & Carga Média & $-0,1785$ & 0,7302 \\
\hline Segunda a Sábado & Carga Pesada & 0,3549 & 0,8826 \\
\hline
\end{tabular}

Através dos resultados obtidos apresentados na Tabela 16, determinou-se que a corrente harmônica na LT Interlagos-Xavantes possui a maior correlação com a corrente harmônica na LT Ibiúna-Interlagos durante a maior parte do tempo, de modo que o estudo priorizou a investigação desta LT. 


\subsubsection{Correlações das Linhas da SE Xavantes}

Foram avaliadas as correlações das correntes de $5^{a}$ ordem harmônica nas LTs Xavantes-Bandeirantes e Xavantes-Milton Fornasaro, com relação às correntes da LT Interlagos-Xavantes.

A LT Xavantes-Milton Fornasaro possui em média 8 Ampères de corrente de $5^{\text {a }}$ ordem, enquanto que a LT Interlagos-Xavantes possui em média 25 Ampères.

\begin{tabular}{|c|c|c|c|c|}
\hline \multicolumn{5}{|c|}{ Interlagos-Xavantes e na LT Xavantes-Milton Fornasaro. } \\
\hline \multicolumn{5}{|c|}{$\begin{array}{l}\text { CORRELAÇÃO: LT Interlagos-Xavantes versus LT Xavantes-Milton } \\
\text { Fornasaro } \\
\text { Avaliação das Correntes de 5a Ordem Harmônica } \\
\text { Coeficiente de Correlação Linear Populacional }\end{array}$} \\
\hline Período da Semana & Patamar de carga & Fase A & Fase B & Fase C \\
\hline Domingo & Carga Leve & * & 0,5916 & 0,6621 \\
\hline Domingo & Carga Média & * & 0,5848 & 0,6623 \\
\hline Segunda a Sábado & Carga Leve & * & 0,8745 & 0,8817 \\
\hline Segunda a Sábado & Carga Média & * & 0,8900 & 0,8951 \\
\hline Segunda a Sábado & Carga Pesada & * & 0,8844 & 0,8919 \\
\hline
\end{tabular}

No período de segunda a sábado a correlação é forte. No domingo, a correlação desta LT com a LT Interlagos-Xavantes é moderada. Vale mencionar que a amplitude das correntes da LT Xavantes-Milton Fornasaro é da ordem de $30 \%$ da amplitude das correntes da LT Interlagos-Xavantes. Embora os resultados da correlação sejam favoráveis, a contribuição das correntes desta LT para as correntes na LT Ibiúna-Interlagos é baixa.

A LT Xavantes-Bandeirantes possui em média 24 Ampères de corrente de $5^{\text {a }}$ ordem, enquanto que a LT Interlagos-Xavantes possui em média 25 Ampères. 
Tabela 18 - Resultados de correlação das correntes de $5^{\mathrm{a}}$ ordem medidas na LT Interlagos-Xavantes e na LT Xavantes-Bandeirantes.

\begin{tabular}{ccccc}
\hline $\begin{array}{c}\text { CORRELAÇÃO: LT Interlagos-Xavantes versus LT Xavantes-Bandeirantes } \\
\text { Avaliação das Correntes de 5a Ordem Harmônica } \\
\text { Coeficiente de Correlação Linear Populacional }\end{array}$ \\
\hline Período da Semana & Patamar de carga & Fase A & Fase B & Fase C \\
\hline Domingo & Carga Leve & 0,2889 & 0,4732 & 0,4987 \\
Domingo & Carga Média & 0,3203 & 0,3691 & 0,5079 \\
Segunda a Sábado & Carga Leve & 0,8958 & 0,8981 & 0,8838 \\
Segunda a Sábado & Carga Média & 0,8900 & 0,8943 & 0,8779 \\
Segunda a Sábado & Carga Pesada & 0,8934 & 0,8975 & 0,8837 \\
\hline
\end{tabular}

No período de segunda a sábado a correlação é forte. No domingo, a correlação desta LT com a LT Interlagos-Xavantes se mantém entre moderada e fraca. Vale mencionar que a amplitude das correntes da LT Xavantes-Bandeirantes é da mesma ordem de grandeza da amplitude das correntes da LT Interlagos-Xavantes, indicando que a maior parte da corrente que flui pela LT Ibiúna-Interlagos circula por esta LT.

Tabela 19 - Resultados de correlação das correntes de $5^{\text {a }}$ ordem medidas nas LTs de Xavantes com as correntes na LT Interlagos-Xavantes.

\begin{tabular}{cccc}
\hline \multicolumn{4}{c}{$\begin{array}{c}\text { CORRELAÇÃO: LTs de Xavantes com LT Interlagos-Xavantes } \\
\text { Avaliação das Correntes de 5a Ordem Harmônica } \\
\\
\text { Coeficiente de Correlação Linear Populacional }\end{array}$} \\
\hline Período da Semana & $\begin{array}{c}\text { Patamar } \\
\text { de carga }\end{array}$ & $\begin{array}{c}\text { Xavantes- } \\
\text { Milton Fornasaro }\end{array}$ & $\begin{array}{c}\text { Xavantes- } \\
\text { Bandeirantes }\end{array}$ \\
\hline Domingo & Carga Leve & 0,6269 & 0,4203 \\
Domingo & Carga Média & 0,6236 & 0,3991 \\
Segunda a Sábado & Carga Leve & 0,8781 & 0,8926 \\
Segunda a Sábado & Carga Média & 0,8926 & 0,8874 \\
Segunda a Sábado & Carga Pesada & 0,8882 & 0,8915 \\
\hline
\end{tabular}

Através dos resultados obtidos apresentados na Tabela 19 e das amplitudes medidas nas duas LTs, determinou-se que a corrente harmônica na LT XavantesBandeirantes é a principal fonte da corrente harmônica na LT Interlagos-Xavantes. 
Uma curiosidade detectada na campanha foi que as correntes de $5^{\text {a }}$ ordem harmônica medidas nos extremos da LT Xavantes-Bandeirantes possuem amplitudes diferentes. Enquanto a corrente de $5^{\mathrm{a}}$ ordem harmônica medida no extremo de Xavantes se mantém com amplitude média de 24 Ampères, a corrente de $5^{a}$ ordem harmônica medida no extremo de Bandeirantes se mantém com amplitude média de 7 Ampères. Devido a esta LT ser composta por 3 circuitos de cabos subterrâneos com aproximadamente $8,5 \mathrm{~km}$ de extensão, que possuem característica predominantemente capacitiva, a investigação suspeita que a capacitância dos cabos subterrâneos entrou em um estado de ressonância com o resto do sistema formado pelas LTs Interlagos-Xavantes, Ibiúna-Interlagos e a baixa impedância dos Filtros de dupla sintonia de Ibiúna, na frequência de $5^{\mathrm{a}}$ ordem harmônica.

Constatou-se que a amplitude da corrente foi aumentada da ordem de 4 vezes devido ao efeito de ressonância harmônica desse sistema. A comparação das correntes em ambos os extremos pode ser feita observando-se os registros de correntes em cada SE nos Gráficos 8 e 9.

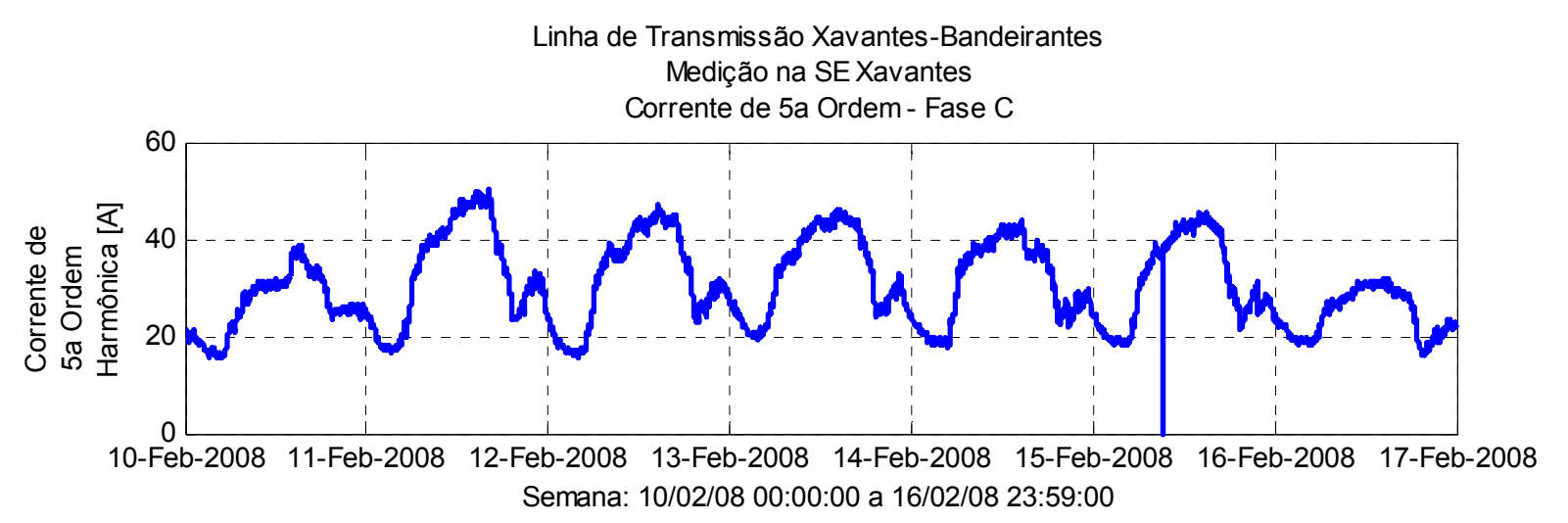

Gráfico 8 - Registro semanal dos valores eficazes das correntes de $5^{\mathrm{a}}$ ordem harmônica da LT Xavantes-Bandeirantes, realizado na SE Xavantes. 


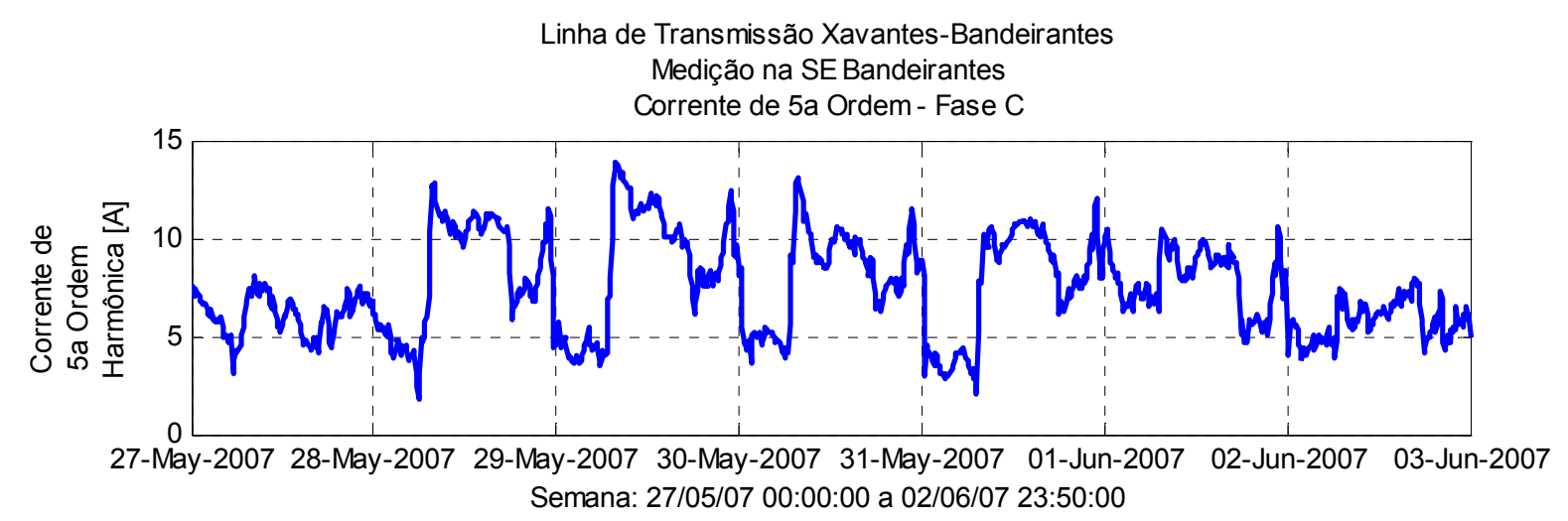

Gráfico 9 - Registro semanal dos valores eficazes das correntes de $5^{\mathrm{a}}$ ordem harmônica da LT Xavantes-Bandeirantes, realizado na SE Bandeirantes.

Embora os períodos de registro em ambos os gráficos sejam diferentes, as correntes medidas em ambos os locais mantém este perfil de correntes e amplitudes semanalmente, permitindo que se possa fazer essa comparação.

\subsubsection{Correlações das Cargas Industriais}

Foram avaliadas as correlações das correntes de $5^{a}$ ordem harmônica nas cargas industriais Carbocloro, Cosipa, Gerdau e CBA, com relação às correntes drenadas por um dos três filtros que estavam em operação em Ibiúna.

A Carbocloro possui em média 1,5 Ampères de corrente de $5^{\mathrm{a}}$ ordem, enquanto que os filtros de Ibiúna absorvem em torno de 70 Ampères. 
Tabela 20 - Resultados de correlação das correntes de $5^{\mathrm{a}}$ ordem medidas na carga Carbocloro e nos Filtros de $3^{a}$ e $5^{a}$ harmônicas.

\begin{tabular}{ccccc}
\hline \multicolumn{5}{c}{ CORRELAÇÃO: Carbocloro versus Filtro-série } \\
Avaliação das Correntes de 5a Ordem Harmônica \\
Coeficiente de Correlação Linear Populacional \\
\hline Período da Semana & Patamar de carga & Fase A & Fase B & Fase C \\
\hline Domingo & Carga Leve & 0,8018 & 0,7670 & 0,6831 \\
Domingo & Carga Média & 0,3432 & $-0,1604$ & $-0,2404$ \\
Segunda a Sábado & Carga Leve & 0,6375 & 0,6233 & 0,4637 \\
Segunda a Sábado & Carga Média & 0,7459 & 0,6426 & 0,3275 \\
Segunda a Sábado & Carga Pesada & 0,8970 & 0,8981 & 0,7406 \\
\hline
\end{tabular}

Durante a carga leve dos domingos e a carga pesada de segunda a sábado a correlação entre esta carga e o perfil de correntes nos filtros é forte. Contudo, a amplitude da corrente harmônica da indústria Carbocloro não é superior a $2 \%$ da amplitude da corrente harmônica absorvida pelos filtros. Isso indica que não há contribuição de correntes desta indústria para as correntes nos filtros de lbiúna.

A Cosipa possui em média 1,5 Ampères de corrente de $5^{\mathrm{a}}$ ordem, enquanto que os filtros de Ibiúna absorvem em torno de 70 Ampères.

Tabela 21 - Resultados de correlação das correntes de $5^{a}$ ordem medidas na carga Cosipa e nos Filtros de $3^{a}$ e $5^{a}$ harmônicas.

\begin{tabular}{ccccc}
\hline \multicolumn{5}{c}{ CORRELAÇÃO: Cosipa versus Filtro-série } \\
$\begin{array}{c}\text { Avaliação das Correntes de 5a Ordem Harmônica } \\
\text { Coeficiente de Correlação Linear Populacional }\end{array}$ \\
\hline Período da Semana & Patamar de carga & Fase A & Fase B & Fase C \\
\hline Domingo & Carga Leve & 0,0502 & 0,3064 & 0,0326 \\
Domingo & Carga Média & $-0,0914$ & $-0,3568$ & $-0,3649$ \\
Segunda a Sábado & Carga Leve & 0,1740 & 0,0749 & 0,0183 \\
Segunda a Sábado & Carga Média & $-0,1946$ & $-0,2494$ & 0,1483 \\
Segunda a Sábado & Carga Pesada & 0,4487 & 0,4842 & 0,3317 \\
\hline
\end{tabular}

Durante a carga pesada de segunda a sábado, a correlação desta carga com os filtros é moderada e nos demais períodos de carga a correlação é fraca ou nula. Isso indica que não há contribuição de correntes desta indústria para as correntes nos filtros de lbiúna. 
A Gerdau possui em média 0,8 Ampères de corrente de $5^{\mathrm{a}}$ ordem, enquanto que os filtros de lbiúna absorvem em torno de 70 Ampères.

Tabela 22 - Resultados de correlação das correntes de $5^{\mathrm{a}}$ ordem medidas na carga Gerdau e nos Filtros de $3^{a}$ e $5^{a}$ harmônicas.

\begin{tabular}{ccccc}
\hline \multicolumn{5}{c}{ CORRELAÇÃO: Gerdau versus Filtro-série } \\
\multicolumn{4}{c}{ Avaliação das Correntes de 5a Ordem Harmônica } \\
Coeficiente de Correlação Linear Populacional \\
\hline Período da Semana & Patamar de carga & Fase A & Fase B & Fase C \\
\hline Domingo & Carga Leve & $-0,1237$ & 0,5732 & $-0,7375$ \\
Domingo & Carga Média & 0,4491 & 0,3406 & 0,2107 \\
Segunda a Sábado & Carga Leve & $-0,1905$ & $-0,0553$ & 0,0026 \\
Segunda a Sábado & Carga Média & 0,3761 & 0,2148 & $-0,0565$ \\
Segunda a Sábado & Carga Pesada & 0,2783 & 0,2984 & 0,3243 \\
\hline
\end{tabular}

No domingo, a correlação desta carga com os filtros é moderada em diferentes fases. Enquanto que nos demais períodos a correlação torna-se fraca ou nula. As correlações negativas indicam um comportamento completamente oposto entre a carga e o filtro, isto é, quanto maior a corrente na carga, menor a corrente no filtro e vice-versa. Isso indica que não há contribuição de correntes desta indústria para as correntes nos filtros de Ibiúna.

A CBA possui em média 1,7 Ampères de corrente de $5^{\mathrm{a}}$ ordem, enquanto que os filtros de Ibiúna absorvem em torno de 70 Ampères.

Tabela 23 - Resultados de correlação das correntes de $5^{\mathrm{a}}$ ordem medidas na carga CBA e nos Filtros de $3^{\mathrm{a}}$ e $5^{\mathrm{a}}$ harmônicas.

\begin{tabular}{ccccc}
\hline \multicolumn{5}{c}{ CORRELAÇÃO: CBA versus Filtro-série } \\
\multicolumn{4}{c}{$\begin{array}{c}\text { Avaliação das Correntes de 5a Ordem Harmônica } \\
\text { Coeficiente de Correlação Linear Populacional }\end{array}$} \\
\hline Período da Semana & Patamar de carga & Fase A & Fase B & Fase C \\
\hline Domingo & Carga Leve & $-0,0972$ & $-0,4416$ & $-0,0052$ \\
Domingo & Carga Média & 0,4420 & 0,7205 & 0,4403 \\
Segunda a Sábado & Carga Leve & 0,6573 & 0,6098 & 0,5441 \\
Segunda a Sábado & Carga Média & 0,3774 & 0,1723 & 0,0624 \\
Segunda a Sábado & Carga Pesada & 0,4373 & 0,4082 & 0,4074 \\
\hline
\end{tabular}


Durante a carga média do domingo e as cargas leve e pesada de segunda a sábado, a correlação desta carga com os filtros de Ibiúna é moderada. Porém, neste caso também a amplitude da corrente harmônica medida na CBA não é superior a 2,5\% da amplitude da corrente harmônica medida nos filtros. Isso indica que não há contribuição de correntes desta indústria para as correntes nos filtros de lbiúna.

Tabela 24 - Resultados de correlação das correntes de $5^{\mathrm{a}}$ ordem medidas nas cargas industriais com as correntes dos Filtros de $3^{a}$ e $5^{a}$ harmônicas.

\begin{tabular}{cccccc}
\hline \multicolumn{6}{c}{$\begin{array}{c}\text { CORRELAÇÃO: Cargas Industriais versus Filtro-série } \\
\text { Avaliação das Correntes de 5a Ordem Harmônica } \\
\text { Coeficiente de Correlação Linear Populacional }\end{array}$} \\
\hline Período da Semana & de carga & Carbocloro & Cosipa & Gerdau & CBA \\
\hline Domingo & Carga Leve & 0,7506 & 0,1297 & $-0,0960$ & $-0,1813$ \\
Domingo & Carga Média & $-0,0192$ & $-0,2710$ & 0,3335 & 0,5343 \\
Segunda a Sábado & Carga Leve & 0,5748 & 0,0891 & $-0,0811$ & 0,6037 \\
Segunda a Sábado & Carga Média & 0,5720 & $-0,0986$ & 0,1781 & 0,2040 \\
Segunda a Sábado & Carga Pesada & 0,8452 & 0,4215 & 0,3003 & 0,4176 \\
\hline
\end{tabular}

Embora a indústria Carbocloro tenha apresentado correlação significativa em determinados períodos de carga, a corrente de $5^{\mathrm{a}}$ ordem harmônica medida sobre a indústria é muito pequena, não caracterizando que a contribuição desta carga seja a causadora de algum problema nos filtros de Ibiúna.

As demais cargas industriais não contribuem para a corrente harmônica nos filtros.

\subsubsection{Correlações das Linhas da SE Guarulhos}

Foram avaliadas as correlações das correntes de $5^{a}$ ordem harmônica nas LTs Guarulhos-Anhanguera e Guarulhos-Norte, com relação às correntes da LT IbiúnaGuarulhos. 
A LT Guarulhos-Anhanguera possui em média 5 Ampères de corrente de $5^{a}$ ordem, enquanto que a LT Ibiúna-Guarulhos possui em média 23 Ampères.

Tabela 25 - Resultados de correlação das correntes de $5^{\mathrm{a}}$ ordem medidas na LT Ibiúna-Guarulhos e na LT Guarulhos- Anhanguera.

\begin{tabular}{ccccc}
\hline \multicolumn{4}{c}{ CORRELAÇÃO: LT Ibiúna-Guarulhos versus LT Guarulhos-Anhanguera } \\
\multicolumn{4}{c}{$\begin{array}{c}\text { Avaliação das Correntes de 5a Ordem Harmônica } \\
\text { Coeficiente de Correlação Linear Populacional }\end{array}$} \\
\hline Período da Semana & Patamar de carga & Fase A & Fase B & Fase C \\
\hline Domingo & Carga Leve & 0,1078 & 0,2285 & 0,1057 \\
Domingo & Carga Média & 0,0040 & 0,1502 & 0,0831 \\
Segunda a Sábado & Carga Leve & $-0,3168$ & $-0,2457$ & $-0,3348$ \\
Segunda a Sábado & Carga Média & $-0,3336$ & $-0,2726$ & $-0,3438$ \\
Segunda a Sábado & Carga Pesada & $-0,3042$ & $-0,2564$ & $-0,3199$ \\
\hline
\end{tabular}

Durante todos os períodos de carga, a correlação desta LT com a LT IbiúnaGuarulhos é fraca ou nula.

A LT Guarulhos-Norte possui em média 22 Ampères de corrente de $5^{\mathrm{a}}$ ordem, enquanto que a LT Ibiúna-Guarulhos possui em média 23 Ampères.

Tabela 26 - Resultados de correlação das correntes de $5^{\mathrm{a}}$ ordem medidas na LT Ibiúna-Guarulhos e na LT Guarulhos-Norte.

\begin{tabular}{ccccc}
\hline \multicolumn{5}{c}{$\begin{array}{c}\text { CORRELAÇÃO: LT Ibiúna-Guarulhos versus LT Guarulhos-Norte } \\
\text { Avaliação das Correntes de } \\
\text { Coeficiente de Cordem Harmônica }\end{array}$} \\
\hline Período da Semana & Patamar de carga & Fase A & Fase B & Fase C \\
\hline Domingo & Carga Leve & 0,8759 & 0,8977 & 0,8364 \\
Domingo & Carga Média & 0,9336 & 0,9382 & 0,9279 \\
Segunda a Sábado & Carga Leve & 0,9133 & 0,9087 & 0,8436 \\
Segunda a Sábado & Carga Média & 0,8108 & 0,7936 & 0,7362 \\
Segunda a Sábado & Carga Pesada & 0,9081 & 0,8971 & 0,8247 \\
\hline
\end{tabular}

Durante todos os períodos de carga, a correlação desta LT com a LT IbiúnaGuarulhos é forte. Também pode ser avaliada a ordem de grandeza das correntes, que indicam que a amplitude da corrente harmônica da LT Guarulhos-Norte possui 
aproximadamente a mesma amplitude da corrente que passa pela LT IbiúnaGuarulhos.

Tabela 27 - Resultados de correlação das correntes de $5^{a}$ ordem medidas nas LTs de Guarulhos com as correntes na LT Ibiúna-Guarulhos.

\begin{tabular}{cccc}
\hline \multicolumn{4}{c}{ CORRELAÇÃO: LTs de Guarulhos versus LT Ibiúna-Guarulhos } \\
& $\begin{array}{c}\text { Avaliação das Correntes de 5a Ordem Harmônica } \\
\text { Coeficiente de Correlação Linear Populacional }\end{array}$ \\
\hline Período da Semana & Patamar & Guarulhos- & Guarulhos- \\
& de carga & Anhanguera & 0,8700 \\
\hline Domingo & Carga Leve & 0,1473 & 0,9332 \\
Domingo & Carga Média & 0,0791 & 0,8885 \\
Segunda a Sábado & Carga Leve & $-0,2991$ & 0,7802 \\
Segunda a Sábado & Carga Média & $-0,3167$ & 0,8766 \\
Segunda a Sábado & Carga Pesada & $-0,2935$ & \\
\hline
\end{tabular}

Através dos resultados obtidos apresentados na Tabela 27, determinou-se que a corrente harmônica na LT Guarulhos-Norte possui a maior correlação com a corrente harmônica na LT Ibiúna-Guarulhos durante a maior parte do tempo, de modo que o estudo priorizou a investigação desta LT.

\subsubsection{Avaliação da LT Norte-Miguel Reale}

Durante a campanha de medições se observou que os cabos subterrâneos da LT Xavantes-Bandeirantes levaram o sistema a entrar em ressonância na frequência de $5^{\mathrm{a}}$ ordem harmônica, levando a elevação da corrente que flui para os Filtros de $3^{\mathrm{a}} \mathrm{e}$ $5^{\text {a }}$ harmônicas em Ibiúna.

Como a LT Norte-Miguel Reale é composta por dois circuitos de cabos subterrâneos de aproximadamente $14,5 \mathrm{~km}$ de extensão, foi realizada a medição nos extremos desta LT com o objetivo de determinar se houve ressonância com o sistema formado pelas LTs Guarulhos-Norte, Ibiúna-Guarulhos e os Filtros de $3^{a}$ e $5^{a}$ harmônicas em lbiúna. 


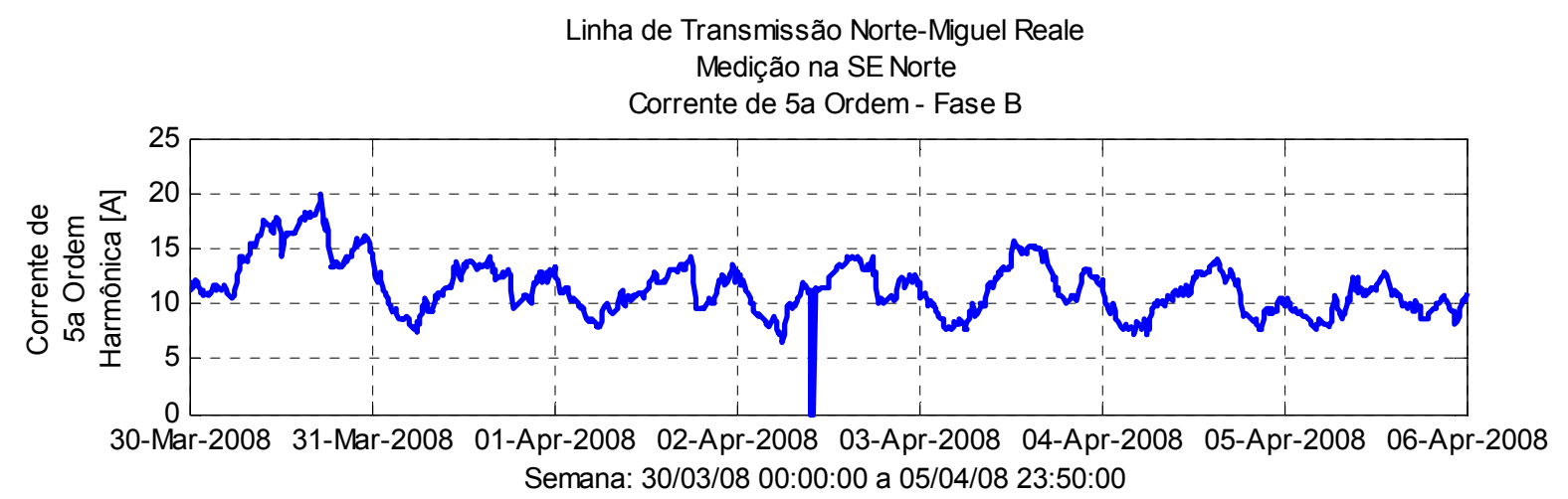

Gráfico 10 - Registro semanal dos valores eficazes das correntes de $5^{\mathrm{a}}$ ordem harmônica da LT Norte-Miguel Reale, realizado na SE Norte.

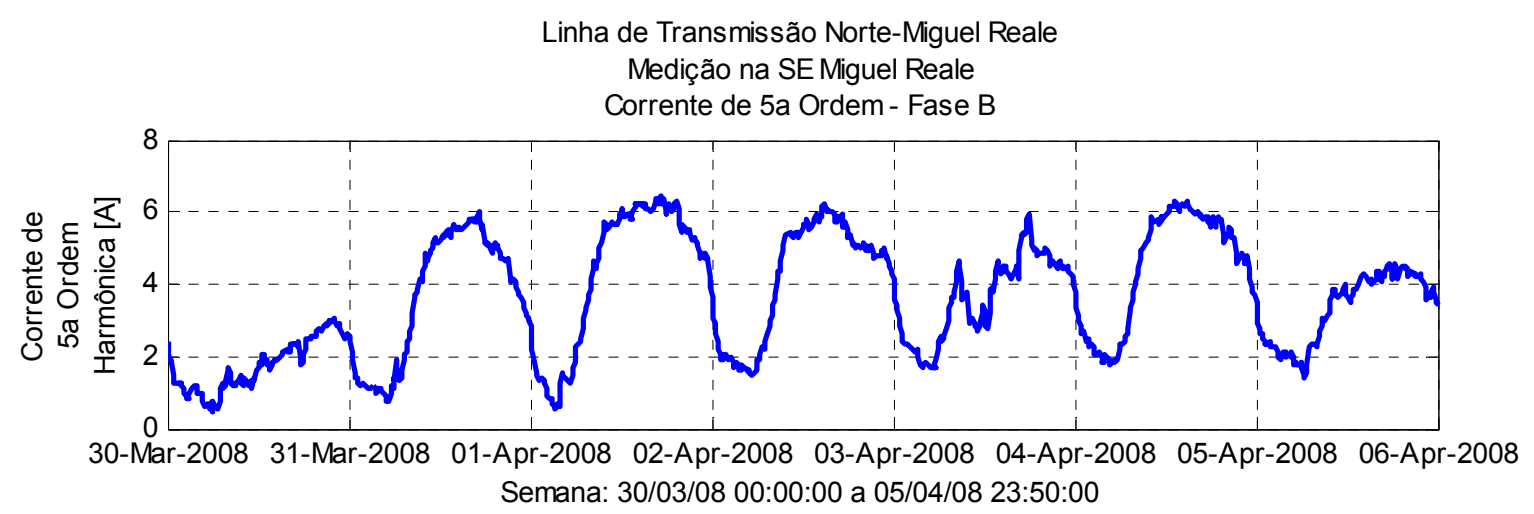

Gráfico 11 - Registro semanal dos valores eficazes das correntes de $5^{\mathrm{a}}$ ordem harmônica da LT Norte-Miguel Reale, realizado na SE Miguel Reale.

Os Gráficos 10 e 11 apresentam as correntes eficazes de $5^{a}$ ordem harmônica medidas nos extremos das SEs Norte e Miguel Reale, respectivamente. Neste caso, a amplitude da corrente foi aumentada da ordem de 2,5 vezes devido a outro efeito de ressonância harmônica. 


\subsection{Discussão dos Resultados}

Inicialmente avaliou-se que a medição de correntes na frequência de $5^{\mathrm{a}}$ ordem harmônica sobre qualquer um dos extremos das LTs aéreas curtas é equivalente, indicando que a medição em um dos extremos é suficiente para determinar a corrente harmônica que circula sobre a LT (Gráficos 3-5 e Tabelas 3-5).

Também foi observado que a medição em qualquer um dos elementos do filtro é equivalente em comportamento, porém os elementos paralelos do filtro estão submetidos a um efeito de circulação de corrente harmônica interna que impactam na amplitude da corrente medida (Tabelas 6-7).

A avaliação das correntes de $5^{\mathrm{a}}$ ordem harmônica das LTs conectadas à SE Ibiúna resultou nas seguintes observações, de acordo com os resultados da Tabela 13:

- as correntes da LT Ibiúna-Bateias possuem correlação negativa fraca a moderada com as correntes dos Filtros de $3^{\mathrm{a}}$ e $5^{\mathrm{a}}$ harmônicas, indicando que esta LT não contribui para as correntes de $5^{a}$ ordem harmônica que são absorvidas pelo filtro. Dada a correlação negativa, pode-se supor que as correntes harmônicas são drenadas das fontes conectadas à SE Ibiúna para esta LT;

- as correntes da LT Ibiúna-Campinas possuem correlação positiva moderada a fraca com as correntes do filtro, indicando que há pouca contribuição desta LT para as correntes absorvidas pelo filtro;

- as correntes da LT Ibiúna-Guarulhos possuem correlação positiva moderada a forte, indicando que há contribuição desta LT para as correntes absorvidas pelo filtro;

- as correntes da LT Ibiúna-Interlagos possuem correlação positiva moderada a forte durante a maior parte do tempo, indicando que esta LT contribui para as correntes absorvidas pelo filtro;

- as correntes da LT Ibiúna-Tijuco Preto possuem correlação positiva moderada a fraca, indicando que esta LT contribui pouco com as correntes do filtro. 
A campanha prosseguiu na avaliação das LTs conectadas com a SE Interlagos, buscando averiguar as origens das correntes harmônicas que passam pela LT Ibiúna-Interlagos. Os resultados obtidos são os seguintes:

- as correntes da LT Interlagos-Embuguaçú possuem correlação fraca com as correntes da LT Ibiúna-Interlagos, sendo forte somente aos domingos, durante a carga média. Isto indica que esta LT contribui pouco para as correntes medidas na LT Ibiúna-Interlagos;

- as correntes da LT Interlagos-Xavantes possuem correlação forte com as correntes da LT Ibiúna-Interlagos, inclusive com amplitudes da mesma ordem de grandeza, indicando que esta LT contribui para as correntes da LT IbiúnaInterlagos.

Continuando com a avaliação das LTs conectadas com a SE Xavantes, os resultados obtidos são os seguintes:

- as correntes da LT Xavantes-Milton Fornasaro possuem correlação moderada a forte com as correntes da LT Interlagos-Xavantes. Contudo, a amplitude das correntes desta LT é da ordem de $30 \%$ da amplitude das correntes da LT Interlagos-Xavantes;

- as correntes da LT Xavantes-Bandeirantes possuem correlação forte com as correntes da LT Ibiúna-Interlagos, inclusive com amplitudes da mesma ordem de grandeza, indicando que esta LT contribui para as correntes da LT Interlagos-Xavantes;

- através de medições nos extremos da LT Xavantes-Bandeirantes foi possível detectar uma amplificação da corrente de $5^{\mathrm{a}}$ ordem harmônica da ordem de 4 vezes causada por uma possível ressonância dos cabos subterrâneos com o resto do sistema.

Os resultados obtidos da avaliação das cargas industriais são os seguintes:

- as correntes da carga Carbocloro possuem correlação moderada a forte com as correntes medidas sobre os Filtros de $3^{a}$ e $5^{a}$ harmônicas em Ibiúna. Contudo, a amplitude das correntes desta carga é inferior a $2 \%$ da amplitude das correntes sobre o filtro em Ibiúna, indicando que esta LT contribui pouco para as correntes sobre o filtro; 
- as correntes da carga Cosipa possuem correlação fraca a nula com as correntes medidas sobre o filtro em Ibiúna, indicando que esta carga não contribui para as correntes sobre o filtros;

- as correntes da carga Gerdau possuem correlação fraca a nula com as correntes medidas sobre o filtro em Ibiúna, indicando que esta carga não contribui para as correntes sobre o filtro;

- as correntes da carga CBA possuem correlação fraca a moderada com as correntes medidas sobre o filtro em Ibiúna, indicando que esta carga contribui pouco para as correntes sobre o filtro.

A avaliação das LTs conectadas com a SE Guarulhos apresentaram os seguintes resultados:

- as correntes da LT Guarulhos-Anhanguera possuem correlação fraca a nula com as correntes da LT Ibiúna-Guarulhos, indicando que esta LT não contribui para as correntes da LT Ibiúna-Guarulhos;

- as correntes da LT Guarulhos-Norte possuem correlação forte com as correntes da LT Ibiúna-Guarulhos, indicando que esta LT contribui para as correntes da LT Ibiúna-Guarulhos.

Verificou-se que a LT Norte-Miguel Reale é formada por dois circuitos de cabos subterrâneos. Pela possibilidade de haver semelhança com o fenômeno observado na LT Xavantes-Bandeirantes, foram medidas as correntes em ambos os terminais desta LT e os resultados obtidos indicam que há, também, uma amplificação da ordem de 2 vezes na amplitude das correntes de $5^{\mathrm{a}}$ ordem harmônica injetadas nesta LT. 


\section{APRESENTAÇÃO DE RESULTADOS DA ANÁLISE FASORIAL}

Serão apresentados os resultados de análises fasoriais obtidas ao longo da campanha de medição, os quais visam identificar:

- os fluxos de correntes harmônicas em todos os elementos conectados à barra de 345 kV da SE Ibiúna;

- os fluxos de correntes harmônicas presentes em todas as LTs conectadas à barra da SE Xavantes;

- os fluxos de correntes harmônicas presentes em todas as LTs e cargas conectadas à barra da SE Norte, além de comparar as correntes nos extremos dos cabos subterrâneos entre as SEs Norte e Miguel Reale.

Os resultados da análise fasorial também permitem verificar se os resultados obtidos pela análise por correlação foram coerentes, validando assim a metodologia de análise utilizada.

\subsection{Resultados da Análise Fasorial}

Para validar os resultados obtidos, realizou-se a avaliação dos fasores nos principais pontos medidos, visando observar quais os principais sentidos de fluxo de corrente de $5^{\mathrm{a}}$ ordem harmônica que alimentam os Filtros de $3^{\mathrm{a}}$ e $5^{\mathrm{a}}$ harmônicas de Ibiúna.

O Gráfico 12 apresenta a composição obtida a partir do tratamento dos fasores das correntes de $5^{\mathrm{a}}$ ordem harmônica medidas em todos os componentes da SE Ibiúna, para uma única fase. 
Comparação de Correntes da fase B

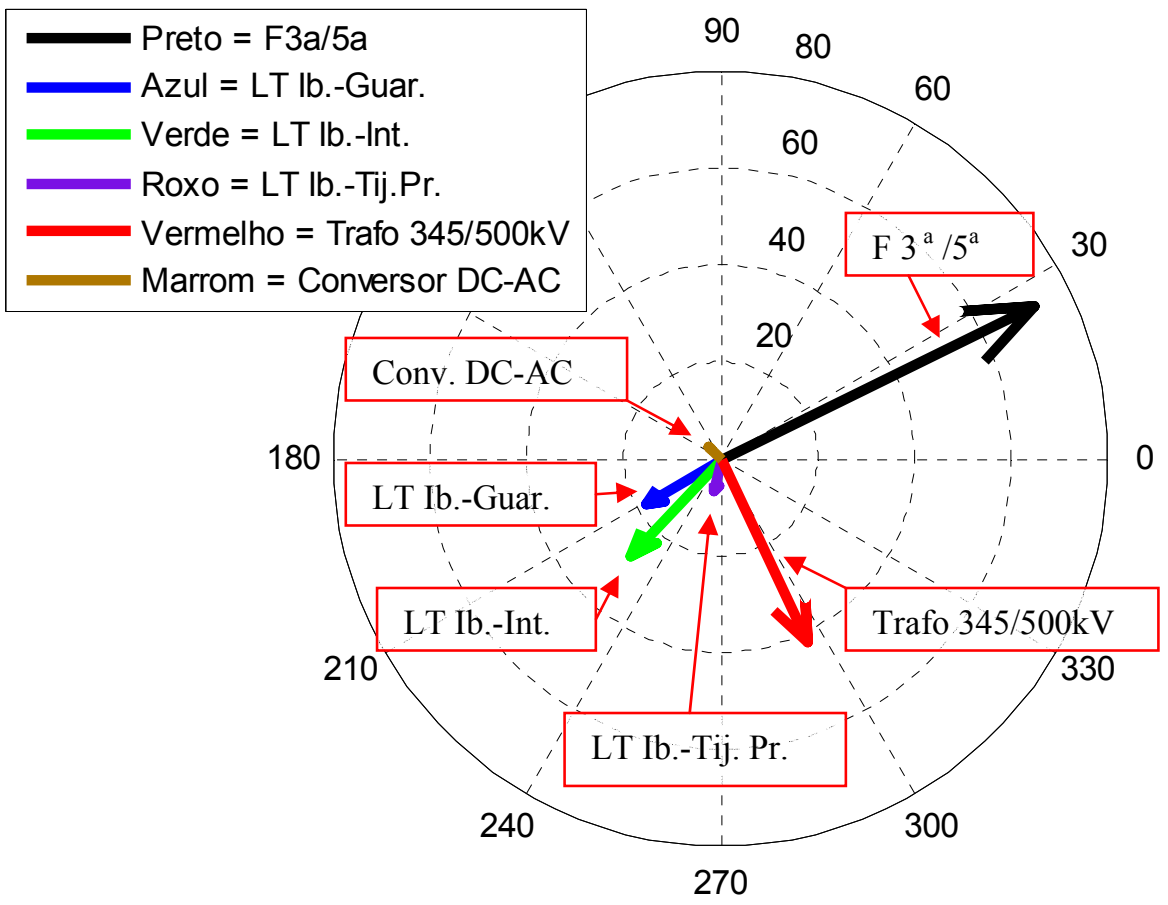

2/10/2008 00:30

Gráfico 12 - Registro dos fasores das correntes de $5^{\mathrm{a}}$ ordem harmônica das LTs da SE Ibiúna.

É possível observar que, neste instante de tempo, apenas as correntes das LTs Ibiúna-Guarulhos e Ibiúna-Interlagos estão em fase com a corrente dos Filtros de $3^{a}$ e $5^{a}$ harmônicas de lbiúna.

Este resultado valida a análise de correlação que indicou que as LTs IbiúnaGuarulhos e Ibiúna-Interlagos possuem maior correlação com as correntes harmônicas medidas nos Filtros de $3^{a}$ e $5^{a}$ harmônicas.

O Gráfico 13 apresenta os fasores das correntes de $5^{a}$ ordem harmônica medidas em todos os componentes da SE Xavantes, para uma única fase. 


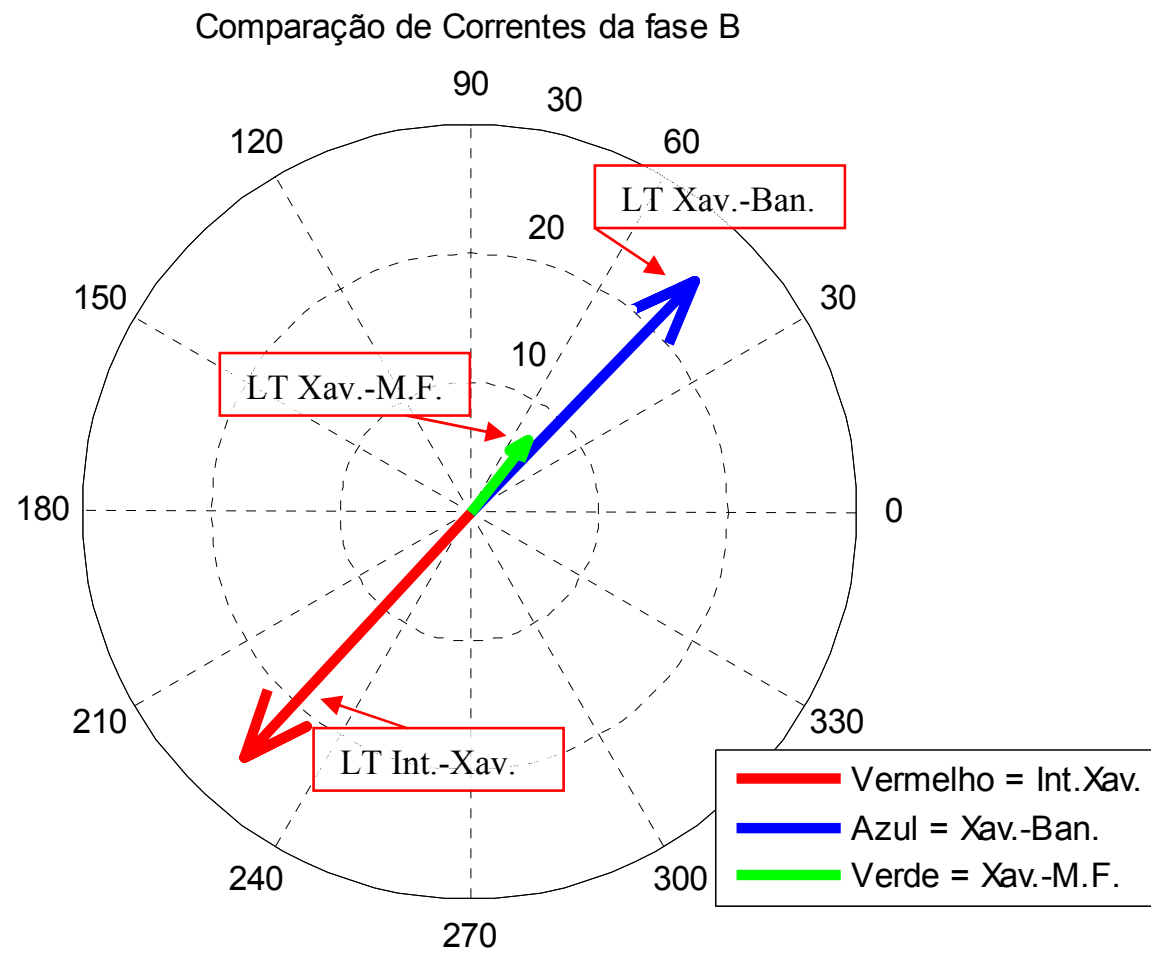

02-09-08 10:15:00

Gráfico 13 - Registro dos fasores das correntes de $5^{\mathrm{a}}$ ordem harmônica das LTs da SE Xavantes.

É possível observar que, neste instante de tempo, ambas as correntes das LTs Xavantes-Bandeirantes e Xavantes-Milton Fornasaro estão em fase com a corrente da LT Interlagos-Xavantes. Contudo, conforme apontado anteriormente, a amplitude da corrente da LT Xavantes-Bandeirantes é muito superior à amplitude da corrente da LT Xavantes-Milton Fornasaro, indicando que a LT Xavantes-Bandeirantes mantém o principal fluxo de corrente com a LT Interlagos-Xavantes.

Este resultado valida a análise de correlação que indicou que a LT XavantesBandeirantes possui maior correlação com as correntes harmônicas medidas na LT Interlagos-Xavantes.

O Gráfico 14 apresenta os fasores das correntes de $5^{a}$ ordem harmônica medidas em todos os componentes da SE Norte, para uma única fase, bem como o fasor da LT Norte-Miguel Reale medido no terminal de Miguel Reale para que fosse feita a 
visualização do efeito de amplificação por ressonância dos cabos subterrâneos que compõem esta LT.

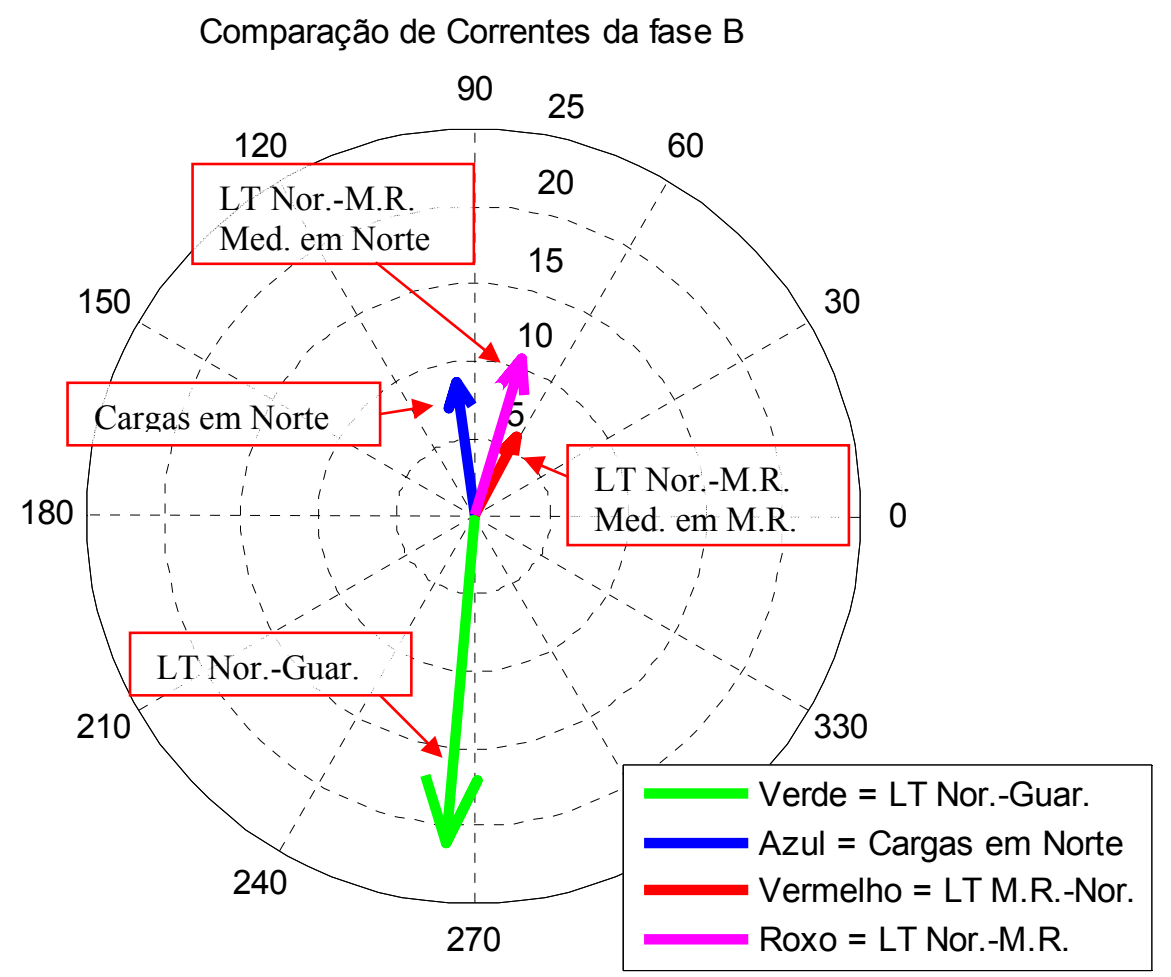

05-13-08 11:45:00

Gráfico 14 - Registro dos fasores das correntes de $5^{\mathrm{a}}$ ordem harmônica das LTs da SE Norte e dos extremos da LT Norte-Miguel Reale.

É possível observar que, neste instante de tempo, ambas as correntes das cargas da SE Norte e da LT Norte-Miguel Reale estão em fase com a corrente da LT Guarulhos-Norte. Isso indica que as contribuições de ambas as fontes compõem a corrente harmônica da LT Guarulhos-Norte. Note-se que a corrente da LT NorteMiguel Reale ainda é superior à corrente das cargas da SE.

Ainda é possível visualizar a amplificação da ordem de 2 vezes sobre as correntes harmônicas injetadas no terminal de Miguel Reale na LT Norte-Miguel Reale, ao se compararem as correntes medidas, onde o fasor indicado por Nor.-M.R. significa que 
a medição foi no terminal de Norte e o fasor indicado por M.R.-Nor. Significa que a medição foi no terminal de Miguel Reale.

Este resultado valida a análise de correlação que indicou que a LT Norte-Miguel Reale possui maior correlação com as correntes harmônicas medidas na LT Guarulhos-Norte.

\subsection{Discussão dos Resultados}

A avaliação fasorial das correntes de $5^{\mathrm{a}}$ ordem harmônica das LTs conectadas à SE Ibiúna resultou nas seguintes observações, de acordo com o Gráfico 12:

- as correntes das LTs Ibiúna-Guarulhos e lbiúna-Interlagos contribuem diretamente para o fluxo das correntes absorvidas pelo filtro. Esses resultados comprovam a existência da forte correlação destas LTs com as correntes absorvidas pelo filtro;

- as correntes da LT Ibiúna-Tijuco Preto e dos conversores DC-AC contribuem pouco para as correntes absorvidas pelo filtro.

Continuando com a avaliação fasorial das LTs conectadas com a SE Xavantes, os resultados obtidos do Gráfico 13 são os seguintes:

- as correntes da LT Xavantes-Milton Fornasaro possuem amplitude da ordem de $30 \%$ da amplitude das correntes da LT Interlagos-Xavantes;

- as correntes da LT Xavantes-Bandeirantes possuem amplitude da mesma ordem de grandeza da amplitude das correntes da LT Interlagos-Xavantes, indicando que o fluxo principal da corrente harmônica que passa pela LT Interlagos-Xavantes provém da LT Xavantes-Bandeirantes.

A avaliação fasorial das LTs conectadas com a SE Norte, apresentada no Gráfico 14, tiveram os seguintes resultados:

- as correntes das cargas conectadas à SE Norte e da LT Norte-Miguel Reale contribuem diretamente para o fluxo das correntes da LT Guarulhos-Norte, 
indicando que ambas as fontes formam o sentido principal do fluxo de correntes;

- a amplificação de corrente harmônica sobre os cabos subterrâneos da LT Norte-Miguel Reale pode ser verificada pela medição fasorial, indicando uma amplificação da ordem de 2 vezes em amplitude.

Estes resultados foram verificados com a análise fasorial das correntes em uma das fases.

Verificou-se que a LT Norte-Miguel Reale é formada por dois circuitos de cabos subterrâneos. Pela possibilidade de haver semelhança com o fenômeno observado na LT Xavantes-Bandeirantes, foram medidas as correntes em ambos os terminais desta LT e os resultados obtidos indicam que há, também, uma amplificação da ordem de 2 vezes na amplitude das correntes de $5^{a}$ ordem harmônica injetadas nesta LT.

\subsection{Análise de Ressonância}

Com base nas medições das correntes harmônicas que fluem para os Filtros de $3^{a} \mathrm{e}$ $5^{a}$ harmônicas da SE Ibiúna, inferiu-se que a diferença de amplitude das correntes de $5^{\mathrm{a}}$ ordem harmônica que fluem nos extremos da LT Xavantes-Bandeirantes teria ocorrido devido a um fenômeno de ressonância do sistema.

Essa ressonância acontece devido às características naturais dos elementos da rede. Para baixas frequências, em linhas aéreas curtas, há a predominância de efeito indutivo, enquanto que em linhas subterrâneas curtas há a predominância de efeito capacitivo. Em circunstâncias favoráveis, a interação entre as características predominantes destes elementos pode resultar em ressonâncias para determinadas frequências, em particular quando a reatância capacitiva dos cabos subterrâneos cancela a reatância indutiva do sistema. 
A Figura 17 apresenta um circuito simples de ressonância harmônica. Uma injeção de corrente harmônica em um extremo da linha percorre o circuito até atingir o terra. Durante a ressonância, entre a capacitância $C p$ e a indutância $L p$ que estão em paralelo (ambas ligadas à terra), surge uma circulação de corrente harmônica na mesma frequência da corrente injetada. A corrente medida sobre a indutância $L p$ é igual à corrente injetada somada à corrente circulante do ramo paralelo do circuito.

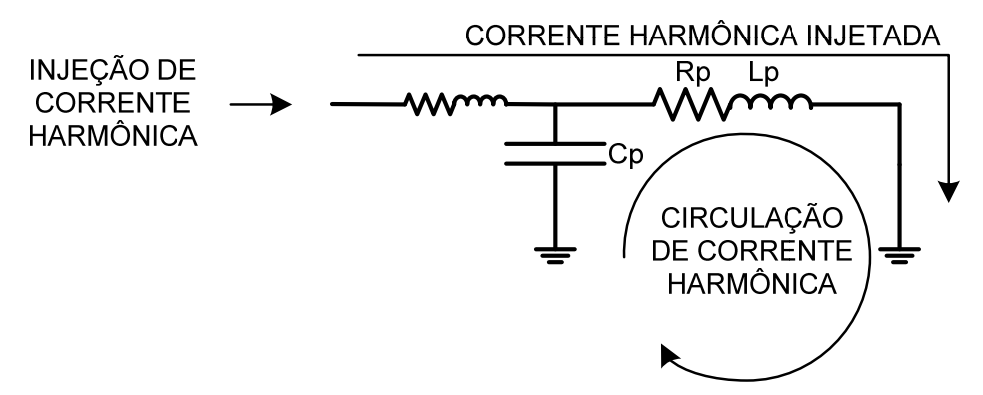

Figura 17 - Circuito simplificado de ressonância harmônica.

Para demonstrar o fenômeno de amplificação de correntes harmônicas observado no estudo do sistema de transmissão de energia foi feita a modelagem simplificada no programa $P S I M \circledR$ versão 9.0, versão de demonstração. Os dados das principais LTs envolvidas no fenômeno e dos Filtros de $3^{a}$ e $5^{a}$ harmônicas, instalados junto à saída dos conversores DC-AC da SE Ibiúna foram obtidos do ONS e de outras referências apresentadas neste capítulo.

A injeção de corrente harmônica no terminal do cabo subterrâneo localizado na SE Bandeirantes pelas cargas do sistema conectadas a esta barra foi modelada por uma fonte de corrente alternada sintonizada na frequência de $300 \mathrm{~Hz}$.

O diagrama unifilar da Figura 18 ilustra a representação simplificada do sistema que será modelado, para a simulação do fenômeno: 


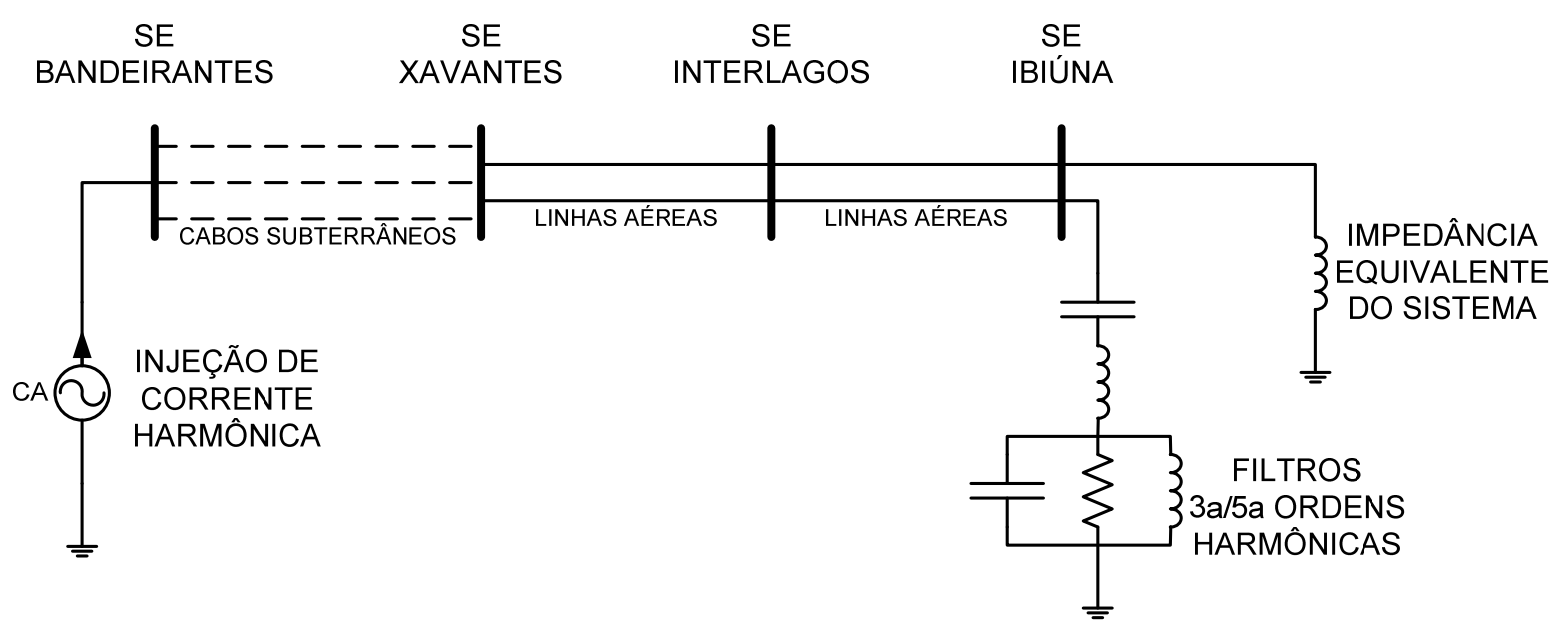

Figura 18 - Ilustração do Sistema Modelado para a Simulação do Fenômeno de Amplificação.

Para realizar a modelagem dos três cabos subterrâneos da LT XavantesBandeirantes, foram obtidas as impedâncias de sequência positiva da LT na frequência fundamental, encontradas nos diagramas de impedâncias publicados pelo ONS (Procedimento..., 2009):

Para os três cabos subterrâneos em paralelo:

$$
\begin{aligned}
& Z_{e q}^{{ }^{\text {XAVANTES-BANDEIRANTES }}}=\frac{(0,00333+j .0,06) \%}{100 \%} \cdot \frac{(345 \mathrm{kV})^{2}}{100 \mathrm{MVA}} \\
& Z_{e q}^{{ }^{\text {XAVANTES-BANDEIRANTES }}}=0,039675+j .1,071 \Omega \\
& L_{e q}{ }^{\text {XAVANTES-BANDEIRANTES }}=\frac{x_{e q} \text { XAVANTES-BANDEIRANTES }}{\omega}=\frac{1,071}{2 . \pi .60} \\
& L_{e q}{ }^{\text {XAVANTES-BANDEIRANTES }}=2,841 \mathrm{mH}
\end{aligned}
$$

Para obter a capacitância do cabo, foi utilizado o cálculo descrito em Citron (2004):

$$
C_{e q}{ }^{C A B O}=\frac{2 \cdot \pi \cdot \varepsilon \cdot \varepsilon_{0}}{\ln (D / d)} \cdot L
$$


Onde, para o cabo tipo OF (Oil Filled): $d=43,63 \mathrm{~mm}$

$$
\begin{aligned}
& \mathrm{D}=81,33 \mathrm{~mm} \\
& \mathrm{~L}=8500 \mathrm{~m} \\
& \varepsilon=3,3 \\
& \varepsilon_{0}=8,8542 \cdot 10^{-12} \mathrm{~F} / \mathrm{m} \\
& C_{e q}{ }^{C A B O}=\frac{2 \cdot \pi \cdot 3,3 \cdot 8,8542 \cdot 10^{-12}}{\ln (81,33 / 43,63)} \cdot 8500=2,5057 \mu \mathrm{F} / \mathrm{cabo}
\end{aligned}
$$

Dividindo-se esta capacitância por 2 para atender ao modelo m-equivalente, temos:

$$
\frac{C_{e q}{ }^{C A B O}}{2}=1,2529 \mu \mathrm{F} / \text { cabo }
$$

Considerando-se que há 3 cabos na LT Xavantes-Bandeirantes, a capacitância do modelo m-equivalente fica:

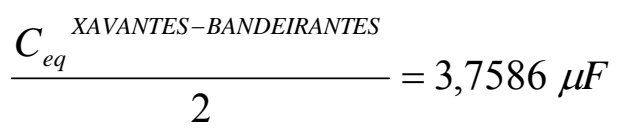

Dado que a parte resistiva da impedância dos cabos resultou em um valor muito baixo, a parte resistiva dos cabos será desconsiderada do modelo. A modelagem dos três cabos subterrâneos da LT Xavantes-Bandeirantes foi concebida dividindose a LT em três trechos de $4 \mathrm{~km}$ cada:

$$
\begin{aligned}
& x_{\text {eq }}{ }^{\text {TRECHO }}=j .1,071 \Omega / 3 \text { trechos }=j .0,357 \Omega / \text { trecho } \\
& L_{e q}{ }^{\text {TRECHO }}=\frac{0,357}{2 . \pi \cdot 60}=0,947 \mathrm{mH} / \text { trecho } \\
& \frac{C_{e q}{ }^{\text {TRECHO }}}{2}=\frac{3,7586}{3 \text { trechos }}=1,2529 \mu \mathrm{F} / \text { trecho }
\end{aligned}
$$


A partir destes resultados foi possível modelar os três cabos subterrâneos da LT Xavantes-Banteirantes através do circuito equivalente apresentado na Figura 19:

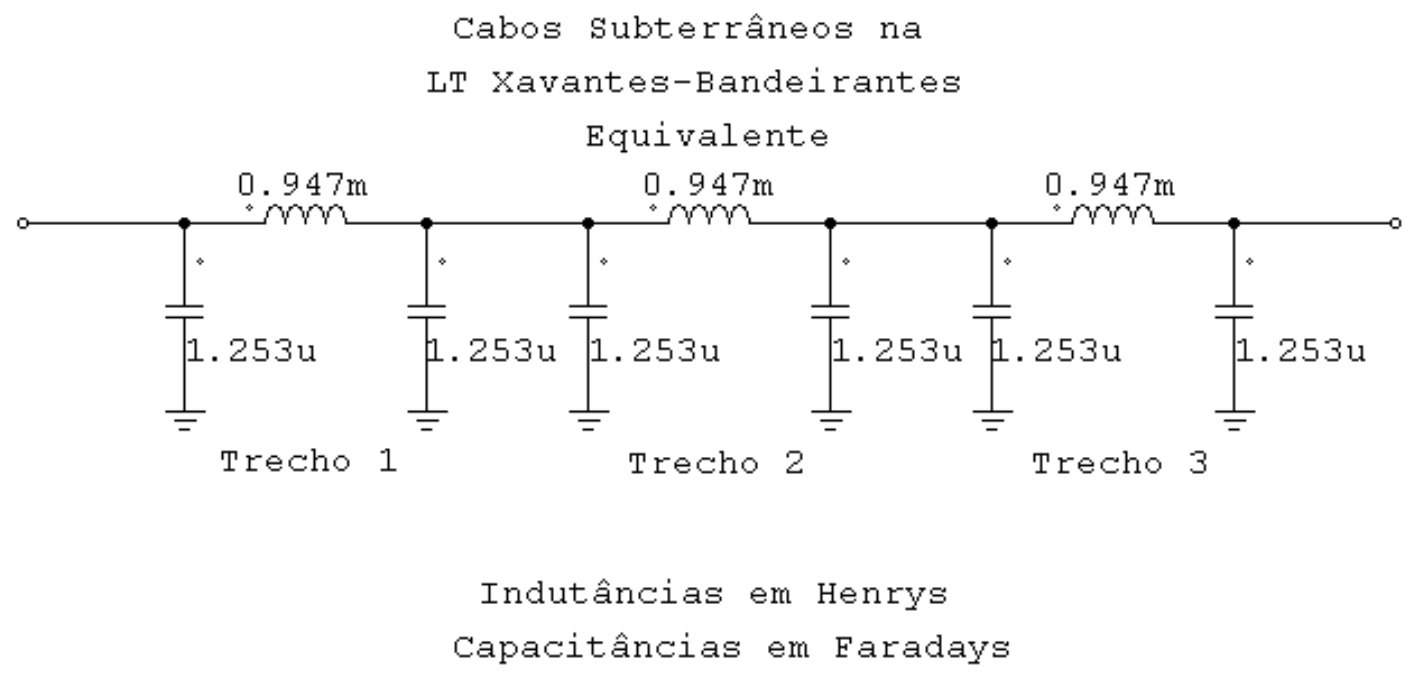

Figura 19 - Modelo equivalente dos três Cabos Subterrâneos da LT XavantesBandeirantes.

Para realizar a modelagem das LTs Ibiúna-Interlagos e Interlagos-Xavantes, foram utilizados os mesmos diagramas de impedâncias do ONS (Procedimento..., 2009) para a determinação dos circuitos m-equivalentes de cada linha:

Para os dois circuitos da LT Ibiúna-Interlagos em paralelo:

$$
\begin{aligned}
& Z_{e q}^{\text {IBIÚNA-INTERLAGOS }}=\frac{(0,045+j .0,77) \%}{100 \%} \cdot \frac{(345 \mathrm{kV})^{2}}{100 \mathrm{MVA}} \\
& Z_{\text {eq }}^{{ }^{\text {IBIÚNA-INTERLAGOS }}}=0,5356+j \cdot 9,1649 \Omega \\
& L_{\text {eq }}^{\text {IBIÚNA-INTERLAGOS }}=\frac{x_{e q}{ }^{\text {IBIÚNA-INTERLAGOS }}}{\omega}=\frac{9,1649}{2 . \pi \cdot 60} \\
& L_{e q}^{\text {IBIÚNA-INTERLAGOS }}=24,311 \mathrm{mH}
\end{aligned}
$$


Para os dois circuitos da LT Interlagos-Xavantes em paralelo:

$$
\begin{aligned}
& Z_{e q}^{\text {INTERLAGOS-XAVANTES }}=\frac{(0,005+j .0,09) \%}{100 \%} \cdot \frac{(345 \mathrm{kV})^{2}}{100 \mathrm{MVA}} \\
& Z_{e q}^{{ }^{\text {INTERLAGOS-XAVANTES }}}=0,0595+j .1,0712 \Omega \\
& L_{e q}{ }^{\text {INTERLAGOS-XAVANTES }}=\frac{x_{e q}{ }^{\text {INTERLAGOS-XAVANTES }}}{\omega}=\frac{1,0712}{2 . \pi \cdot 60} \\
& L_{e q}{ }^{\text {INTERLAGOS-XAVANTES }}=2,8415 \mathrm{mH}
\end{aligned}
$$

A partir destas impedâncias, calculou-se o comprimento aproximado das LTs considerando-se como reatância média de LTs aéreas o valor de 0,45 $\Omega$ / km:

$$
\begin{aligned}
& l_{\text {LT }}^{\text {IBIÚNA-INTERLAGOS }}=\frac{2 \cdot x_{e q}{ }^{\text {IBIÚNA-INTERLAGOS }}}{0,45 \Omega / \mathrm{km}}=\frac{(2.9,1649 \Omega)}{0,45 \Omega / \mathrm{km}} \\
& l_{\text {LT }}^{{ }^{\text {IBIÚNA-INTERLAGOS }}}=40,733 \mathrm{~km} \\
& l_{\text {LT }}^{\text {INTERLAGOS-XAVANTES }}=\frac{2 \cdot x_{e q}{ }^{\text {INTERLAGOS-XAVANTES }}}{0,45 \Omega / \mathrm{km}}=\frac{(2.1,0712 \Omega)}{0,45 \Omega / \mathrm{km}} \\
& l_{\text {LT }}^{{ }^{\text {INTERLAGOS-XAVANTES }}}=4,761 \mathrm{~km}
\end{aligned}
$$

A partir dos comprimentos obtidos, estimou-se o valor das capacitâncias paralelas equivalentes das LTs considerando-se como capacitância média de LTs aéreas o valor típico de $12 \mathrm{nF} / \mathrm{km}$ :

$$
\begin{aligned}
& C_{e q}^{{ }^{\text {IBIÚNA-INTERLAGOS }}}=l_{\text {LT }}^{\text {IBIÚNA-INTERLAGOS }} .12 \mathrm{nF} / \mathrm{km} \\
& C_{e q}^{\text {IBIÚNA-INTERLAGOS }}=488,8 \mathrm{nF} \\
& C_{e q}^{\text {INTERLAGOS-XAVANTES }}=l_{L T}^{\text {INTERLAGOS-XAVANTES }} .12 \mathrm{nF} / \mathrm{km} \\
& C_{e q}^{\text {INTERLAGOS-XAVANTES }}=57,132 \mathrm{nF}
\end{aligned}
$$

No modelo de circuito m-equivalente construído, estas capacitâncias foram divididas em duas partes iguais, conectadas no início e fim dos circuitos equivalentes das LTs. 
Além disso, como ambas as LTs são compostas por dois circuitos, as capacitâncias foram dobradas.

A partir destes resultados foi possível construir o modelo m-equivalente das LTs Ibiúna-Interlagos e Interlagos-Xavantes através do circuito equivalente apresentado na Figura 20, já considerando que cada LT é composta por dois circuitos:

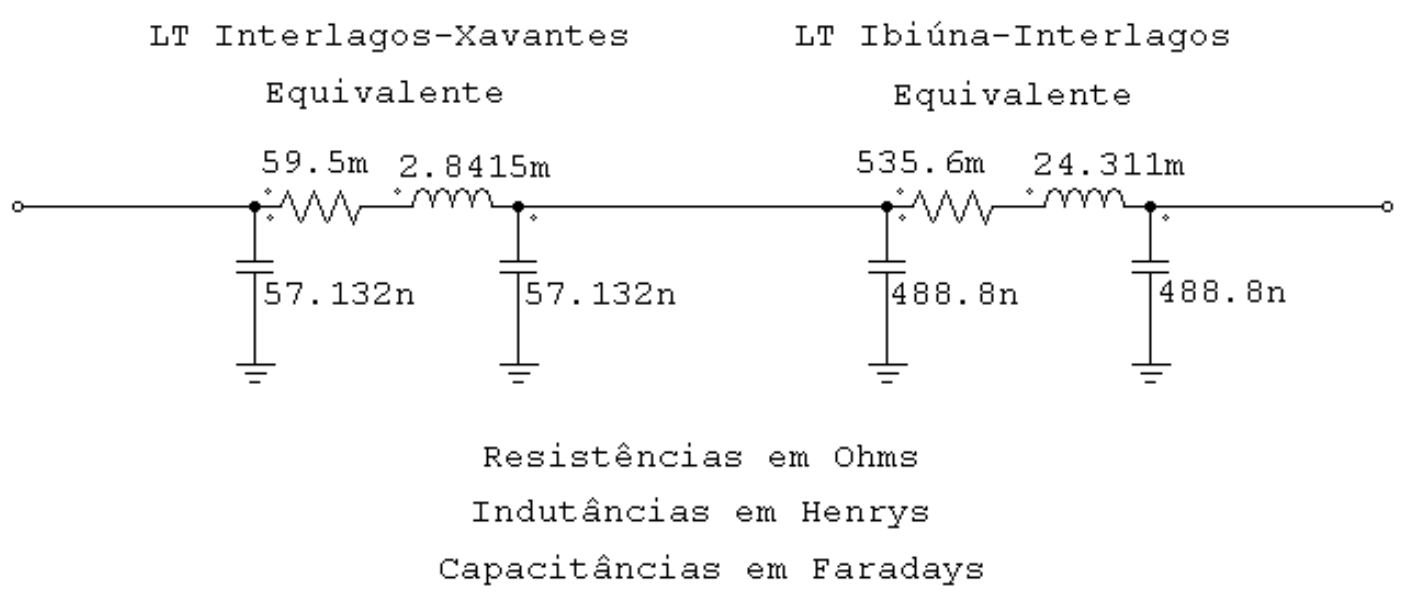

Figura 20 - Modelo т-equivalente das LTs Ibiúna-Interlagos e Interlagos-Xavantes.

A modelagem de cada um dos três filtros de dupla sintonia, sintonizados para as frequências de $3^{a}$ e $5^{a}$ ordens harmônicas, atualmente em operação na SE Ibiúna baseou-se no projeto do filtro apresentado em Gonçalves (2009).

Para cada um dos filtros, tem-se:

$$
Z^{\text {FLTRO }}(h)=h . j \cdot 377 . L_{1}+\frac{1}{h \cdot j .377 . C_{1}}+\left(\frac{1}{\frac{1}{R}+h \cdot j \cdot 377 . C_{2}+\frac{1}{h \cdot j \cdot 377 . L_{2}}}\right)
$$


Onde: $\mathrm{C}_{1}=1,2 \mu \mathrm{F}$

$$
\begin{aligned}
& \mathrm{L}_{1}=391 \mathrm{mH} \\
& \mathrm{C}_{2}=4,43 \mu \mathrm{F} \\
& \mathrm{R}=3,3796 \mathrm{k} \Omega \\
& \mathrm{L}_{2}=106,29 \mathrm{mH}
\end{aligned}
$$

Portanto, a impedância de um dos filtros em função da ordem harmônica pode ser calculada por:

$$
Z^{\text {FILTRO }}(h)=h \cdot j \cdot 147,4+\frac{1}{h \cdot j \cdot 452,4 \cdot 10^{-6}}+\left(\frac{1}{2,959 \cdot 10^{-4}+h \cdot j \cdot 1,67 \cdot 10^{-3}+\frac{1}{h \cdot j \cdot 40,07}}\right)
$$

Para os três filtros operando em paralelo, a impedância equivalente em função da ordem harmônica pode ser dada por:

$$
Z_{e q}^{\text {FILTROS }}(h)=h \cdot j \cdot 49,14+\frac{1}{h \cdot j \cdot 1,36 \cdot 10^{-3}}+\left(\frac{1}{8,88 \cdot 10^{-4}+h \cdot j \cdot 5,01 \cdot 10^{-3}+\frac{1}{h \cdot j \cdot 13,36}}\right)
$$

A curva de impedância equivalente dos três filtros em paralelo em função da frequência, calculada através da eq.(56) é dada por: 


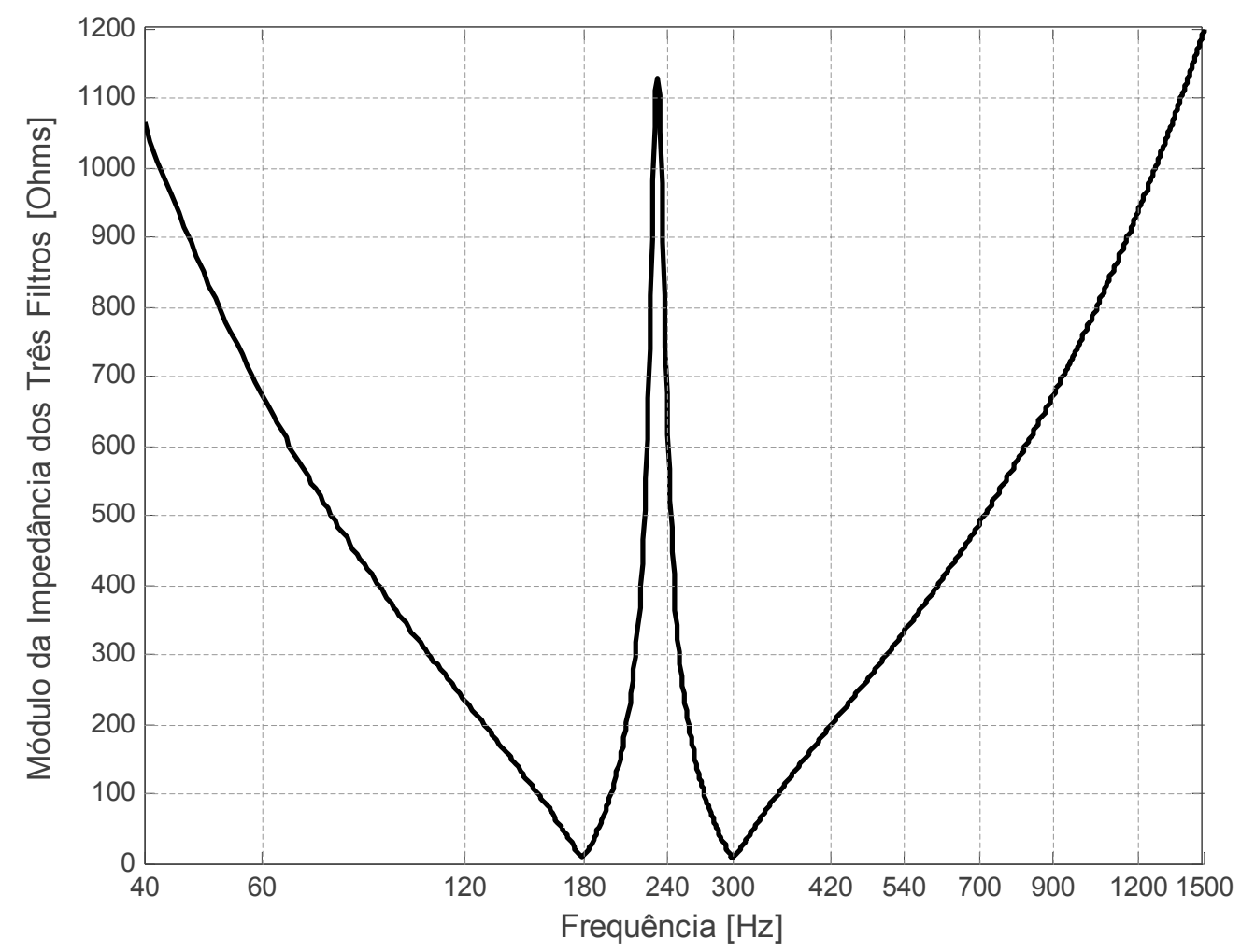

Gráfico 15 - Impedância Equivalente dos três Filtros de $3^{a}$ e $5^{\mathrm{a}}$ Harmônicas de Ibiúna em função da frequência.

A partir destes resultados foi possível modelar os três filtros de Ibiúna através do circuito equivalente apresentado na Figura 21: 


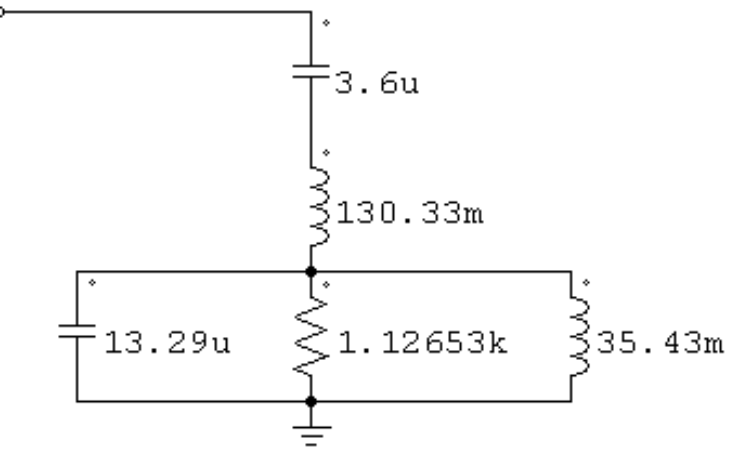

Resistencias em ohms

Indutancias em Henrys

Capacitancias em Faradays

Figura 21 - Modelo dos três Filtros Paralelos de $3^{\mathrm{a}}$ e $5^{\mathrm{a}}$ Harmônicas de Ibiúna.

Para calcular a impedância equivalente do SIN na barra de Ibiúna, foi consultada a potência de curto-circuito trifásica da barra de $345 \mathrm{kV}$ dos estudos de curto-circuito do ONS (Estudos..., 2009). Com a potência registrada no ano de 2008, foi possível calcular a impedância equivalente do sistema vista da barra de Ibiúna:

$$
\begin{aligned}
& S_{3 \phi}{ }^{\text {IBIÚNA }}=20162,2 \mathrm{MVA} \\
& Z_{\text {th }}{ }^{\text {IBIÚNA }}=\frac{\sqrt{3} \cdot V_{\text {nom }}{ }^{2}}{S_{3 \phi}}=\frac{\sqrt{3} \cdot 345^{2}}{20162,2}=10,225 \Omega \\
& L_{\text {th }}{ }^{\text {IBIÚNA }}=\frac{Z_{\text {th }}{ }^{\text {IBIÚNA }}}{\omega}=\frac{10,225}{2 \cdot \pi \cdot 60}=27,1225 \mathrm{mH}
\end{aligned}
$$




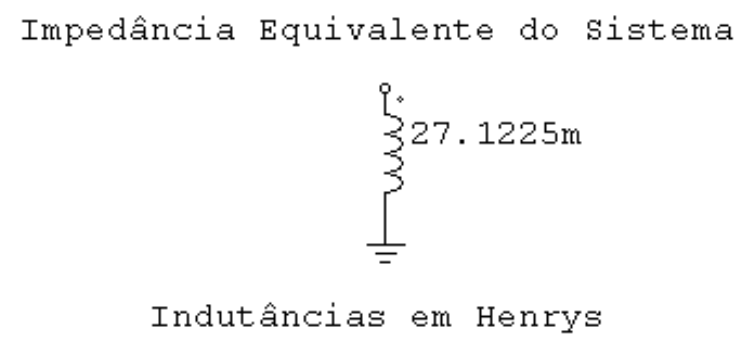

Figura 22 - Modelo da Impedância Equivalente do SIN na Barra de lbiúna.

A partir destes modelos, foi possível realizar a simulação da injeção de uma corrente de $5^{\mathrm{a}}$ ordem harmônica em um extremo do cabo, conforme o circuito apresentado na Figura 23: 

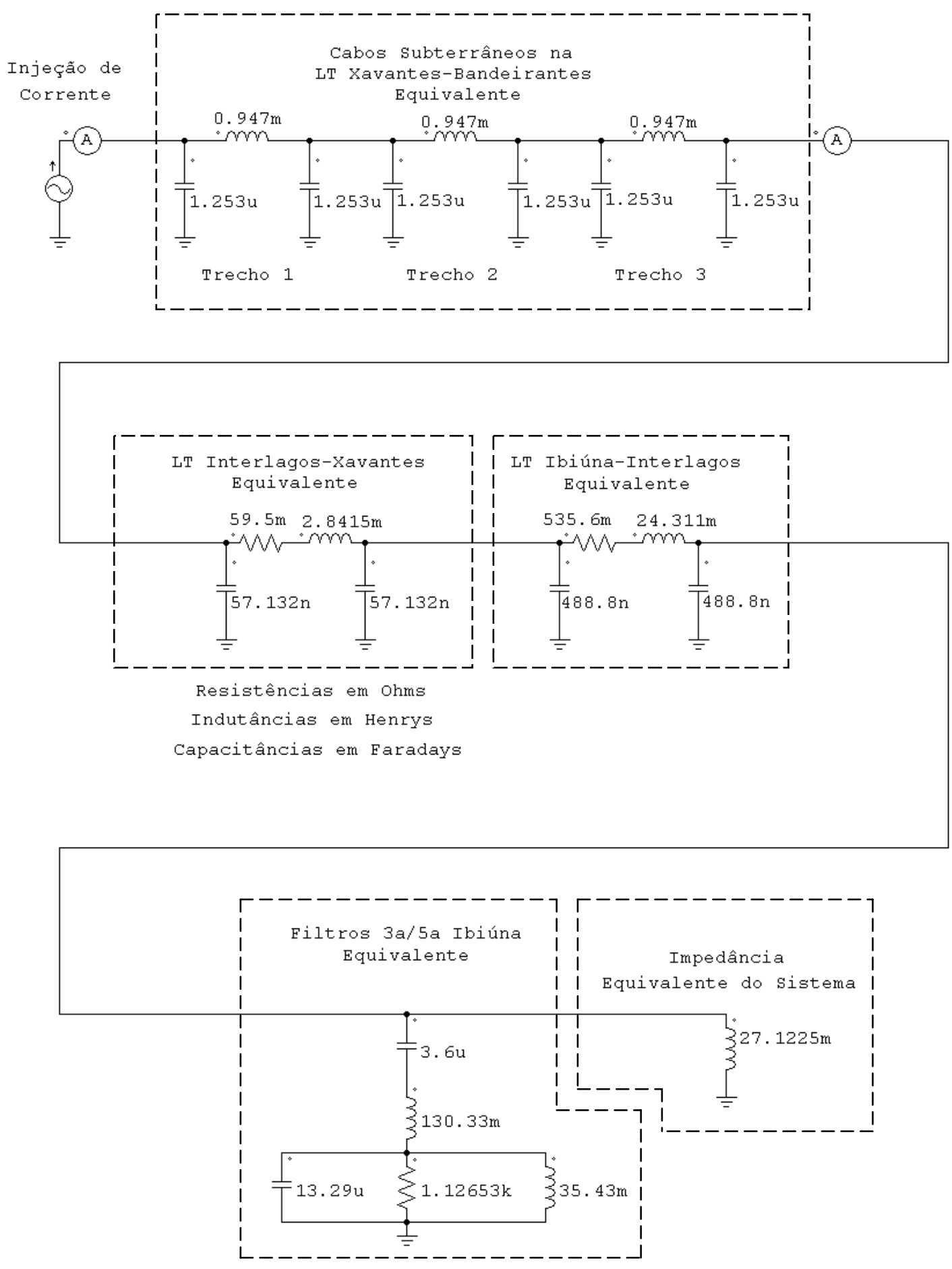

Figura 23 - Circuito Modelado para a Simulação de Amplificação de Harmônicos.

Simulando a injeção de uma corrente com amplitude de pico de 10 Ampères e frequência de $300 \mathrm{~Hz}$, obtêm-se os resultados apresentados no Gráfico 16. 


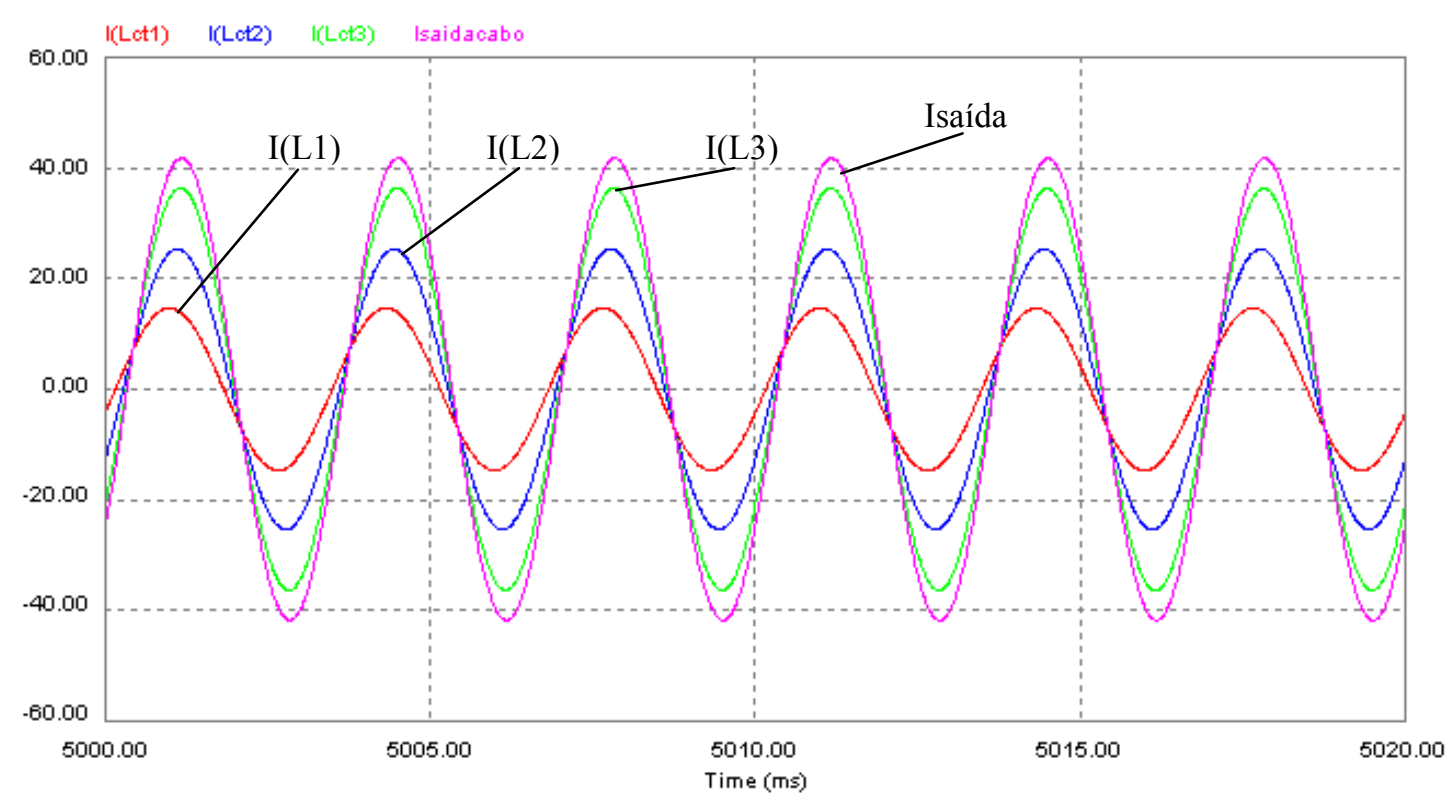

Gráfico 16 - Correntes sobre os Trechos dos Cabos Subterrâneos.

No Gráfico 16, I(L1) é a corrente sobre o indutor do primeiro trecho dos cabos, I(L2) é a corrente sobre o indutor do segundo trecho dos cabos, I(L3) é a corrente sobre o indutor do terceiro trecho dos cabos e Isaída é a corrente na saída dos cabos.

A amplitude da corrente no primeiro trecho dos cabos subterrâneos sofre um aumento de 1,46 vezes em sua amplitude. A amplitude da corrente no segundo trecho do cabo chega a atingir 2,54 vezes o valor da amplitude original. A amplitude da corrente no terceiro trecho do cabo chega a atingir 3,63 vezes o valor da amplitude original. Finalmente, a corrente que sai dos cabos subterrâneos possui uma amplificação em sua amplitude de 4,17 vezes em relação à amplitude original de entrada.

A corrente que sai dos cabos e flui para as linhas aéreas de transmissão é apresentada no Gráfico 17. 


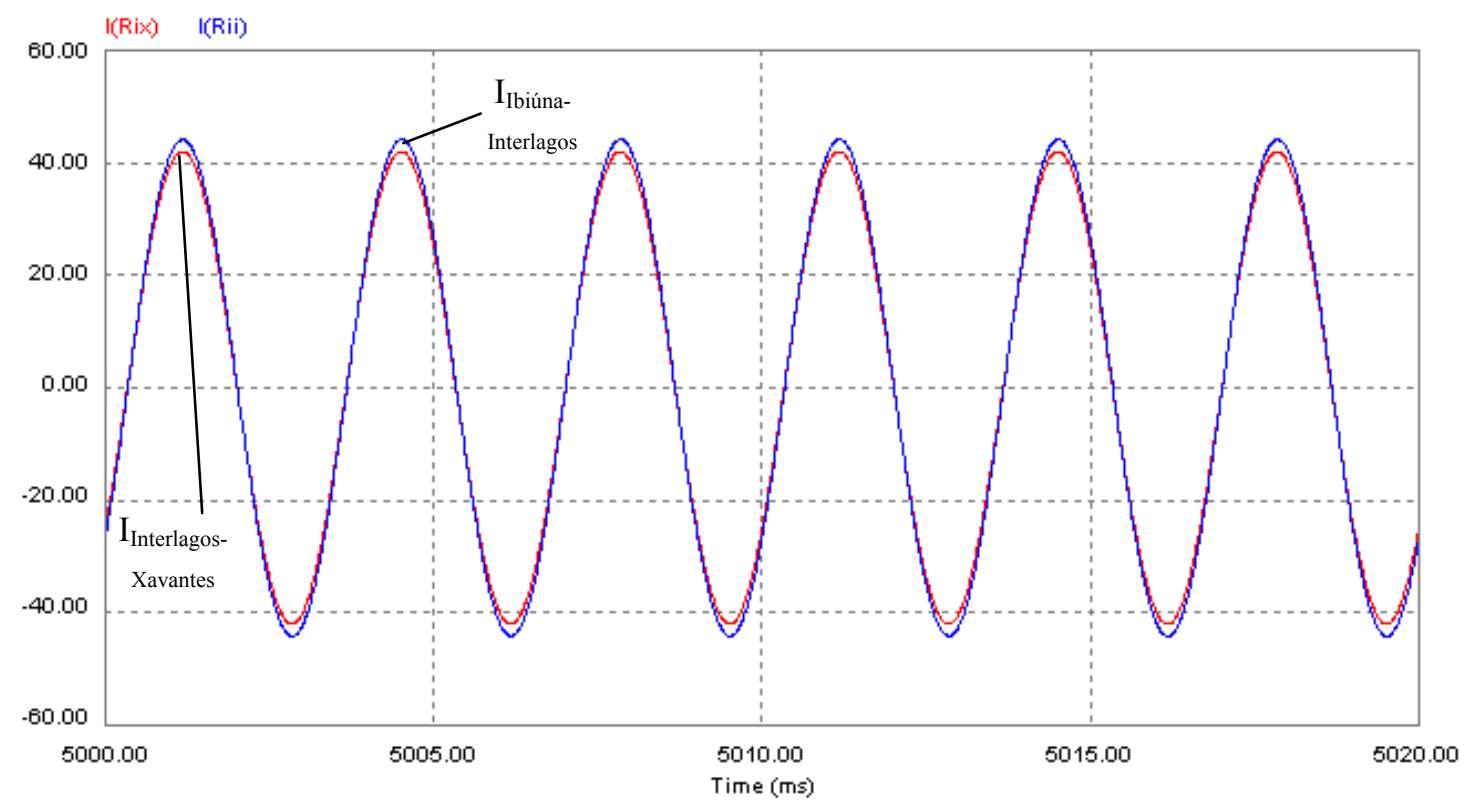

Gráfico 17 - Correntes nas LTs Interlagos-Xavantes e Ibiúna-Interlagos.

No Gráfico 17, I Interlagos-Xavantes é a corrente na LT Interlagos-Xavantes e $I_{\text {Ibiúna-Interlagos }}$ é a corrente na LT Ibiúna-Interlagos. As correntes nas LTs Interlagos-Xavantes e Ibiúna-Interlagos já possuem uma amplitude da ordem de 4 vezes a amplitude da corrente injetada no cabo subterrâneo.

E, no Gráfico 18, são comparadas a corrente na entrada dos cabos subterrâneos, indicada por linjetada, a corrente absorvida pelos Filtros de $3^{a}$ e $5^{a}$ harmônicas de Ibiúna, indicada por Ifiltros, e a corrente resultante que flui para o resto do sistema, indicada por Isistema. 


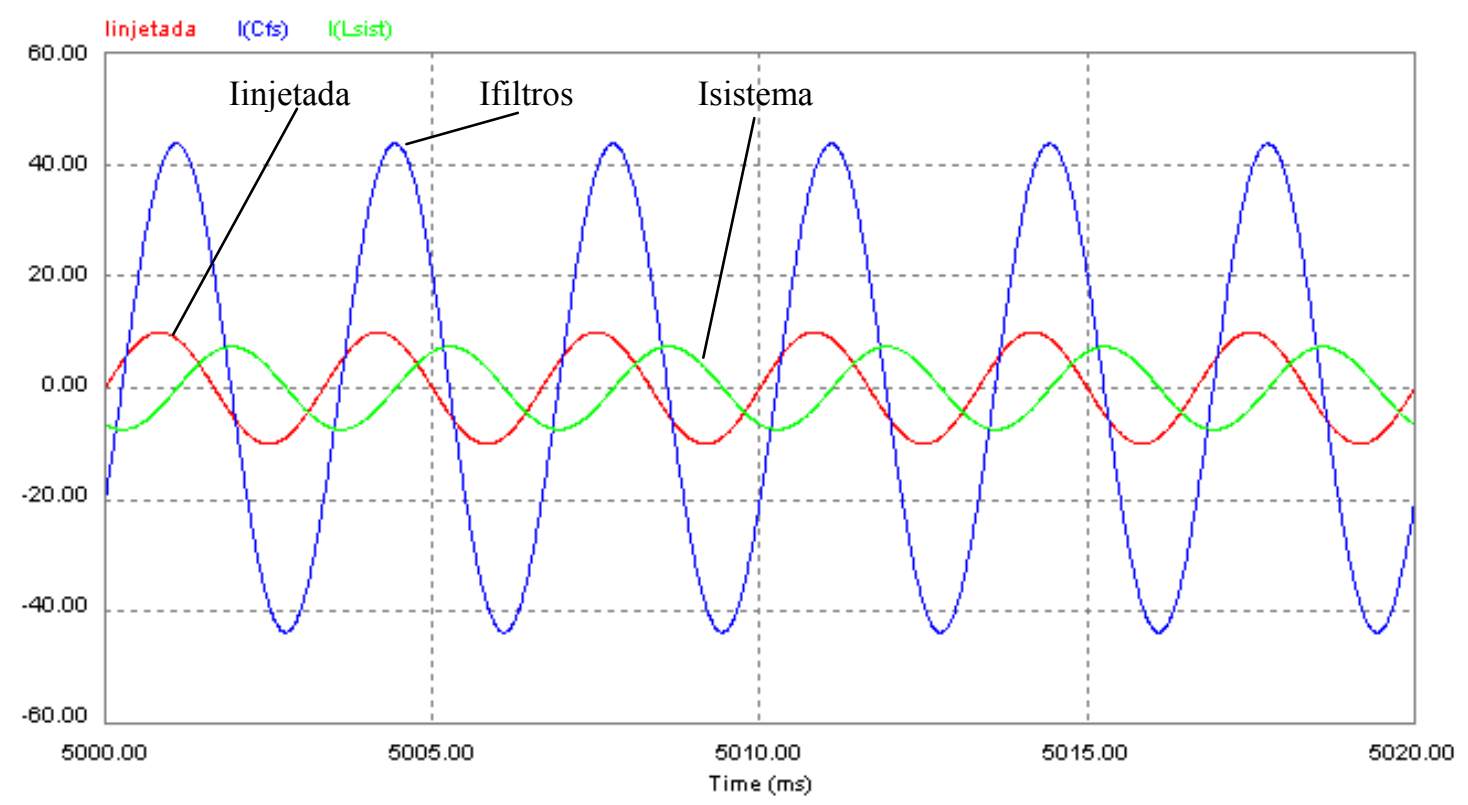

Gráfico 18 - Comparação das Correntes na Entrada dos Cabos, nos Filtros e no Sistema.

É possível observar no modelo simulado que há uma ressonância do sistema composto pelos cabos subterrâneos, linhas aéreas de transmissão e filtro. A corrente de $5^{\mathrm{a}}$ ordem harmônica injetada no circuito equivalente sofre uma amplificação da ordem de 4 vezes em amplitude, que se mantém ao longo das linhas aéreas até ser absorvida pelos Filtros de $3^{\mathrm{a}}$ e $5^{\mathrm{a}}$ harmônicas.

Estes resultados confirmam a amplificação encontrada nos registros de medição apresentados nos Gráficos 8 e 9. 


\section{CONCLUSÕES E TÓPICOS PARA DESENVOLVIMENTO FUTURO}

Neste capítulo, serão apresentadas as conclusões gerais do trabalho e tópicos para desenvolvimento futuro.

\subsection{Conclusões Gerais}

Este trabalho apresentou um método para a avaliação da contribuição de correntes harmônicas em redes elétricas, baseando-se em análises por correlação e fasoriais. O método tem por requisitos o sincronismo no tempo entre os medidores para que sejam realizados os registros simultaneamente e que sejam registrados os valores eficazes e fasoriais das tensões e correntes harmônicas ao longo dos locais medidos para que seja feita a avaliação.

A instalação dos medidores nas SEs precisa obedecer às normas de segurança NR $N^{\circ} 10$ e NR $N^{\circ}$, além da equipe de instalação estar munida de EPIs e EPCs para proteção. A conexão dos medidores aos pontos de medição normalmente é feita através dos secundários dos TPs e TCs, mas de um modo geral não se permite a abertura dos secundários dos TCs para a inserção do equipamento de medição. Esta dificuldade pode ser contornada através do uso de equipamentos que se acoplem aos secundários dos TCs, fornecendo em sua saída a mesma corrente medida nos secundários.

Os registros de valores eficazes devem ser tratados para que sejam desconsiderados intervalos perdidos ou afetados por fatores externos, descaracterizando a medição naqueles instantes. $O$ tratamento consiste em desconsiderar os períodos com estes intervalos nos registros de todos os medidores simultaneamente, mesmo que somente um medidor tenha registrado os valores incorretos. 
Os registros fasoriais devem ser normalizados através da escolha de um fasor de referência como, por exemplo, uma das tensões da barra mais próxima da geração. Os ângulos das fases de todos os registros serão ajustados com relação a esta referência para que os fasores possam ser analisados em qualquer instante.

A análise estatística dos resultados consiste em montar os diagramas de dispersão semanais dos registros de valores eficazes harmônicos e compará-los através do uso do coeficiente de correlação linear para identificar se existe relação entre os comportamentos das grandezas em análise. A análise é mais refinada se a comparação for realizada dividindo os registros por patamares de carga.

A análise fasorial é a ferramenta conclusiva para validar os resultados obtidos da análise estatística por correlação, servindo para verificar os caminhos de fluxos reais, além de identificar as contribuições dos elementos de rede ligados à barra em estudo.

Os maiores benefícios deste método são a obtenção de resultados precisos e reais, fazendo o uso apenas de uma estratégia baseada na topologia geral da rede em estudo, sem que seja preciso se conhecer ou obter as impedâncias atualizadas do sistema para cálculos de fluxo de potência harmônico ou de estimação de estados.

As principais desvantagens deste método são a necessidade de se realizar medições sincronizadas no tempo e de se possuir ao menos três ou mais medidores capazes de realizar estes registros com estas características. Além disso, há a dificuldade de se realizar a instalação dos medidores dadas as restrições de acoplamento dos mesmos e de ser possível deixar os medidores em local protegido.

No estudo de caso realizado no sistema de 345 kV alimentado pela SE de Ibiúna, através dos resultados das análises sobre as correntes de $5^{a}$ ordem harmônica pode-se concluir que as LTs com maior contribuição para as correntes harmônicas absorvidas pelos Filtros de $3^{a}$ e $5^{a}$ harmônicas em Ibiúna são as LTs IbiúnaGuarulhos e Ibiúna-Interlagos, esta última com grande correlação e durante a maior parte do tempo. 
Analisando-se as LTs conectadas com a LT Ibiúna-Interlagos, foi possível observar que a LT Interlagos-Xavantes possui uma forte correlação com a LT Ibiúna Interlagos, indicando que as correntes que passam pela LT Ibiúna-Interlagos são provenientes da SE Xavantes.

Através da análise das LTs conectadas à SE Xavantes, determinou-se que a principal fonte das correntes harmônicas desta SE é a amplificação por ressonância que ocorre nos cabos subterrâneos que formam a LT Xavantes-Bandeirantes, amplificando a corrente injetada no cabo em até 4 vezes. Este resultado foi explorado em uma análise teórica simplificada do fenômeno, na qual foram obtidos resultados compatíveis com os valores medidos.

$\mathrm{Na}$ avaliação das linhas conectadas à LT Ibiúna-Guarulhos, determinou-se que o mesmo fenômeno de amplificação por ressonância ocorre na LT Norte-Miguel Reale, também formada por cabos subterrâneos, amplificando a corrente injetada no cabo em até 2 vezes.

Estas conclusões mostram que a metodologia apresentada foi capaz de identificar as principais origens das correntes que afetam os Filtros de $3^{\mathrm{a}}$ e $5^{\mathrm{a}}$ harmônicas e os principais fluxos de correntes harmônicas que as compõem.

Embora este método possua suas próprias desvantagens, o benefício da alta confiabilidade dos resultados na identificação das principais fontes de harmônicos é suficiente para sua validação. 


\subsection{Tópicos para Desenvolvimento Futuro}

O estudo apresentado desperta um maior interesse para os fenômenos harmônicos que ocorrem no sistema elétrico. Os efeitos observados nos filtros harmônicos em Ibiúna mostram que a injeção de harmônicos no sistema tem aumentado e que, se nada for feito, isso poderá trazer riscos para a operação da rede.

Referente aos filtros em Ibiúna, a corrente harmônica produzida pelos conversores DC-AC não é muito elevada (da ordem de 8 Ampères) quando comparada às correntes harmônicas drenadas do resto do sistema (da ordem de 90 Ampères). Isso traz algumas dúvidas a serem estudadas:

- Os filtros harmônicos em lbiúna são necessários para a operação dos conversores DC-AC? Se eles fossem retirados, haveria grande distorção na tensão resultante fornecida em Ibiúna?

- Seria possível substituir os filtros passivos de Ibiúna por um sistema de filtros ativos, dimensionados para corrigir somente as distorções originárias dos conversores DC-AC?

Por outro lado, a circulação de harmônicos no sistema elétrico tende a causar uma maior distorção harmônica nas tensões das barras mais fracas do sistema. Isso traz a necessidade de avaliar onde estão as principais fontes de harmônicos no sistema elétrico. Em uma nova etapa do estudo, a metodologia proposta poderia ser aplicada nos sistemas de subtransmissão para realizar a identificação dos principais centros de carga que injetam harmônicos na rede. Esse estudo permitirá avaliar:

- Se há soluções de baixo custo que poderiam ser aplicadas em pontos da rede mais próximos das principais fontes de harmônicos.

- A necessidade de aplicar novos limites para a emissão de harmônicos no sistema para controlar a injeção harmônica das cargas.

Se as concessionárias possuírem uma modelagem adequada e atualizada dos sistemas de subtransmissão, poderia ser aplicado um estudo de estimação de 
harmônicos para identificar as principais fontes de harmônicos no sistema e manter a monitoração dessas injeções.

Por outro lado, embora seja uma sugestão de custo mais elevado, é recomendável que seja feita a instalação de medidores de harmônicos em diversos pontos do sistema de subtransmissão e que essa monitoração seja mantida para que os níveis de harmônicos no sistema sejam acompanhados constantemente. Isso permitirá às concessionárias tomar medidas com a eficiência e rapidez necessárias para evitar problemas mais graves causados por harmônicos no sistema. 


\section{REFERÊNCIAS}

AGÊNCIA NACIONAL DE ENERGIA ELÉTRICA. Procedimentos de Distribuição Módulo 8 - Qualidade de Energia Elétrica. Rio de Janeiro, 2010. Disponível em: $<$ http://www.aneel.gov.br/arquivos/PDF/Modulo8_Revisao_2.pdf>. Acesso em: 13 Dez. 2010.

Arbiter Systems. Model 1133A Power Sentinel GPS-synchronized power quality/revenue stardard operation manual. Paso Robles: Arbiter Systems, 2006. $218 \mathrm{p}$.

Arrillaga, J. et.al. Power system harmonic analysis. Chichester: John Wiley \& Sons, 1997. $382 \mathrm{p}$.

Arrillaga, J.; Watson, N.R.; Chen, S. Power system quality assessment. Chichester: John Wiley \& Sons, 2001. 312 p.

Arrillaga, J.; Watson, N.R. Power system harmonics. Chichester: John Wiley \& Sons, 2003. $386 \mathrm{p}$.

Brasil, D.O.C. et.al. Resultados relacionados à campanha de medição de harmônicas para identificação de causas da sobrecarga observada em componentes dos filtros de $3^{a}$ e $5^{a}$ ordem harmônicas localizado na SE Ibiúna. In: Conferência Brasileira sobre Qualidade da Energia Elétrica, 8, 2009, Blumenau. Disponível em: <http://www.sbqee.com.br/artigos_cbqee_2009.htm>. Acesso em 25 Nov. 2010.

BRASIL. Ministério do Trabalho e do Emprego. Norma regulamentadora $\mathbf{N}^{\circ} 10-$ Segurança em instalações e serviços em eletricidade. 07 de dezembro de 2004. Disponível em: <http://www.mte.gov.br/legislacao/normas_regulamentadoras/ default.asp>. Acesso em 25 Nov. 2010.

BRASIL. Ministério do Trabalho e do Emprego. Norma regulamentadora $\mathbf{N}^{\circ} 7-$ Programa de controle médico de saúde ocupacional. 09 de abril de 1998. 
Disponível em: <http://www.mte.gov.br/legislacao/normas_regulamentadoras/ default.asp>. Acesso em 25 Nov. 2010.

Cataliotti, A.; Cosentino, V. A new measurement method for the detection of harmonic sources in power systems based on the approach of the IEEE Std. 1459-2000. IEEE Transactions on Power Delivery, v. 25, p. 332-340, 2009.

Chang, G.W.; Chen, C.Y.; Wu, M.C. A modified algorithm for harmonics and interharmonics measurement. In: Power Engineering Society General Meeting. p. 1-5, 2007.

Citron, E.W. et.al. Cabos de alta tensão do tipo of (oil filled) - determinação dos tempos de espera. São Paulo, 2004. Disponível em: <http://www.cteep.com.br/ port/institucional/artigos/Artigo_T16.pdf>. Acesso em: 13 Out. 2010.

Crespo, A.A. Estatística Fácil. São Paulo, 2004. 224 p.

Cristaldi, L.; Ferrero, A. Harmonic power flow analysis for the measurement of the electric power quality. IEEE Transactions on Power Delivery, v. 44, p. 683-685, 1995.

De La Rosa, F.C. Harmonics and power systems. Boca Raton: Taylor \& Francis, 2006. 208 p.

Dugan, R.C. et.al. Electrical power system quality. $2^{\text {nd }}$ Edition, New York: McGraw-Hill, 2004. 528 p.

Etezadi-Amoli, M.; Choma, K.; Louie, R. Analysis of high voltage harmonic distortion measurements. In: North American Power Symposium, 39, 2007, p. 511-517.

Fernandes, R.M. Análise de medidas operativas para controle de harmônicos na rede elétrica: um estudo de caso. Dissertação (Mestrado) Instituto Alberto Luiz 
Coimbra de Pós-Graduação e Pesquisa de Engenharia, Universidade Federal do Rio de Janeiro, Rio de Janeiro, 2007. 143 p.

Figueiredo Filho, D.B.; Silva Júnior, J.A. Desvendando os mistérios do coeficiente de correlação de Pearson (r). Revista Política Hoje, v. 18, n. 1, p. 115-146, 2009. Disponível em: <www.ufpe.br/politicahoje/index.php/politica/article/download/6/6>. Acesso em 12 Mai. 2010.

Gonçalves, R.A.A. et.al. Elo de Itaipu - filtros de 3/5 harmônicos da estação inversora de Ibiúna - Necessidade, Especificação e Projeto. In: Encontro Regional Ibero-americano do Cigré, 13, 2009, Puerto Iguazú. Disponível em: < www.cigre.org.br/archives/files/bienal2008/B4-03.pdf >. Acesso em: 13 Out. 2010.

IEC 61000-3-2 (2001-10): Electromagnetic compatibility (EMC) - part 3-2: limits - limits for harmonic current emissions (equipment input current $\leq 16 \mathrm{~A}$ per phase). Geneva, 2001. 55 p.

IEEE 100: The Authorative Dictionary of IEEE Standarts Terms - Seventh Edition. New York, 2000. 10 p. Disponível em: <http://ieeexplore.ieee.org/stamp/ stamp.jsp?arnumber=04116787>. Acesso em: 23 Ago. 2010.

IEEE Std. 519-1992: Recommended practices and requirements for harmonic control in electric power systems. New York, 1992. 101 p.

Kagan, N. et.al. A methodology for monitoring harmonic distortions in electric power distribution systems. In: International Conference on Harmonics and Quality of Power, 10, 2002. p. 322-327.

Kumar, A.; Das, B.; Sharma, J. Genetic algorithm-based meter placement for static estimation of harmonic sources. IEEE Transactions on Power Delivery, v. 11 , p. $1659-1665,1996$. 
Mack Grady, W.; Santoso, S. Understanding power system harmonics. Power Engineering Review IEEE, v. 21, n. 11, 2001.

OPERADOR NACIONAL DO SISTEMA ELÉTRICO. Estudos de curto-circuito período 2008-2011. v. 2, Rio de Janeiro, 2009. Disponível em: <http://www. ons.org.br/download/basedados/curtocircuito/RE_3_061_2009_volume2.pdf> .

Acesso em: 13 Out. 2010.

OPERADOR NACIONAL DO SISTEMA ELÉTRICO. Procedimentos de Rede Submódulo 2.8 - Gerenciamento dos indicadores de desempenho da rede básica e dos barramentos dos transformadores de fronteira, e de seus componentes. Rio de Janeiro, 2010. Disponível em: <http://www. ons.com.br/download/procedimentos/modulos/Modulo_2/Subm\%C3\%B3dulo\%202.8 _Rev_1.1.pdf>. Acesso em: 13 Dez. 2010.

OPERADOR NACIONAL DO SISTEMA ELÉTRICO. Procedimento de rede 11.3 diagrama de impedâncias - São Paulo 02/13 - plano de obras até 2011. Rio de Janeiro, 2009. Disponível em: <http://www.ons.org.br/operacao/diagramas impedancias.aspx>. Acesso em: 13 Out. 2010.

Powersim Inc. PSIM User's guide version 9.0. v. 3, Powersim Inc., 2010. 216 p.

Saraiva Filho, F.C.; Duarte, S.X.; Goldenberg, C. Desenvolvimento de transdutor de corrente: espelho de corrente. In: Conferência Brasileira sobre Qualidade da Energia Elétrica, 7, 2007, Santos. Disponível em: <http://www.sbqee.com.br/artigos _cbqee_2007.htm>. Acesso em 25 Abr. 2010.

Steimetz, C.P.; Alger, P.L. Lectures on electrical engineering. v. 3, New York: Dover Phoenix, 2003. 480 p.

Wiechowski, J.L.W.; Bak-Jensen, C.L.B.B.; Wasilewski, J. GPS-synchronized harmonic measurements performed on a $400 \mathrm{kV}$ transmission network. In: 
International Conference on Electrical Power Quality and Utilization, 9, 2007, p. 1-6. 